\title{
Geoprocessamento como ferramenta de análise integrada de riscos de acidentes industriais
}

Marco Antônio Rodrigues de Oliveira Junior

Dissertação apresentada ao Programa de Pós-Graduação em Saúde Pública da Faculdade de Saúde Pública da Universidade de São Paulo para obtenção do título de Mestre em Saúde Pública.

Área de Concentração:

Saúde Ambiental

Orientador:

Profa. Dra. Adelaide Cássia Nardocci

São Paulo

2008 
É expressamente proibida a comercialização deste documento tanto na sua forma impressa como eletrônica. Sua reprodução total ou parcial é permitida exclusivamente para fins acadêmicos e científicos, desde que na reprodução figure a identificação do autor, título, instituição e ano da dissertação. 
Para minha mãe, Regina.

In memoriam de Marcelo Guimarães, "Grande Mestre", exemplo de orientador, pesquisador e profissional. 


\section{AGRADECIMENTOS}

Primeiramente agradeço a Deus que me deu forças para encarar o desafio deste projeto e colocar pessoas especiais e queridas para me ajudar e apoiar ao longo dessa trajetória.

A todas as pessoas e instituições que de alguma forma apoiaram o desenvolvimento deste trabalho. Em especial, registro meu agradecimento:

A Profa. Dra. Adelaide Cássia Nardocci, pela orientação, valiosas contribuições, apoio e dedicação em todas as etapas deste trabalho

Ao Prof. Dr. Alejandro Jorge Dourado, pelo apoio, amizade e preciosas contribuições durante minha vida acadêmica e profissional;

A Profa. Dra. Helena Ribeiro, pelo apoio, sugestões e participação na banca de argüição;

A Profa. Dra. Diana Sarita Hamburger, pelo apoio, sugestões e participação na banca de argüição;

A Mariana Gutierres, Profa. Dra. Wanda Gunther, Profa. Dra. Maria Tereza Razzolini e demais colegas, professores e funcionários da USP;

Ao Marcos Portela, pelo apoio na produção dos gráficos;

A CETESB e a Prefeitura de Paulínia, pelos materiais cedidos;

Ao Prof. Paulo Sztutman, Cristiane Miuki Isogai e colegas da ERM;

Ao amigo Mariano Maudet Bergel e colegas da Meta Ambiental;

Aos queridos Marcos, Milene, Francisco, Beatriz, Analu e demais companheiros do PAVS (Projeto Ambientes Verdes e Saudáveis);

A Minha mãe, Dra. Regina, pelos almoços, conversas, incentivo, apoio e compreensão nos momentos difíceis;

Ao meu pai, Marco Antônio, pelo incentivo e apoio.

A Minha irmã, Carolina, pela revisão. Aos meus irmãos, Marcelo e Fernanda; meu cunhado, Vladson; meus tios, Paulo e Vânia; Izabel e Mario; e demais familiares, pelo apoio e incentivo.

Aos amigos Mimi, Vanessa, Amilcar e tantos outros amigos da IBAB (Igreja Batista de Água Branca), pelo carinho e incentivo. 
"O cuidado é, na verdade, o suporte real da criatividade, da liberdade e da inteligência. No cuidado se encontra o ethos fundamental do humano. Quer dizer, no cuidado identificamos os princípios, os valores e as atitudes que fazem da vida um bem-viver e das ações um reto agir." 


\section{RESUMO}

Oliveira Junior MAR. Geoprocessamento como ferramenta de análise integrada de riscos de acidentes industriais [dissertação de mestrado]. São Paulo: Faculdade de Saúde Pública da USP; 2008.

O uso do geoprocessamento em estudos de saúde pública permite, entre outros, a identificação de variáveis espaciais que revelem a estrutura social, econômica e ambiental, onde estão presentes riscos à saúde humana. O objetivo deste trabalho foi desenvolver uma metodologia de integração das informações de riscos de acidentes maiores para o Distrito Industrial de Paulínia por meio do uso de técnicas de geoprocessamento. Foram consideradas diversas hipóteses acidentais de 31 instalações de armazenamento e distribuição de GLP e de combustíveis líquidos. Para o tratamento dos dados foram empregados softwares específicos de análise de risco e Sistema de Informação Geográfica (SIG). O software de análise de risco foi responsável por simular possíveis cenários acidentais, gerando polígonos de extensão das áreas atingidas. Já o SIG foi utilizado para a sobreposição dos resultados, geração de um banco de dados, soma dos valores de risco e elaboração de mapas para a análise integrada dos riscos. Os resultados obtidos evidenciam que a sobreposição dos riscos de vários empreendimentos é significativa e que políticas de uso e ocupação do solo são necessárias para evitar o adensamento populacional no entorno, bem como, disciplinar a distribuição das instalações dentro de áreas industriais, de tal forma a minimizar os riscos individuais e sociais.

Descritores: geoprocessamento, acidentes industriais maiores, análise de risco. 


\section{ABSTRACT}

Oliveira Junior MAR. Geoprocessamento como ferramenta de análise integrada de riscos de acidentes industriais. / Using of geoprocessing techniques for integrated analysis of risks of the major technological accidents [dissertation]. São Paulo (BR): Faculdade de Saúde Pública da Universidade de São Paulo; 2008.

The use of the geoprocessing techniques in public health allows the identification of spatial variable that disclose social, economic and environmental structure in risks' areas. The aim was to develop a methodology for integration of risks of industrial accidents in the Industrial District of Paulínia by using geoprocessing techniques. Accidental hypotheses of 31 installations of storage and distribution of LPG and liquid fuels had been considered. For the treatment of the specific data were used softwares of risk analysis and Geographical Information System (GIS). With the software of risk analysis were simulated all the possible accidental scenarios, generating polygons of extension of the reached areas. The GIS was used for the overlapping of the results, generation of database, adds values of to risk and elaboration of maps for the integrated analysis of the risks. The results demonstrated that the overlay of the risk areas was significant and land use policies are necessary to avoid increasing of population around risks area, as well as, to discipline the distribution of installations inside the industrial areas to minimize individual and social risks

Descriptors: geoprocessing, major technological accidents, risk analysis. 


\section{ÍNDICE}

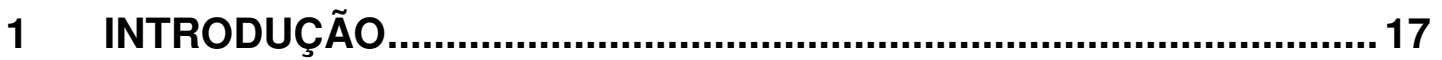

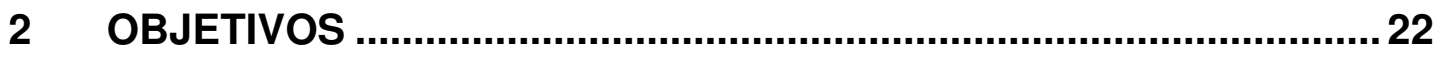

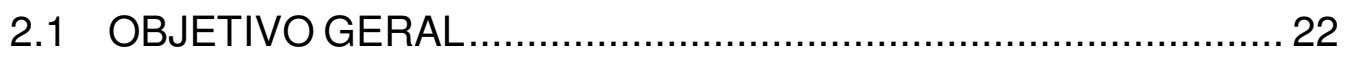

2.2 OBJETIVOS ESPECÍFICOS ..................................................... 22

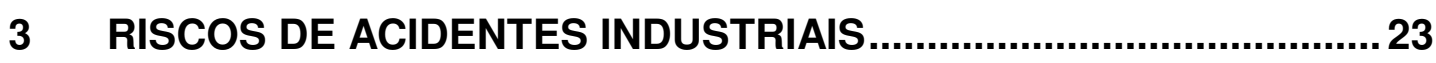

3.1 ANÁLISE QUANTITATIVA DE RISCOS .................................. 26

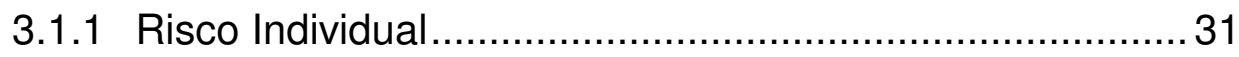

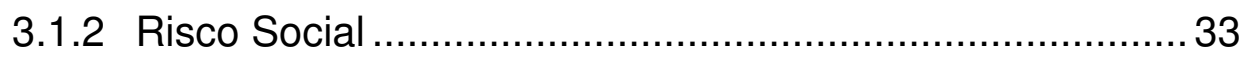

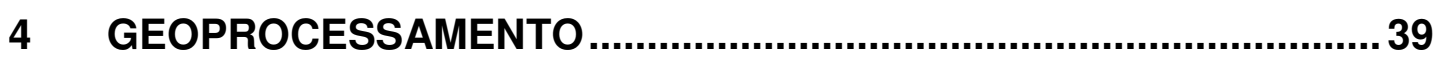

4.1 SISTEMA DE INFORMAÇÃO GEOGRÁFICA ........................... 40

4.2 BANCO DE DADOS ESPACIAIS ............................................ 42

4.3 PLANOS DE INFORMAÇÃO - LAYER ....................................... 43

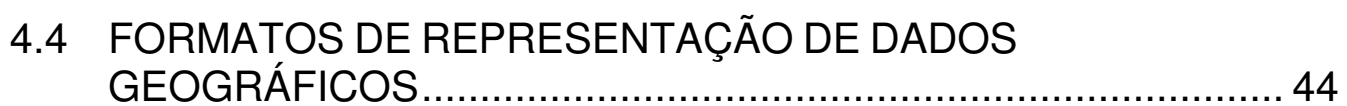

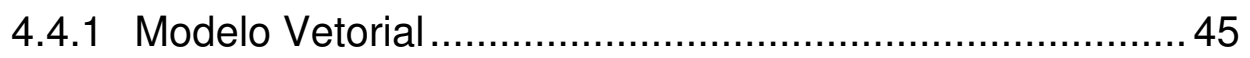

4.4.2 Modelo Raster ou Matricial ............................................... 45

4.5 ANÁLISE ESPACIAL DE DADOS .............................................. 45

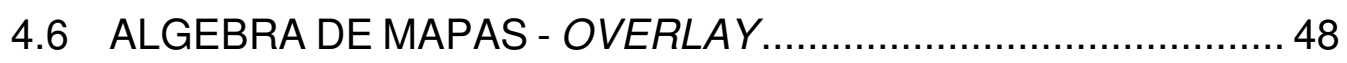

4.7 GEOPROCESSAMENTO E ANÁLISE DE RISCO...................... 49

5 MATERIAIS E MÉTODOS...........................................................51

5.1 MATERIAL BIBLIOGRÁFICO, CARTOGRÁFICO E

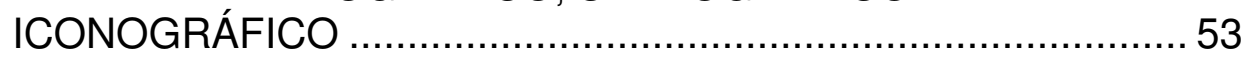

5.2 EQUIPAMENTOS E APLICATIVOS ............................................ 54

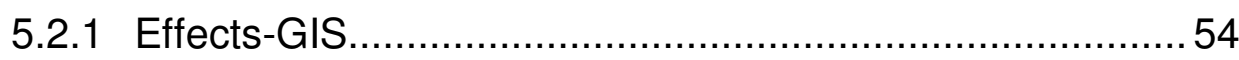

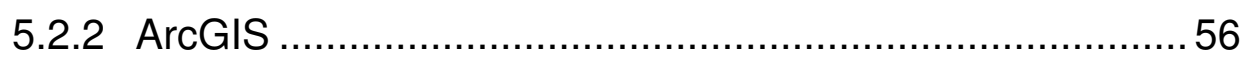

5.3 SELEÇÃO E COMPATILIZAÇÃO DOS DADOS

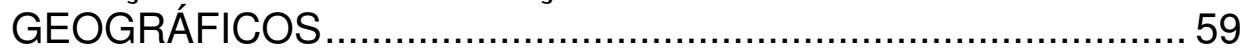

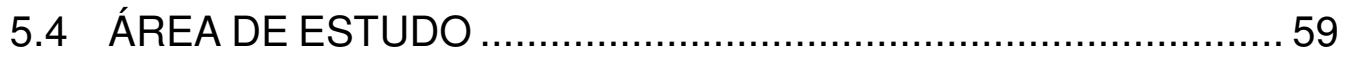

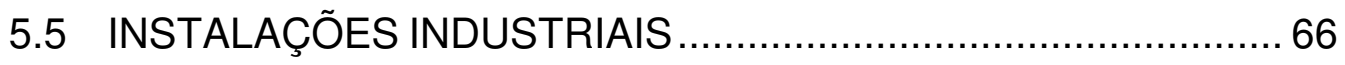




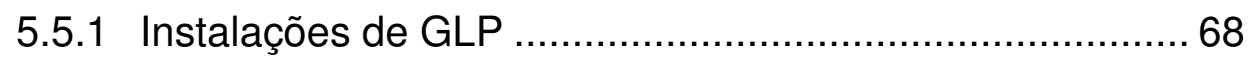

5.5.2 Instalações de combustíveis líquidos ................................ 69

5.6 SIMULAÇÃO DOS CENÁRIOS ACIDENTAIS ........................... 71

5.7 AQUISIÇÃO DOS DADOS DOS CENÁRIOS ACIDENTAIS ........ 78

5.7.1 Polígonos gerados pelo Effects-GIS................................. 78

5.7.2 Valores de risco individual .............................................. 80

5.8 CRIAÇÃO DO BANCO DE DADOS DE CENÁRIOS

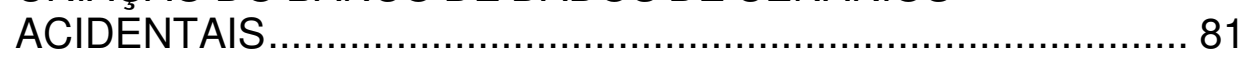

5.9 SOMATÓRIA DOS VALORES DE RISCO INDIVIDUAL ............... 85

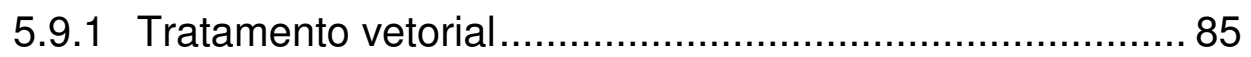

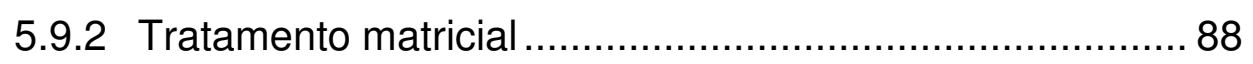

5.10 CÁLCULO DO NÚMERO DE PESSOAS EXPOSTAS ..................90

5.11 APRESENTAÇÃO DOS RESULTADOS ................................... 92

6 RESULTADOS E DISCUSSÃO ........................................................ 93

6.1 BANCO DE DADOS ESPACIAIS .............................................. 93

6.2 ANÁLISE INTEGRADA DOS RISCOS ..................................... 94

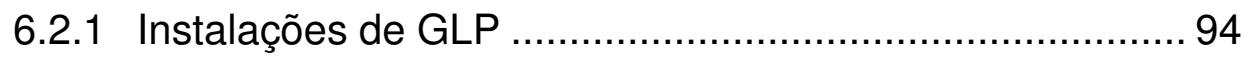

6.2.2 Instalações de combustíveis líquidos .............................. 97

6.2.3 Instalações de GLP + combustíveis líquidos .................. 100

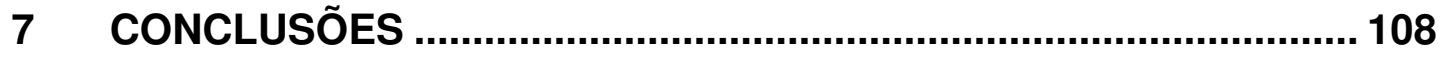

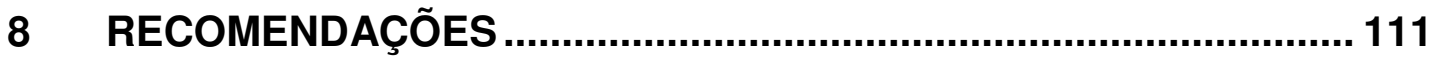

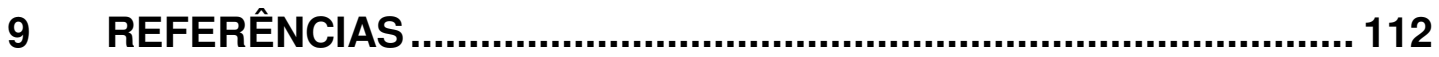




\section{LISTA DE FIGURAS}

Figura 1 - Etapas para a elaboração de estudos de análise de riscos. 28

Figura 2 - Estimativa do número de vítimas para o cálculo do risco social. . 35

Figura 3 - Exemplo de diversos planos de informação 43

Figura 4 - Localização do Município de Paulínia. 61

Figura 5 - Municípios da Região Metropolitana de Campinas. 62

Figura 6 - Sobreposição de cenários de BLEVE, do período diurno, para uma instalação de GLP: áreas de 1\% e 50\% de probabilidade de fatalidade.

Figura 7 - Sobreposição de cenários de Flashfire, do período diurno, para uma instalação de GLP: cada uma das oito direções preferenciais do vento.

Figura 8 - Sobreposição de cenários de UVCE, do período diurno, para uma instalação de GLP: áreas de $1 \%$ e $50 \%$ de probabilidade de fatalidade, para cada uma das oito direções preferenciais do vento.

Figura 9 - Sobreposição de cenários de VCE, do período diurno, para uma instalação de GLP: áreas de $1 \%$ e 50\% de probabilidade de fatalidade.

Figura 10 - Sistema de código identificador do cenário 79

Figura 11 - Tela do Effects-GIS, com destaque para o nome da simulação.

Figura 12 - Sistema de código identificador do valor de risco. 82

Figura 13 - Relacionamento entre as entidades alfanuméricas e espaciais.

Figura 14 - Seleção de um cenário e seleção de uma secção de cálculo .... 87

Figura 15 - Fluxograma do processo de soma dos dados em formato vetorial.

Figura 16 - Conversão do formato vetorial para matricial, com células de $1 \times 1 \mathrm{~m}$

Figura 17 - Fluxograma do processo de soma dos dados em formato matricial

Figura 18 - Definição da população exposta com base nos setores censitários 


\section{LISTA DE GRÁFICOS}

Gráfico 1 - Curva F-N de tolerabilidade para risco social.

Gráfico 2 - Risco social para as instalações de armazenamento e distribuição de GLP.

Gráfico 3 - Risco social para as instalações de armazenamento e distribuição de combustível líquido.

Gráfico 4 - Risco social total para o Distrito Industrial de Paulínia (instalações de GLP + combustível líquido). 


\section{LISTA DE MAPAS}

Mapa 1 - Distribuição da população de Paulínia por setor censitário, segundo dados do IBGE do ano de 2000, e localização do Distrito Industrial.

Mapa 2 - Zoneamento do uso do solo na região do Distrito Industrial de Paulínia. 66

Mapa 3 - Localização das instalações industriais estudadas. 67

Mapa 4 - Risco individual para as Instalações de armazenamento e distribuição de GLP.

Mapa 5 - Classes de risco individual para as instalações de armazenamento e distribuição de GLP.

Mapa 6 - Risco individual para as instalações de armazenamento distribuição de combustível líquido.

Mapa 7 - Classes de risco individual para as instalações de armazenamento e distribuição de combustível líquido.

Mapa 8 - Classes de risco individual total (instalações de GLP + combustível líquido).

Mapa 9 - Vista geral da área e classes de risco individual total (instalações de GLP + combustível líquido) 


\section{LISTA DE TABELAS}

Tabela 1 - População do Município de Paulínia, por área de residência e sexo, segundo dados do Censo Demográfico do IBGE de 2000.

Tabela 2 - Informações gerais das instalações de armazenamento e distribuição de GLP, consideradas neste estudo..... 68

Tabela 3 - Informações gerais das instalações de armazenamento e distribuição de combustíveis líquidos, consideradas neste estudo.... 70 


\section{LISTA DE QUADROS}

Quadro 1 - Hipóteses acidentais definidas para as instalações de GLP.....71

Quadro 2 - Hipóteses acidentais definidas para as instalações de combustíveis líquidos inflamáveis. 72

Quadro 3 - Número de cenários simulados para cada instalação de GLP...76

Quadro 4 - Número de cenários simulados para cada instalação de combustível liquido.

Quadro 5 - Campos das tabelas de atributos dos Shapefiles..................... 81

Quadro 6 - Campos das novas tabelas de atributos. ............................. 83

Quadro 7 - Campos da tabela de valores de risco. ............................... 83

Quadro 8 - Campos do banco de dados. ............................................. 84

Quadro 9 - Grupos de cenários para a somatória dos riscos de instalações de GLP................................................................. 85

Quadro 10 - Grupos de cenários para a somatória dos riscos de instalações de combustíveis líquidos. 86 


\section{LISTA DE ABREVIATURAS E SIGLAS}

AAE: Análise de Árvore de Eventos

AAF: Análise de Árvores de Falhas

ALARP: As Low As Reasonably Practicable (Tão Baixo Quanto

Razoavelmente Praticável)

AQR: Avaliação Quantitativa de Risco

AMFE: Análise de Modo de Falha e Efeito

APP: Análise Preliminar de Perigos

CAD: Computer-Aided Design (Desenho Auxiliado por Computador)

EAR: Estudos de Análise de Risco

BLEVE: Boiling Liquid Expanding Vapor Explosion (Explosão de Vapor em

Expansão de Líquido em Ebulição)

ESRI: Environmental Systems Research Institute (Instituto de Pesquisa de

Sistemas Ambientais)

FAPESP: Fundação de Amparo à Pesquisa do Estado de São Paulo

FISPQ: Ficha de Informação de Segurança de Produto Químico

GIS: Geographic Information System (o mesmo que SIG)

GLP: Gás Liquefeito de Petróleo

HAZOP: Hazard and Operability Study (Estudo de Perigos e Operabilidade)

IBGE: Instituto Brasileiro de Geografia e Estatística

LII: Limite Inferior de Inflamabilidade

LPG: Liquefied Petroleum Gas (o mesmo que GLP)

LUP: Land Use Planning (Planejamento de Uso do Solo)

MAP: Map Analysis Package (Pacote de Análise de Mapa)

RAM: Random Access Memory (Memória de Acesso Aleatório)

REPLAN: Refinaria do Planalto Paulista

SAD: South America Datum

SIG: Sistema de Informação Geográfica

TRANSPETRO: Petrobrás Transportes S/A 
USP: Universidade de São Paulo

UTM: Universal Transversa de Mercator

UVCE: Unconfined Vapor Cloud Explosion (Explosão de Nuvem de Vapor Não-Confinada)

VCE: Vapor Cloud Explosion (Explosão de Nuvem de Vapor) 


\section{INTRODUÇÃO}

As relações saúde e ambiente têm ganhado importância em estudos científicos e em termos de preocupação social. Estas questões variam de uma escala global, como os efeitos decorrentes das mudanças climáticas à saúde, até uma escala local, como, por exemplo, os efeitos de poluentes, emitidos por uma indústria, à saúde da população residente no seu entorno.

No entanto, independentemente da abrangência, estas relações são complexas e influenciadas por um amplo espectro de fatores ambientais e sócio-econômicos, e, o seu entendimento demanda, entre outros, a coleta e análise de um conjunto de informações geográficas. Esta demanda, aliada ao desenvolvimento dos computadores, faz com que as ferramentas de geoprocessamento se destaquem como um importante instrumento para o estudo de problemas ambientais e de saúde pública.

O uso do geoprocessamento permite, nestes casos, a identificação de variáveis que revelem a estrutura social, econômica e ambiental, onde estão presentes riscos à saúde humana. (BARCELLOS e BASTOS, 1996; MAHESWARAN e CRAGLIA, 2004). Com as ferramentas hoje disponíveis é possível mapear áreas de concentração de poluentes, bem como, áreas de risco de desastres naturais e de acidentes tecnológicos, além de auxiliar no planejamento de medidas de intervenção junto a fontes poluidoras e populações expostas.

Existem experiências significativas envolvendo a análise espacial em estudos que avaliam a contaminação de recursos naturais e a exposição de pessoas. Nestes casos, a elaboração de mapas de riscos à saúde pode 
empregar métodos geoestatísticos, como a krigagem ${ }^{1}$, para o mapeamento de áreas contaminadas. Estas metodologias são de grande valia para a geração de modelos de confiança para a distribuição de poluentes, favorecendo os processos de investigação destas áreas. (CARVALHO, 1997; DRUCK et al, 2004; LOURENÇO e LANDIM, 2005). Da mesma forma, técnicas de geoprocessamento podem ser aplicadas no mapeamento de áreas de risco de acidentes, auxiliando na identificação de prioridades e na definição de políticas de uso e ocupação do solo.

A ocorrência de graves acidentes industriais, como por exemplo, o de Seveso, na Itália, em 1976, o de Bhopal, na Índia, em 1984, entre outros, despertaram preocupação de autoridades nacionais, organismos internacionais e da população de um modo geral, uma vez que as conseqüências destes acidentes podem ser severamente amplificadas pela proximidade de áreas densamente povoadas.

Várias iniciativas foram implantadas com a finalidade de desenvolver ferramentas para o gerenciamento dos riscos destes eventos, entre as quais se destaca a Diretiva de Seveso I, da Comunidade Européia, em 1982.

Os objetivos do gerenciamento de riscos têm focado, por um lado, a redução da ocorrência de acidentes, por meio de políticas e instrumentos de avaliação de segurança dos empreendimentos industriais, e por outro, a minimização das conseqüências destes eventos caso eles ocorram. Essa última abordagem busca reduzir os danos através de políticas de uso e ocupação do solo no entorno de instalações perigosas e, também, do planejamento de ações emergenciais, para responder prontamente e de maneira eficaz, quando da ocorrência de um grave acidente.

\footnotetext{
${ }^{1}$ Do francês krigeage e do inglês kriging, é um termo cunhado pela escola francesa de geoestatística em homenagem ao engenheiro de minas sul-africano e pioneiro na aplicação de técnicas estatísticas em avaliação mineira, D.G. Krige. É um processo de estimação de valores de variáveis distribuídas no espaço a partir de valores adjacentes enquanto considerados como interdependentes pelo semivariograma. Tratando-se, em último caso, de um método de estimação por médias móveis. (LANDIM, 1998).
} 
Para responder a estes objetivos, a avaliação quantitativa de riscos (AQR) tem se caracterizado como uma importante ferramenta. Seja para a avaliação de segurança das instalações, para a definição de critérios de uso e ocupação do solo, e, como subsídio ao planejamento emergencial. No âmbito da Comunidade Européia foi introduzida pela Diretiva de Seveso em vários países membros, como Holanda, França, Itália e no Reino Unido.

Esses estudos caracterizam-se pela aplicação de técnicas e modelos específicos de identificação de cenários acidentais, a avaliação de efeitos físicos e a quantificação dos riscos para a população do entorno dos empreendimentos (MOLAK, 1996).

No contexto de análise de acidentes, risco é definido como uma medida da probabilidade de ocorrência do evento versus a magnitude das perdas ou danos (conseqüências). Neste caso, os resultados são estimados e apresentados na forma de risco social e individual, onde os valores são calculados em termos de fatalidades ou, em alguns casos, da incidência de doenças irreversíveis. O risco social refere-se ao número de pessoas afetadas por um evento indesejável. O risco individual é a probabilidade de uma pessoa, presente na vizinhança de um perigo, sofrer algum dano. (NARDOCCI, 1999; CETESB, 2001; CAMACHO, 2004).

A divulgação, em nível nacional, de dados quantitativos de risco, pode ser feita através de mapas síntese, facilitando a integração das informações. $\mathrm{Na}$ Holanda, por exemplo, esses valores podem ser encontrados em termos de risco de mortalidade/ano para substâncias carcinogênicas, substâncias radioativas e acidentes químicos ampliados. (PRUPPERS et al, 1998; BARTELS e BEURDEN, 1998).

Quanto ao mapeamento e análise espacial de riscos tecnológicos à saúde, ou seja, riscos sociais e individuais, objeto deste estudo, existem 
experiências expressivas em alguns países da comunidade européia, entre eles, a Holanda (FEDRA, 1998; WIERSMA, ROSS e de WIT, 2005), Itália (CONTINI et al, 2000; COZZANI et al, 2006), Grécia (IOANNIDIS et al, 1999) e Inglaterra (BRAZIER e GREENWOOD, 1998).

No Brasil, por sua vez, ocorreram trágicos acidentes industriais, entre os quais cabe citar o acidente de Vila Socó, em Cubatão, Estado de São Paulo, em 1984, quando o vazamento de um duto de gasolina da Petrobrás, seguido por incêndio, resultou na morte 500 moradores de uma favela. Este e outros eventos colocaram o Brasil em segundo lugar, entre os principais países do mundo, em termos de óbitos por acidentes (FREITAS, PORTO e GOMEZ, 1995).

A avaliação de riscos foi introduzida como ferramenta de gestão, na década de 1980, após a ocorrência de acidentes de vazamento de óleo no Porto de São Sebastião. Atualmente, Estudos de Análise de Risco (EAR) são solicitados no processo de licenciamento ambiental de todos os empreendimentos que utilizam, manipulam, transportam ou armazenam substâncias químicas perigosas (SÃO PAULO, 1998).

Entretanto, apesar de quase três décadas de uso da $A Q R$, muito pouco foi desenvolvido em termos de definição de regulamentações específicas quanto ao escopo e aplicação destes estudos. A definição e a utilização de metodologias para o mapeamento e análise espacial de riscos individuais e sociais, assim como, a análise integrada dos riscos de grandes áreas industriais não tem sido utilizada, e poucas experiências envolvendo a análise espacial e o gerenciamento de riscos podem ser citadas.

Visando a minimização de impactos ao meio ambiente, podemos citar a experiência desenvolvida pela Petrobras/TRANSPETRO. Na qual, foi elaborada uma metodologia de Mapeamento de Riscos Ambientais em 
faixas de dutos, de forma a auxiliar nas ações de emergência em caso de derramamento de óleo. (MENDES, et al, 2005).

O uso da AQR no licenciamento tem como objetivo a avaliação da segurança das instalações. No entanto, no caso de áreas industriais que concentram várias instalações perigosas há uma sobreposição dos riscos de cada unidade, e o fato das empresas atenderem aos critérios individuais não garante que o risco total do conjunto seja tolerável, portanto, uma análise integrada do conjunto de empreendimentos é necessária a fim de orientar o uso e ocupação do solo no entorno destas áreas.

No entanto, esta integração dos riscos demanda o desenvolvimento de metodologias específicas, as quais têm sido facilitadas pelo desenvolvimento das ferramentas de geoprocessamento, favorecendo a elaboração de mapas de risco, os quais têm se caracterizado como importante instrumento de planejamento. 


\section{OBJETIVOS}

\subsection{OBJETIVO GERAL}

Desenvolver uma metodologia de integração dos riscos de acidentes industriais para o Distrito Industrial de Paulínia por meio do uso de técnicas de geoprocessamento.

\subsection{OBJETIVOS ESPECÍFICOS}

- Construir um banco de dados dos possíveis cenários de acidentes envolvendo instalações de GLP e combustíveis líquidos;

- Gerar estimativas para a análise integrada dos riscos de acidentes industriais no Município de Paulínia.

- Contribuir para ampliar o uso da análise de risco como um instrumento de planejamento e gestão ambiental. 


\section{RISCOS DE ACIDENTES INDUSTRIAIS}

Os acidentes industriais, geralmente, são eventos agudos, tais como explosões, incêndios e emissões, individuais ou combinados, envolvendo uma ou mais substâncias perigosas com potencial de causar simultaneamente múltiplos danos ao meio ambiente e à saúde dos seres humanos expostos. (FREITAS, PORTO e GOMEZ, 1995). Geralmente, são caracterizados por efeitos imediatos, pela capacidade de causar um grande número de vítimas fatais, atingir ampla extensão geográfica e, em alguns casos, por acumular efeitos ao longo do tempo, como os resultantes da contaminação por substâncias perigosas.

Estes eventos ocorrem em função de um descontrole das condições

operacionais normais em instalações industriais, unidades de armazenamento; ou durante o transporte rodoviário, ferroviário, hidroviário, aeroviário e dutoviário. (FREITAS, PORTO e GOMEZ, 1995).

Os efeitos de um acidente podem ser imediatos ou em longo prazo, internamente e externamente ao estabelecimento industrial. (FREITAS, PORTO e GOMEZ, 1995). Os danos mais expressivos são os associados à saúde humana. A gravidade de um acidente pode ser avaliada, sobretudo, pelo número de óbitos e feridos, como observado nos casos a seguir:

1. Flixborough - Inglaterra: Em 1974 ocorreu a explosão de uma nuvem de vapor de solventes, ocasionando a morte de 28 pessoas. Como imediata reação a este acidente, foi constituído o Comitê Consultor para Riscos Maiores do Reino Unido, que passou a regular as plantas industriais consideradas perigosas (KIRCHSTEIGER et al, 1998; GLASMEYER, 2006). 
2. Seveso - Itália: Em 1976 o vazamento de uma nuvem tóxica contendo tetraclorodibenzenoparadioxina (TCDD) atingiu milhares de pessoas e muitas adquiriram cloroacne, uma erupção na pele. $O$ acidente também provocou a morte de uma grande quantidade de animais. Anos depois, surgiu a primeira diretiva de controle de riscos maiores aplicável à comunidade européia, que ficou conhecida a Diretiva de Seveso de 1982 (KIRCHSTEIGER et al, 1998; GLASMEYER, 2006).

3. Enschede - Holanda: Uma série de explosões de uma fábrica de fogos de artifícios, em Enschede, Holanda, em 2000, matou 24 pessoas, sendo 4 bombeiros, feriu quase 1000 e causou prejuízos em uma grande área, destruindo 350 casas no entorno da fábrica (CHRISTOU, 2006; HSE, 2007).

4. Toulouse - França: Uma explosão envolvendo nitrato de amônio granular fabricado em uma indústria de fertilizante, em Toulouse, França, 2001, matou 30 pessoas e causou danos às construções em um raio de $7 \mathrm{~km}$ da indústria, 1400 pessoas foram evacuadas e 600 casas e 2 escolas destruídas (CHRISTOU, 2006; HSE, 2007).

Entre os principais acidentes industriais, o vazamento de metilisocianato (MIC) da empresa Union Carbide, em Bhopal, Índia, em 1984, é, ainda hoje, considerado o acidente químico de maior gravidade da história, provocando a morte imediata de cerca de 3 mil pessoas (FREITAS, PORTO e GOMEZ, 1995; DEMAJOROVIC, 2003). Outro acidente em uma unidade da Union Carbide, desta vez na Virgínia, Estados Unidos da América, oito meses depois, expôs a fragilidade da empresa e a falta de ações para se evitar e enfrentar tais ocorrências (DEMAJOROVIC, 2003; GLASMEYER, 2006). 
Determinados acidentes podem atingir pequenas áreas, como, por exemplo, uma explosão; outros acidentes podem atingir grandes regiões e, da mesma forma, provocar sérios danos, como o vazamento de substâncias químicas perigosas para a atmosfera. Cabe citar o acidente de Chernobyl, ocorrido na Ucrânia, em 1984, em um reator nuclear, cujos danos atingiram uma região de centenas de quilômetros de raio no entorno da usina. $A$ intensidade de um acidente, evidentemente, depende de fatores como o tipo de produto, quantidade, condições operacionais e da vulnerabilidade da área atingida.

No que diz respeito às substâncias químicas, as inflamáveis, explosivas e tóxicas, são as que representam maior perigo para os seres humanos e ecossistemas. E os eventos acidentais mais importantes estão associados ao vazamento e liberação destas substâncias resultantes de falhas operacionais ou de equipamentos.

Desta forma, para fins de análise quantitativa de riscos, os eventos considerados são vazamentos líquidos, gasosos e bifásicos de substâncias tóxicas, resultando nos seguintes efeitos: formação de uma nuvem e conseqüentes probabilidades de mortes de pessoas por exposição aguda; incêndios que resultam em mortes por exposição à radiação térmica (queimaduras letais); e, explosões, seguidas ou não de incêndios as quais resultam em mortes ou lesões graves devido à variação da taxa de sobrepressão, que pode ocasionar hemorragias pulmonares ou lesões provocadas pela emissão de projéteis.

Mesmo no campo da saúde pública existem vários conceitos de risco e diferentes metodologias de avaliação as quais devem ser entendidas no contexto nas quais se aplicam (NARDOCCI, 1999).

Para o estudo de acidentes tecnológicos, risco é caracterizado com base em dois elementos particulares: o perigo e a vulnerabilidade da área. $O$ 
seu cálculo pode ser realizado através da combinação matemática da probabilidade de ocorrência do evento acidental e da probabilidade que este evento resulte em mortes ou danos graves para as pessoas expostas. (RAYNER, 1992; JONES, 1992). Nos métodos e técnicas de avaliação de risco mais utilizados, esta abordagem quantitativa considera, sobretudo, a população sujeita aos perigos de acidentes e a possibilidade de ocorrência de danos imediatos.

Os resultados são estimados em termos de risco individual e risco social. O risco individual é uma medida da probabilidade anual de morte em função de um acidente que possa ocorrer em um empreendimento. O risco social é uma estimativa do número de pessoas atingidas pelos eventos e é representado pelas curvas $\mathrm{F}-\mathrm{N}$, freqüência acumulada dos eventos versus número de fatalidades.

Critérios de análise e gerenciamento de riscos de acidentes maiores baseados no conceito de risco individual e risco social têm sido adotados, no âmbito da comunidade européia, para planejamento do uso e ocupação do solo. Nos últimos anos, por exigência da Diretiva de Seveso, vários países europeus têm desenvolvido critérios específicos para o planejamento (LUP Land Use Planning) de uso do solo no entorno de instalações industriais (COZZANI et al, 2006). Estes critérios procuram evitar a proximidade entre atividades incompatíveis como, por exemplo, instalações perigosas e áreas residenciais.

\subsection{ANÁLISE QUANTITATIVA DE RISCOS}

A análise quantitativa de risco ( $A Q R)$ tem a finalidade de identificar os possíveis cenários acidentais, as probabilidades de ocorrência de cada evento e suas respectivas conseqüências, mensurar os riscos e, ainda, definir medidas para o gerenciamento dos mesmos. 
No Brasil, esta análise é escopo dos chamados Estudos de Análise de Risco (EARs), utilizados como instrumento de licenciamento ambiental. A estrutura destes estudos é definida pela Norma Técnica P4.261 - Termo de Referência para Estudos de Análise de Riscos da CETESB (2003), órgão ambiental do Estado de São Paulo. Este documento estabelece a forma e o conteúdo dos estudos, bem como, apresenta os critérios de aceitabilidade adotados na avaliação dos riscos. A Figura 1, a seguir, apresenta a seqüência de desenvolvimento desses estudos. 


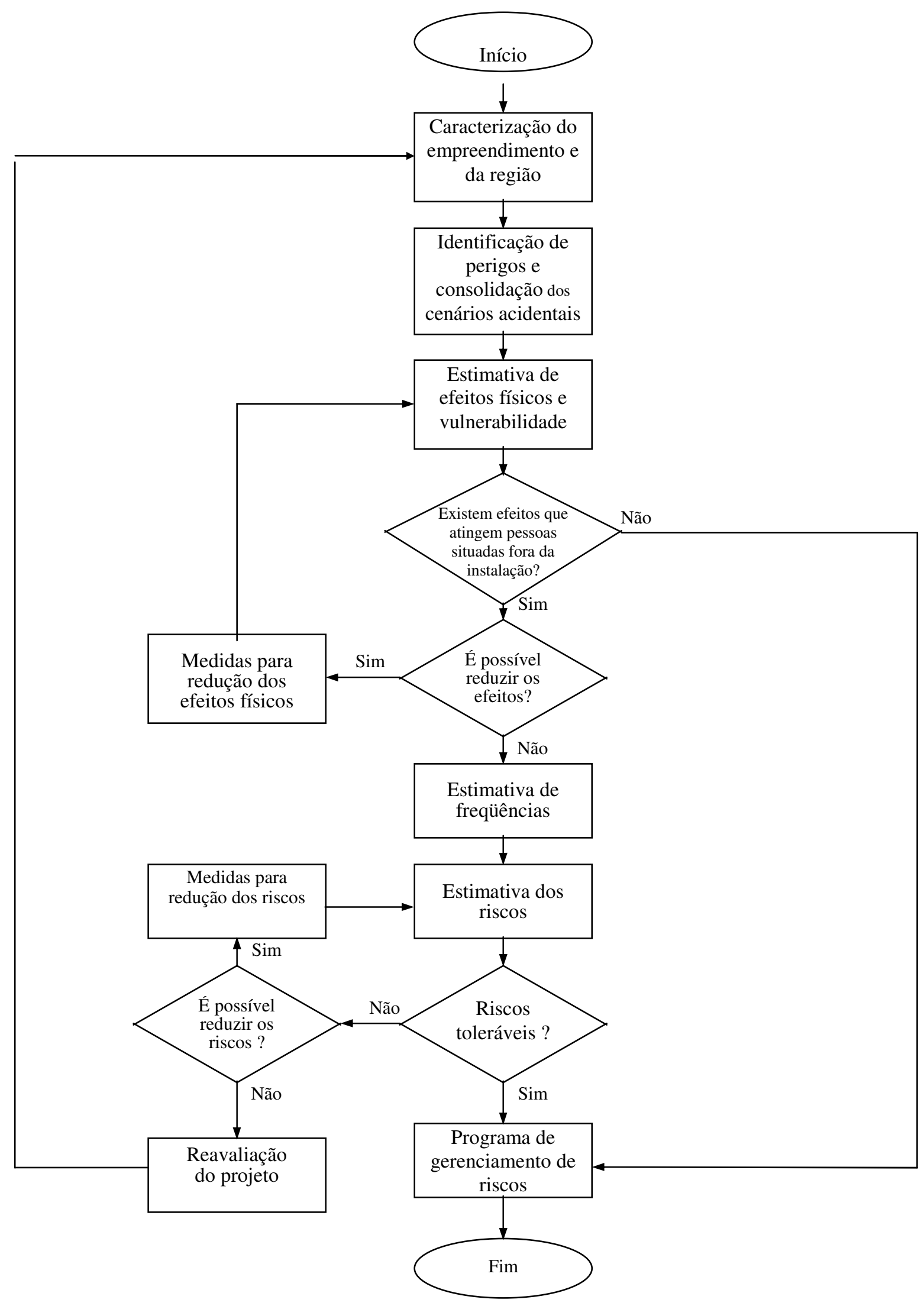

Figura 1 - Etapas para a elaboração de estudos de análise de riscos.

Fonte: CETESB, 2003. 
Estes EARs se aplicam, exclusivamente, à avaliação dos riscos à população externa ao empreendimento, não contemplando, por exemplo, riscos à saúde e à segurança dos trabalhadores ou danos aos bens patrimoniais. Já os impactos ao meio ambiente são avaliados, de forma específica, caso a caso.

O EAR tem início com a caracterização do empreendimento e da região, esta etapa inclui, também, uma descrição detalhada dos produtos e processos envolvidos.

Em seguida, na etapa de identificação de perigos e consolidação dos cenários acidentais, definem-se as possíveis hipóteses de acidentes, de grande e pequena magnitude. Atualmente, existem diversas técnicas específicas de identificação de perigos como HAZOP (Hazardous and Operability Studies), APP (Análise Preliminar de Perigos), AMFE (Análise de Modo de Falha e Efeito), entre outros, sendo a APP e o HAZOP as mais utilizadas nos EARs. Estas técnicas permitem que seja feita uma análise detalhada dos equipamentos, sistemas e procedimentos operacionais da instalação industrial. (CETESB, 2003).

De acordo com os cenários acidentais identificados e das características das substâncias envolvidas, realiza-se a etapa de estimativa dos efeitos físicos através de modelos de simulação de acidentes. Este é um item importante na análise de risco, pois, as modelagens matemáticas dos eventos ajudam a entender a intensidade e a extensão de suas conseqüências, além de indicar as probabilidades de fatalidade e de contribuir para a avaliação de vulnerabilidade dos elementos atingidos.

As freqüências de ocorrência dos efeitos físicos de cada cenário são estimadas através da técnica de Análise de Árvore de Eventos (AAE). Esta análise descreve a seqüência dos fatos que possam se desenvolver a partir 
do cenário acidental em estudo, prevendo situações de sucesso ou falha, de acordo com as interferências existentes até a sua conclusão, com a definição de diferentes tipologias acidentais. (CETESB, 2003).

A seguir estão listados diferentes eventos indesejáveis que usualmente são modelados nos EARs:

- Vazamento: descarga a partir de um tanque ou tubulação; modelos são incorporados para o vazamento de gás, líquido e gás liquefeito pressurizado.

- Evaporação de poça: evaporação de líquido a partir da terra ou de superfícies aquáticas; modelos são incorporados para poças confinadas e espalhadas, e para voláteis e não-voláteis.

- Dispersão: dispersão atmosférica de vazamentos com flutuações positivas, negativas e neutras; modelos são incorporados para gases pesados a partir de jatos ou poças, dispersão de plumas; os resultados em concentração discreta, contorno de concentração, massa explosiva ou carga tóxica dependendo da duração da exposição.

- Explosão: sobrepressão para explosão de nuvens de vapores segundo o método de multi-energia.

- Combustão: incêndio e a formação de produtos de combustão tóxica.

As freqüências de ocorrência dos cenários acidentais podem ser estimadas através de registros históricos constantes de bancos de dados ou de referências bibliográficas, desde que efetivamente tenham 
representatividade para o caso em estudo. No entanto, de acordo com a complexidade da instalação em análise, pode haver a necessidade de ser utilizada a técnica de Análise de Árvores de Falhas (AAF) para a estimativa das freqüências. De modo geral, a AAF é uma técnica dedutiva que permite identificar as causas básicas de acidentes e de falhas no sistema. (CETESB, 2003).

Finalmente, uma estimativa dos riscos é elaborada nas formas de risco individual e risco social, como descrito a seguir:

\subsubsection{Risco Individual}

O risco individual pode ser definido como o risco para uma pessoa presente na vizinhança de um perigo, considerando a natureza do dano que pode ocorrer e o período de tempo em que este pode acontecer (CETESB, 2003).

Os danos às pessoas podem ser expressos de diversas formas, embora as injúrias sejam mais difíceis de serem avaliadas, dada a indisponibilidade de dados estatísticos para serem utilizados em critérios comparativos de riscos; assim, o risco é estimado em termos de danos irreversíveis ou fatalidades.

O risco individual pode ser estimado para aquele mais exposto a um perigo, para um grupo de pessoas ou para uma média de indivíduos presentes na zona de efeito. Para um ou mais acidentes, o risco individual tem diferentes valores.

A apresentação do risco individual é feita através de curvas de isorisco (contornos de risco individual), uma vez que estas possibilitam visualizar a distribuição geográfica do risco em diferentes regiões. Assim, o 
contorno de um determinado nível de risco individual representa a freqüência esperada de um evento capaz de causar um dano num local específico.

Para o cálculo do risco individual num determinado ponto da vizinhança de uma planta industrial, pode-se assumir que as contribuições de todos os eventos possíveis são somados. Dessa forma, o risco individual total num determinado ponto pode ser calculado pelo somatório de todos os riscos individuais nesse ponto, conforme apresentado a seguir:

$$
\mathrm{RI}_{\mathrm{x}, \mathrm{y}}=\sum_{\mathrm{i}=1}^{\mathrm{n}} \mathrm{RI} \mathrm{I}_{\mathrm{x}, \mathrm{y}, \mathrm{i}}
$$

Onde:

$$
\begin{aligned}
& \mathrm{RI}_{\mathrm{x}, \mathrm{y}}= \text { risco individual total de fatalidade no ponto } \mathrm{x}, \mathrm{y} ; \\
& \text { (chance de fatalidade por ano }\left(\mathrm{ano}^{-1}\right) \text { ) } \\
& \mathrm{RI}_{\mathrm{x}, \mathrm{y}, \mathrm{i}}= \text { risco de fatalidade no ponto } \mathrm{x}, \mathrm{y} \text { devido ao evento } \mathrm{i} ; \\
& \text { (chance de fatalidade por ano }\left(\mathrm{ano}^{-1}\right) \text { ) } \\
& \mathrm{n} \quad=\text { número total de eventos considerados na análise. }
\end{aligned}
$$

Os dados de entrada na equação anterior são calculados a partir da equação:

$$
R I_{x, y, i}=f_{i} \cdot p_{f i}
$$

Onde:

$\mathrm{RI}_{\mathrm{x}, \mathrm{y}, \mathrm{i}}=$ risco de fatalidade no ponto $\mathrm{x}, \mathrm{y}$ devido ao evento $\mathrm{i}$; (chance de fatalidade por ano $\left(\mathrm{ano}^{-1}\right)$ )

$\mathrm{f}_{\mathrm{i}} \quad$ = freqüência de ocorrência do evento $\mathrm{i}$;

$\mathrm{p}_{\mathrm{fi}}=$ probabilidade que $\mathrm{o}$ evento $\mathrm{i}$ resulte em fatalidade no ponto $\mathrm{x}, \mathrm{y}$, de acordo com os efeitos resultantes das conseqüências esperadas. 
Para o risco individual, os seguintes critérios de tolerabilidade são utilizados pela CETESB:

- Risco máximo tolerável: 1 x 10-5 .ano-1;

- Risco negligenciável: < 1 x 10-6 .ano-1.

\subsubsection{Risco Social}

O risco social é uma medida direta da magnitude de um acidente em termos de fatalidades diretas, e é o critério principal de decisão em caso de acidentes maiores. O risco social refere-se ao risco para um determinado número ou agrupamento de pessoas expostas aos danos decorrentes de um ou mais cenários acidentais (CETESB, 2003). A forma de apresentação do risco social é feita através da curva F-N, obtida por meio da plotagem dos dados de freqüência acumulada do evento final e seus respectivos efeitos representados em termos de número de vítimas fatais.

A estimativa do risco social num estudo de análise de riscos requer as seguintes informações:

- Tipo de população (residências, estabelecimentos comerciais, indústrias, áreas rurais, escolas, hospitais, etc.);

- Efeitos em diferentes períodos (diurno e noturno) e respectivas condições meteorológicas, para o adequado dimensionamento do número de pessoas expostas; 
- Características das edificações onde as pessoas se encontram, de forma que possam ser levadas em consideração eventuais proteções.

Diferentes distribuições ou características das pessoas expostas podem ser consideradas na estimativa dos riscos por intermédio de simplificações, como por exemplo, através do uso de dados médios de distribuição populacional; no entanto, deve-se estar atento quanto ao emprego dessas generalizações, que podem induzir a erros significativos na estimativa dos riscos, razão pela qual esses procedimentos devem ser tratados com a devida cautela.

Para cada tipologia acidental, é estimado o número provável de vítimas fatais, de acordo com as probabilidades de fatalidades associadas aos efeitos físicos e em função das pessoas expostas nas oito direções de vento, considerando-se em cada uma destas direções as duas velocidades médias de vento, correspondentes aos períodos diurno e noturno.

No Estado de São Paulo, a CETESB especifica que a estimativa do número de vítimas fatais deve ser realizada, considerando-se probabilidades médias de morte, conforme segue:

- aplicar a probabilidade de $75 \%$ para as pessoas expostas entre a fonte do vazamento e a curva de probabilidade de fatalidade de $50 \%$; curva;

- aplicar a probabilidade de $25 \%$ para as pessoas expostas entre as probabilidades de fatalidade de $50 \%$ e $1 \%$.

A Figura 2 mostra de forma mais clara a estimativa do número de fatalidades. 


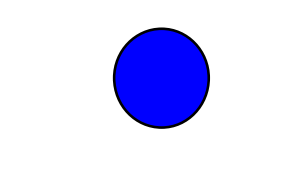

Fonte do Vazamento

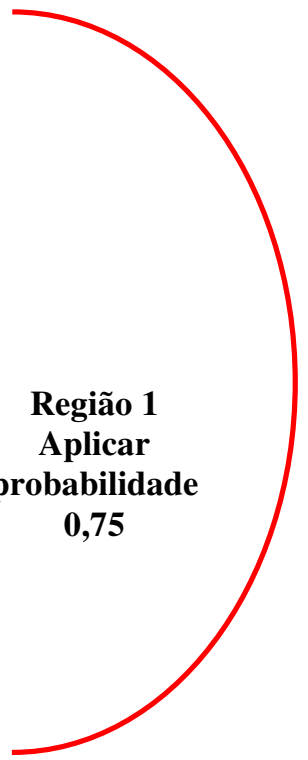

Curva de $50 \%$ de probabilidade de fatalidade

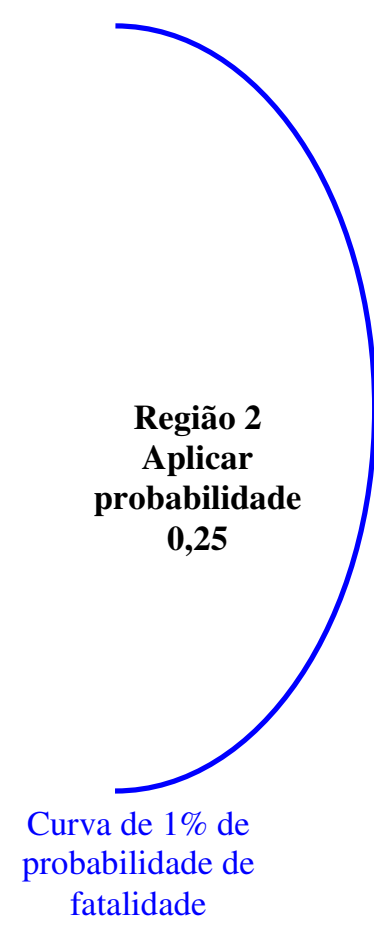

Figura 2 - Estimativa do número de vítimas para o cálculo do risco social.

Fonte: CETESB, 2003.

Considerando o anteriormente exposto, o número de vítimas fatais para cada um dos eventos finais poderá ser estimado, conforme segue:

$\mathrm{N}_{\mathrm{ik}}=\mathrm{Ne}_{\mathrm{k} 1} \cdot 0,75+\mathrm{Ne}_{\mathrm{k} 2} \cdot 0,25$

Onde:

$\mathrm{N}_{\mathrm{ik}} \quad$ = número de fatalidades resultante do evento final $\mathrm{i}$;

$\mathrm{Ne}_{\mathrm{k} 1}=$ número de pessoas presentes e expostas no

quadrante $\mathrm{k}$ até a distância delimitada pela curva correspondente à probabilidade de fatalidade de 50\%;

$\mathrm{Ne}_{\mathrm{k} 2}=$ número de pessoas presentes e expostas no

quadrante $\mathrm{k}$ até a distância delimitada pela curva correspondente à probabilidade de fatalidade de $1 \%$. 
Para o caso do incêndio de uma nuvem de vapor, o número de pessoas expostas é o correspondente a $100 \%$ do número das pessoas presentes sob a nuvem até o limite da curva correspondente ao Limite Inferior de Inflamabilidade (LII); assim tem-se:

\section{$\mathrm{N}_{\mathrm{ik}}=\mathrm{Ne}_{\mathrm{k}}$}

Onde:

$$
\begin{aligned}
\mathrm{N}_{\mathrm{ik}} \quad= & \text { número de fatalidades resultante do evento final } \mathrm{i} ; \\
\mathrm{Ne}_{\mathrm{k}} \quad= & \text { número de pessoas presentes no quadrante } \mathrm{k} \text { até a } \\
& \text { distância delimitada pela curva correspondente ao LII. }
\end{aligned}
$$

Para cada um dos eventos considerados no estudo, deve ser estimada a freqüência final de ocorrência, considerando-se as probabilidades correspondentes a cada caso, como por exemplo, a incidência do vento no quadrante, probabilidade de ignição e fator de proteção, entre outras; assim, tomando como o exemplo a liberação de uma substância inflamável, a freqüência de ocorrência do evento final i poderá ser calculada da seguinte forma:

$$
F_{i}=f_{i} \cdot p_{k} \cdot p_{i}
$$

Onde:

$$
\begin{array}{ll}
F_{i} & =\text { freqüência de ocorrência do evento final } i ; \\
f_{i} & =\text { freqüência de ocorrência do evento } i ; \\
p_{k} & =\text { probabilidade do vento soprar no quadrante } k ; \\
p_{i} & =\text { probabilidade de ignição. }
\end{array}
$$

O número de pessoas afetadas por todos os eventos finais deve ser determinado, resultando numa lista do número de fatalidades, com as 
respectivas freqüências de ocorrência. Esses dados devem então ser trabalhados em termos de freqüência acumulada, possibilitando assim que a curva F-N seja construída; assim, tem-se:

$$
\begin{gathered}
F_{N}=\sum F_{i} \text { para todos os efeitos decorrentes do evento final } \mathrm{i} \\
\text { para os quais } N_{i} \geq N
\end{gathered}
$$

Onde:

$$
\begin{aligned}
\mathrm{F}_{\mathrm{N}}= & \text { freqüência de ocorrência de todos os efeitos dos } \\
& \text { eventos finais que afetam } \mathrm{N} \text { ou mais pessoas; } \\
\mathrm{F}_{\mathrm{i}} \quad= & \text { freqüência de ocorrência de todos os efeitos } \\
& \text { causados pelo evento final } \mathrm{i} ; \\
\mathrm{N}_{\mathrm{i}} \quad= & \text { número de pessoas afetadas pelos efeitos } \\
& \text { decorrentes do evento final } \mathrm{i} .
\end{aligned}
$$

Os critérios de tolerabilidade estabelecidos para o risco social são valores médios de critérios internacionais atualmente vigentes (Reino Unido, Holanda, Hong Kong, Austrália, Estados Unidos e Suíça). O Gráfico 1 apresenta a curva F-N, adotada como critério para a avaliação do risco social. 


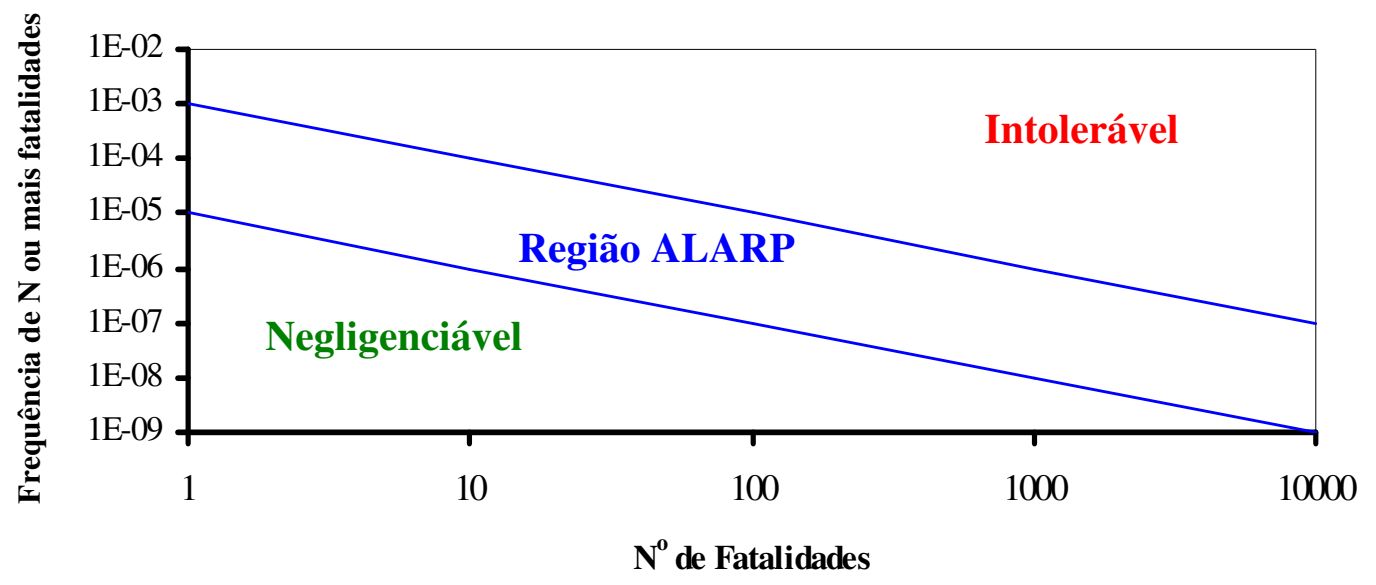

Gráfico 1 - Curva F-N de tolerabilidade para risco social. Fonte: CETESB, 2003.

Os riscos situados na região entre as curvas limites dos riscos intoleráveis e negligenciáveis, denominada ALARP (As Low As Reasonably Practicable), embora situados abaixo da região de intolerabilidade, devem ser reduzidos. 


\section{GEOPROCESSAMENTO}

O desenvolvimento da Informática, na segunda metade do século passado, tornou possível armazenar e representar informações geográficas em ambiente computacional, abrindo espaço para o surgimento do geoprocessamento. Logo, geoprocessamento pode ser definido como uma disciplina do conhecimento que utiliza técnicas matemáticas e computacionais para o tratamento de informação geográfica. (CÂMARA e MEDEIROS, 1996; BURROUGH e MCDONNEL, 1998; CAMARA et al, 2001).

O geoprocessamento, cada vez mais, é aplicado em diferentes áreas, como a cartografia, análise ambiental, transportes, comunicações, energia, saúde e planejamento urbano e regional. (CÂMARA e MEDEIROS, 1996; BURROUGH e MCDONNEL, 1998; CAMARA et al, 2001). O objetivo final dessas aplicações é oferecer respostas a problemas, permitindo melhor compreensão das variáveis dentro do espaço geográfico.

As atividades vinculadas ao geoprocessamento, também podem ser chamadas de geotecnologias, entre elas estão os Sistemas de Informação Geográfica (SIG), a Cartografia Digital, o Sensoriamento Remoto $^{2}$ e a Análise Espacial de Dados.

Um SIG é composto, sobretudo, por quatro componentes principais: software, hardware, dados e profissionais (usuários) (ROCHA, 2000). Tratase de um sistema destinado à aquisição, armazenamento, manipulação, análise e apresentação de dados georreferenciados. Os SIGs automatizam tarefas até então realizadas manualmente e facilitam a realização de

\footnotetext{
${ }^{2}$ Conjunto de técnicas que permitem obter informações de um objeto à distância. Os sensores remotos, geralmente instalados a bordo de satélites artificiais e aeronaves, captam dados sem o contato direto com a superfície da Terra.
} 
análises complexas, através da integração de dados de diversas fontes (ROSA, 1996).

Cada vez mais instituições governamentais, empresas e a população incorporam o uso do geoprocessamento. No entanto, ainda existe um enorme potencial de crescimento, pois se trata de uma tecnologia de custo relativamente baixo e existe uma grande carência de informações adequadas para a tomada de decisões sobre os problemas urbanos, rurais e ambientais.

No âmbito da saúde pública, a evolução do Geoprocessamento tem sido valiosa para diversos campos de pesquisa, particularmente para a epidemiologia e a saúde ambiental. As aplicações são diversas, valorizando o grande potencial dessas tecnologias em processos de implementação de políticas públicas.

\subsection{SISTEMA DE INFORMAÇÃO GEOGRÁFICA}

Os Sistemas de Informações Geográficas evoluíram de uma simples ferramenta analítica para uma nova disciplina, a tecnologia da informação geográfica (GOODCHILD, 1992). O SIG é um poderoso conjunto de ferramentas para coletar, armazenar, recuperar, transformar e visualizar dados espaciais sobre o mundo real para um determinado propósito (BURROUGH e MCDONNEL, 1998). Os sistemas de informações geográficas podem ser manuais ou computacionais. No entanto, com o grande avanço da computação, a maior ênfase é dada aos sistemas informatizados (ARONOFF, 1989).

CÂMARA e MEDEIROS (1996) consideram a existência de três gerações de sistemas, descritas a seguir: 
1) A primeira geração, do "CAD geográfico", desenvolvida no início da década de 80 , esteve orientada para trabalhos apenas com projetos isolados, sem a preocupação de gerar arquivos digitais de bancos de dados.

2) A segunda geração, iniciada na década de 90 , destinava-se aos bancos de dados geográficos, sendo concebida para o uso em ambientes cliente-servidor acoplados à gerenciadores de bancos de dados relacionais e complementadas com pacotes para o processamento de imagens.

3) A terceira geração caracteriza-se pela instalação de bibliotecas geográficas digitais ou centros de dados geográficos. Destinase ao gerenciamento de bases de dados geográficas acessadas por redes locais ou remotas, com interface via Web. São sistemas orientados para a troca de informações entre instituições e a sociedade.

Um SIG geralmente apresenta quatro tipos de componentes básicos: um subsistema de entrada de dados; um de armazenamento e recuperação de dados; um de manipulação permitindo a análise e geração de dados derivados; e um subsistema para apresentação dos dados tanto em forma tabular como gráfica (GOODCHILD e BRUSEGARD, 1989).

O sistema pode integrar dados de diversas fontes e criar bancos de dados georreferenciados, incorporando informações espaciais como imagens de satélite, dados de censo, cadastro urbano e rural. Potencialmente, o SIG é um poderoso recurso que viabiliza a análise, manipulação, integração, representação e disseminação de informações espaciais. Muitos aplicativos disponíveis no mercado agregam diversas funções no mesmo sistema como a modelagem 3D, análise espacial e o processamento digital de imagens. 
Com a evolução da internet e o barateamento dos componentes de hardware, software e disponibilidade de dados, ocorre também uma grande popularização dos SIGs, principalmente com o investimento de empresas de tecnologia da informação como a Google, que em 2006 lançou o Google Earth $^{3}$. Desta forma, cada vez mais, os SIGs ganham espaço fora do meio acadêmico.

\subsection{BANCO DE DADOS ESPACIAIS}

O banco de dados é um componente fundamental em um SIG. Ele consiste em um conjunto de dados organizados de forma ordenada, permitindo um acesso rápido e fácil às informações armazenadas. $O$ banco de dados geográfico é composto basicamente por dois tipos de dados: dados gráficos (entidades espaciais) e seus respectivos atributos.

Os dados espaciais têm a finalidade de representar a forma e posição dos elementos em uma superfície. Na tabela de atributos estão contidas as informações sobre as entidades espaciais, é onde se descrevem as características de cada feição geográfica armazenada, ou seja, os atributos ampliam a riqueza da informação.

Os bancos de dados espaciais possibilitam a representação de redes geográficas complexas, o relacionamento entre classes de feições e a realização de rotinas para a análise espacial dos dados, produzindo novas informações. Pode-se dizer que um banco de dados geográficos é uma coleção de dados referenciados espacialmente, que funciona como um modelo da realidade.

\footnotetext{
${ }^{3}$ Desenvolvido pela Keyhole Inc., uma companhia adquirida pela Google, o programa apresenta um modelo tridimensional do globo terrestre, construído a partir de imagens de satélite obtidas em fontes diversas.
} 


\subsection{PLANOS DE INFORMAÇÃO - LAYER}

No processo de interpretação da realidade em mapas foi estabelecido o conceito de plano de informação. De uma forma mais simples, planos de informação nada mais são do que camadas de informação, geralmente agregados por tema, ou seja, a realidade passa a ser representada por estratos, como exemplifica a Figura 3. Os planos de informação são representações simplificadas da realidade, uma vez que, nestes processos, sempre existe uma perda na informação.

\section{Transportes}

Uso do Solo

Setores Censitários

Infra-estrutura

Limites Administrativos

Imagem Raster

Figura 3 - Exemplo de diversos planos de informação.

Fonte: ESRI, 2004. 
Podem ser encontrados diversos nomes para níveis ou planos de informação, os mais comuns são "tema", "layer" e "overlay".

Layer é o nome difundido pelo AutoCAD, apesar de sistemas CAD se utilizarem do conceito de planos de informação, o modo como eles são armazenados, com vários layers em um único arquivo, limitam as operações analíticas. Uma característica distintiva dos SIGs é a capacidade de lidar com planos de informação das mais diversas origens, possibilitando ao usuário realizar análises e criar mapas a partir de dados de fontes distintas.

\subsection{FORMATOS DE REPRESENTAÇÃO DE DADOS GEOGRÁFICOS}

As operações analíticas dependem do modelo de representação dos dados espaciais no computador. Existem basicamente dois modelos de dados para a representação das informações geográficas: o modelo vetorial e o modelo raster.

Em ambos os modelos, os atributos das entidades espaciais podem ser temáticos ou numéricos, ou seja, a informação associada aos elementos geográficos pode ser qualitativa ou quantitativa.

A existência de vários formatos de representação aumenta o potencial de utilização do sistema devido à possibilidade de incorporar dados provenientes de fontes distintas, possivelmente em formatos diversos (MIRANDA et al, 1995). No entanto, para que seja possível a integração de dados de fontes e formatos distintos, quase sempre se faz necessária a compatibilização das informações.

\footnotetext{
4 Uma camada de papel translúcido utilizado na fotointerpretação e na sobreposição de mapas.
} 


\subsubsection{Modelo Vetorial}

O modelo vetorial representa características da superfície terrestre na forma de pontos, linhas e polígonos. Os pontos representam feições geográficas muito pequenas, ou simplificadas, para serem representadas como linhas ou áreas; linhas representam entidades muito estreitas para serem representadas como áreas; e áreas representam entidades geográficas homogêneas. A localização de cada ponto é armazenada como um único par de coordenadas x e y, linhas são registradas como séries de coordenadas $\mathrm{x}$ e y e áreas são registradas como séries de coordenadas $\mathrm{x} e$ y que definem segmentos de reta circundando uma área (ROCHA, 2000).

\subsubsection{Modelo Raster ou Matricial}

O modelo raster representa os dados espaciais como células em uma matriz bi-dimensional. $\mathrm{O}$ modelo raster pode representar objetos diversos. Um ponto é representado como o valor de uma única célula, uma linha como uma série de células conectadas e áreas como grupos de células conectados. A precisão de representação dos dados depende da área representada por cada célula da matriz. Ao contrário do modelo vetorial, o modelo raster pode representar superfícies contínuas, como um MNT (modelo numérico de terreno) (ROCHA, 2000).

\subsection{ANÁLISE ESPACIAL DE DADOS}

A análise espacial pode ser definida como procedimentos que possibilitam a obtenção de informações adicionais através da manipulação de dados espaciais (BAILEY, 1994). Existem diversas técnicas que envolvem o termo "análise espacial", todas elas buscam obter respostas 
através de operações sobre campos e objetos geográficos, favorecendo assim, um melhor entendimento sobre os fenômenos do mundo real e a possibilidade de se fazer predições.

O SIG é uma ferramenta de análise, que possibilita explorar dados espaciais e estabelecer relações de um fenômeno com sua localização no espaço, através de aspectos topológicos como conectividade, adjacência, proximidade e contingência.

Dentre as operações de análise espacial podemos incluir desde funções básicas, como consulta em bancos de dados à manipulação e sobreposição de mapas, produção de dados estatísticos, investigação de padrões e de relacionamentos dos elementos geográficos. A escolha do método de análise depende da estrutura e do formato dos dados utilizados.

Apesar de existir uma enorme variedade de funções de análise de dados disponíveis nos SIGs, não existe uma padronização dos termos e nenhuma das classificações existentes é totalmente aceita. A seguir, são descritas quatro grandes categorias de funções de análise espacial baseadas na classificação proposta por ARONOFF (1989):

1) Funções de acesso, classificação e medição: envolvem operações de consulta e seleção (query) da informação gráfica e alfanumérica de bancos de dados, bem como, a reclassificação e/ou generalização dos atributos das entidades espaciais, cálculos de distância, área, perímetro e etc.

2) Funções de sobreposição de mapas: permitem a realização de análises que demandam a combinação de duas ou mais camadas de dados (overlay), através de operadores de lógica booleana ou de álgebra de mapas. Usualmente, estas 
operações buscam a integração de dados e a construção de índices que auxiliam processos de tomada de decisão.

3) Funções de análise de vizinhança: muitas destas operações buscam detectar ou estimar valores em localizações não amostradas, assim como investigar padrões de distribuição espacial. Dentre as operações mais desenvolvidas destacamse as funções de interpolação, análise de padrões pontuais, geoestatística e modelagem tridimensional. Assumindo que dados próximos são espacialmente correlacionados entre si (BURROUGH, 1986), essas análises partem do conceito de Waldo Tobler de que "todas as coisas são parecidas, mas coisas mais próximas se parecem mais que coisas mais distantes".

4) Funções de análise de conectividade: envolvem, entre outras funções, a análise de redes. Estas funções caracterizam-se por permitir a descrição e a modelagem de processos de movimento, difusão, acumulação e influência espacial.

OPENSHAW (1991) faz uma distinção entre análise espacial e manipulação de dados, considerando que operações como sobreposições e consultas não são verdadeiramente operações de análise. Por outro lado, as técnicas de análise espacial receberam grande ênfase da área da geografia chamada Geografia Quantitativa (BAILEY e GATTRELL, 1995). Pode-se dizer que a principal característica da análise espacial é o estudo quantitativo da distribuição espacial de fenômenos.

A análise espacial é composta por um conjunto de procedimentos encadeados, cuja finalidade é a escolha de um modelo inferencial que considere explicitamente o relacionamento espacial presente no fenômeno. Os procedimentos iniciais da análise incluem o 
conjunto de métodos genéricos de análise exploratória e a visualização dos dados, em geral através de mapas. Essas técnicas permitem descrever a distribuição das variáveis de estudo, identificar observações atípicas (outliers) não só em relação ao tipo de distribuição, mas também em relação aos vizinhos, e buscar a existência de padrões na distribuição espacial. (CAMARA, 2002).

As técnicas de análise espacial, nos últimos anos, têm se desenvolvido buscando suporte computacional na Inteligência Artificial, por meio de tecnologias como Redes Neurais, Autômatos Celulares e Lógica Nebulosa (fuzzy) (BURROUGH e FRANK, 1996; OPENSHAW e OPENSHAW, 1997). Essas técnicas ampliam a capacidade de análise como, por exemplo, em estudos que buscam a integração de dados por análise de multicritérios.

A Análise Multicritérios é um procedimento metodológico de cruzamento de variáveis, amplamente aceito nas análises espaciais. Ela é também conhecida como Árvore de Decisões ou como Análise Hierárquica de Pesos. O procedimento baseia-se no mapeamento de variáveis por plano de informação e na definição do grau de pertinência de cada plano de informação e de cada um de seus componentes de legenda para a construção do resultado final. A matemática empregada é a simples Média Ponderada, mas há pesquisadores que já utilizam a lógica Fuzzy para atribuir os pesos e notas. (MOURA, 2007).

\subsection{ALGEBRA DE MAPAS - OVERLAY}

Álgebra de Mapas é uma linguagem computacional de alto nível usada para realizar análises espaciais. De uma forma mais simples, trata-se de matemática aplicada a mapas, uma prática que é possível porque os SIGs permitem empilhar planos de informação um sobre 0 outro. Obviamente, dependendo do modelo de dados, pode-se realizar de aritmética simples aos mais sofisticados algoritmos. 
$\mathrm{Na}$ maioria dos SIGs existem conjuntos de ferramentas que, por intermédio da aplicação de cálculos matemáticos sobre as imagens ou mapas, permitem produzir novas informações espaciais. Segundo EASTMAN (1997) apud ROCHA (2000) existem 03 tipos básicos de operações de álgebra com mapas:

1) Modificar aritmeticamente os valores de uma imagem por uma constante escalar;

2) Transformar valores atribuídos por operação padrão como funções trigonométricas ou transformações logarítmicas;

3) Combinar matematicamente diferentes níveis de informação (layers) contidos em imagens produzindo um resultado composto através da adição, subtração, multiplicação ou divisão.

TOMLIN (1990) propõe a linguagem MAP (Map Analysis Package), para realizar operações de modelagem espacial, que serve de base para muitas implementações comerciais. Destas, a implementação mais difundida é a linguagem Grid, disponível nos sistemas ArclNFO e ArcGIS (apresentado no item 5.2.2).

\subsection{GEOPROCESSAMENTO E ANÁLISE DE RISCO}

Atualmente, existem muitos exemplos de aplicações dos SIGs relacionados ao gerenciamento e análise de risco tecnológicos, tendo sido demonstrada a sua utilização como instrumento de suporte ao planejamento e implementação de políticas públicas (BARTELS, 1998; FEDRA, 1998; PRUPPERS, 1998), na análise de risco de instalações industriais (BRAZIER e GREENWOOD, 1998; CONTINI, 2000; COZZANI, 2006; IOANNIDIS et al, 
1999; WIERSMA, et al, 2005), na avaliação de riscos atmosféricos (EPA, 1997), avaliação de riscos á saúde pública de contaminantes no solo (LOURENÇO e LANDIM, 2005), entre outros.

Os SIGs possuem um grande potencial para integração dos dados e cálculo cumulativo dos riscos (PRUPPERS, 1998; COZZANI, 2006). WIERSMA, et al, 2005, aborda métodos de integração dos dados de risco social, inclusive através da definição de áreas de cálculo.

Em função de suas características, os SIGs apresentam-se bastante adequados como ferramentas para o presente estudo, pois, permitem incorporar dados numéricos, cartográficos e imagens de satélite, favorecendo uma análise integrada dos fatores de riscos tecnológicos. 


\section{MATERIAIS E MÉTODOS}

Para desenvolver uma estratégia de análise integrada dos riscos das instalações industriais, foram empregados softwares específicos de análise de risco e Sistema de Informação Geográfica (SIG). O software de análise de risco foi responsável por simular possíveis cenários acidentais, gerando polígonos de extensão das áreas atingidas. Já o SIG foi utilizado para a sobreposição dos resultados, geração de um banco de dados, soma dos valores de risco e plotagem dos mapas.

Os modelos de simulação de acidentes não foram investigados com profundidade, uma vez que o tema deste estudo é a integração das informações geográficas da análise de risco. Foram observadas apenas as possíveis interfaces entre os softwares e as técnicas de tratamento dos dados.

Na organização do SIG foi definida uma base cartográfica, com os seguintes planos de informação: hidrografia, limites regionais, limite da zona industrial, rede de transporte, setores censitários e fotografias aéreas. 0 sistema de projeção utilizado foi o UTM (Universal Transversa de Mercator), fuso 23, Datum ${ }^{5}$ SAD69 (South American Datum of 1969), e a escala de trabalho adotada foi 1:15.000.

Foram pesquisadas na literatura metodologias atualmente utilizadas para a espacialização de riscos, considerando experiências nacionais e internacionais, no intuito de compreender as melhores alternativas para 0 Município de Paulínia.

\footnotetext{
${ }^{5}$ Um conjunto de parâmetros e pontos de controle usados para definir com precisão a forma da Terra. O datum é a base dos sistemas de coordenadas. Fonte: CARVALHO, PINA e SANTOS, 2000.
} 
Os dados gerados pelo software de análise de risco, resultados da modelagem matemática de eventos, assim como os dados quantitativos de risco (freqüências de ocorrência e probabilidade de fatalidade), foram obtidos através de colaboração com o Projeto FAPESP 2004/00366-6. O projeto foi realizado no Departamento de Saúde Ambiental da Faculdade de Saúde Pública da USP, no período de março de 2005 a abril de 2007, com o objetivo inicial de analisar a distribuição dos riscos tecnológicos no pólo industrial de Paulínia, a partir dos Estudos de Análise de Riscos analisados e aprovados pela CETESB.

Entretanto, o Projeto constatou que os EARs, de maneira geral, possuíam uma baixa qualidade técnica e havia muita dificuldade para a caracterização das instalações e a identificação das hipóteses acidentais. Segundo o relatório técnico, muitos estudos estavam incompletos, não apresentavam as informações de forma clara e possuíam erros conceituais ou conflitos de informações (NARDOCCI, 2007).

Assim, foram gerados cenários acidentais a partir de um conjunto de hipóteses e layouts básicos para os empreendimentos. As únicas informações consideradas dos EARs foram alguns valores de volumes e dimensões dos tanques.

Os cenários simulados alimentaram um banco de dados geográficos, com a finalidade de dar suporte à integração dos riscos individuais e sociais relacionados à atividade industrial do Município de Paulínia e estimar os riscos a população. 


\subsection{MATERIAL BIBLIOGRÁFICO, CARTOGRÁFICO E ICONOGRÁFICO}

Para a realização do trabalho foi estruturada uma abrangente base de documentos. Foram levantados materiais bibliográficos, cartográficos e iconográficos, de modo a fornecer subsídios à análise dos dados.

Dentre os materiais bibliográficos foram consultados livros, teses, dissertações, artigos acadêmicos, documentos técnicos, tutoriais de geoprocessamento, páginas da Internet, entre outros. As pesquisas foram realizadas através das bibliotecas da Faculdade de Saúde Pública (FSPUSP), Universidade de Campinas (UNICAMP) e da Companhia de Tecnologia de Saneamento Ambiental (CETESB).

Dentre os materiais cartográficos e iconográficos foram obtidos os seguintes dados:

- Base digital do Município de Paulínia, do ano de 2005, obtida junto à Secretaria de Planejamento e Coordenação do Município de Paulínia, em formato DWG ${ }^{6}$, compatível com a escala 1:10.000 e sistema de projeção UTM SAD69.

- Malha de setores censitários, do ano de 2000, obtida através do Instituto Brasileiro de Geografia e Estatística (IBGE), no formato Shapefile e sistema de projeção UTM SAD69.

- Quatro fotografias aéreas, do ano de 2005, escala do vôo 1:30.000, em formato digital TIFF, sem referência geográfica, obtida através da empresa Base Service.

\footnotetext{
${ }^{6}$ Extensão de arquivos de desenho em 2D e 3D nativa do software AutoCAD.
} 


\subsection{EQUIPAMENTOS E APLICATIVOS}

Foi utilizado um microcomputador com a seguinte configuração: processador Pentium $42.8 \mathrm{GHz}, 1.00 \mathrm{~GB}$ de memória RAM, disco rígido de 80GB, unidade (combo drive) CD-RW/DVD-RW, teclado alfanumérico, mouse óptico, monitor VGA 17", sistema operacional Windows XP e acesso a Internet.

Para a edição dos textos e o tratamento estatístico dos dados foram utilizados 0 editor de texto Word e o editor de planilhas Excel do pacote Microsoft Office XP.

O software de análise de risco adotado foi o Effect-GIS 5.5. O SIG utilizado foi o ArcGIS $9.1 \mathrm{com}$ o pacote ArcView, também foram usados, no tratamento dos dados, o módulo Spatial Analyst?, a extensão ET GeoWizards $^{8}$ e a versão 3.2 do ArcView.

\subsubsection{Effects-GIS}

O Effects-GIS 5.5 é um software comercial de análise de risco, desenvolvido pela empresa holandesa TNO, de grande aceitação no mercado. Ele modela processos de acidentes, desde o vazamento inicial à dispersão, bem como os efeitos envolvendo produtos inflamáveis e tóxicos. O software possui uma interface de fácil compreensão, além disto, possui

\footnotetext{
${ }^{7}$ O ArcGIS Spatial Analyst é uma extensão do ArcGIS, comercializada pela ESRI, que fornece uma grande variedade de funções para a modelagem e análise espacial de dados matriciais; análises integradas entre matrizes e vetores; e análise de informações em múltiplas camadas.

${ }^{8}$ O ET Geowizard é uma extensão do ArcGIS, oferecida gratuitamente, que dispõe de um amplo conjunto de ferramentas para o tratamento de dados vetoriais (pontos, linhas, polígonos e atributos). Disponível em http://www.ian-ko.com.
} 
algumas ferramentas auxiliares para conversão de unidades e cálculo de massa e volume.

O Effects-GIS armazena um Banco de Dados com informações de mais de 100 substâncias perigosas de uso industrial, esses dados podem ser utilizados na execução de modelos como: taxa de vazamento, evaporação de poça, dispersão atmosférica, explosão, combustão e radiação de calor.

Apesar de não possuir o etanol entre as substâncias do Banco de Dados, o sistema permite que novas substâncias sejam inseridas, desde que se tenham todas as informações necessárias. O programa dispõe de recursos que auxiliam na entrada dos dados, buscando dar consistência às informações.

O Effects-GIS importa arquivos georreferenciados, entre eles arquivos Shapefiles e imagens no formato GeoTiff. Facilitando, assim, a inserção de coordenadas dos pontos de liberação e a sobreposição de layouts dos empreendimentos. Desta forma, os resultados também podem ser exibidos diretamente sobre uma base geográfica.

As áreas de influência dos cenários acidentais são representadas por polígonos, em formato vetorial, gerados em um arquivo Shapefile. $O$ software permite que sejam simulados os mesmos cenários para diversos empreendimentos simultaneamente ou para até 16 direções preferenciais do vento. No entanto, não existem recursos para o gerenciamento dos resultados. As informações requeridas na geração dos modelos apenas podem ser salvas em um arquivo de leitura, e, os resultados são sobrepostos a cada novo processamento. Desta forma, existem limitações consideráveis em se trabalhar grandes volumes de dados. 
O Effects-GIS também não oferece uma opção direta para a exportação dos dados georreferenciados, e, por se tratar de um sistema de código fechado, não existe a possibilidade de se construir uma interface para automatizar a saída dos dados. No entanto, o programa constitui uma avançada ferramenta de análise de riscos e auxilia no desenvolvimento de planejamentos regionais e planos de controle de emergências.

\subsubsection{ArcGIS}

O ArcGIS 9.1 é um Sistema de Informações Geográficas, da classe dos sistemas conhecidos como "Desktop GIS", desenvolvido pela ESRI (Environmental Systems Research Institute). Ele dispõe de diversos recursos de geoprocessamento, permite o acesso a bancos de dados geográficos em computadores pessoais e possui uma interface gráfica de fácil acesso. (ESRI, 2004)

A ESRI é uma das principais empresas de software de SIG. O lançamento do ArcGIS 8.3, em 2003, acrescentou novas perspectivas ao mercado de geotecnologias. O ArcGIS Desktop foi desenvolvido para combinar as funcionalidades do ArcView 3.x com as completas funções de edição e análise disponíveis no ArcINFO 7. $x^{*}$, sob uma única arquitetura de software, baseada no Windows.

Com o nome "ArcGIS Desktop" são comercializadas as versões Arclnfo, ArcEditor e ArcView, que compartilham a mesma arquitetura, o que difere um sistema do outro é o número de funções, que varia de uma versão mais simples (ArcView) até a mais completa (Arclnfo), com ferramentas avançadas para manipulação de dados espaciais e alfanuméricos (ESRI, 2004). 
O ArcGIS é um sistema modular constituído, entre outras, por três unidades básicas: o ArcMap, o ArcCatalog e o ArcToolbox. As principais características destes aplicativos estão descritas de forma resumida a seguir:

- O ArcMap pode ser considerado o módulo principal, ele reúne ferramentas para a manipulação, análise e apresentação de mapas. Com ele é possível visualizar dados geográficos, resolver questões de análise espacial e criar layouts para impressão.

- O ArcCatalog permite a rápida visualização dos dados, com ele é possível procurar, gerir, criar, organizar e exportar dados geográficos e alfanuméricos. O Aplicativo também suporta vários modelos para metadados permitindo criar, editar e visualizar informação acerca dos dados.

- O ArcToolbox contém ferramentas usadas para o processamento de dados geográficos. O número de ferramentas varia de acordo com a versão do ArcGIS e de "extensões", comerciais ou gratuitas, distribuídas separadamente pela ESRI.

As operações analíticas dependem do modelo de representação dos dados espaciais no computador. O ArcGIS é um sistema híbrido e suporta diferentes modelos de dados para a representação das informações geográficas, entre eles, modelos vetorial e raster.

$\mathrm{Na}$ versão ArcView do ArcGIS, é possível visualizar e importar arquivos como: DXF e DWG, Coverages e Grids do programa ArcINFO, 
imagens no formato TIFF, IMG, BSQ, BIL, BIP, Sun rasterfiles, BMP, Runlength compressed files e JPEG.

No ArcGIS, podem ser criados dados vetoriais em arquivos Shapefile ou dentro de uma estrutura chamada Geodatabase. Dados matriciais podem ser gerados em arquivos Grid, GeoTiff e IMG, e, também, podem ser armazenados em Geodatabases, dependendo da versão do software.

O Geodatabase é um formato de banco de dados relacional desenvolvido pela ESRI e incorporado a partir do lançamento do ArcGIS. Existem duas categorias de Geodatabases, são elas: "Personal Geodatabases" e "Multiuser Geodatabases". (ESRI, 2004)

O Personal Geodatabase permite a edição dos dados por apenas um usuário, armazena todos os dados em um arquivo do Microsoft Access (MDB) e possui limite de capacidade de armazenamento de 2GB. Já a categoria Multiuser Geodatabases permite a edição dos dados por múltiplos usuários, entretanto ele requer um servidor de banco de dados, como Oracle, SQL Server, IBM DB2 ou Informix. (ESRI, 2004)

Os dados em um Geodatabase são organizados em estruturas de classes de objetos ou feições, com o mesmo tipo de geometria (ponto, linha, polígono), chamadas de "feature class" (classe de feição). E coleções de feature classes, que compartilham a mesma referência espacial, chamadas de "feature dataset".

Outra grande característica do ArcGIS é a linguagem de programação, que permite personalizar o software ou criar funcionalidades para atender as necessidades do usuário. A ESRI estimula 0 desenvolvimento de aplicações utilizando linguagem "Script", a linguagem mais utilizada é a "Python", no entanto, outras também têm sido aplicadas, especialmente "Perl" e "VBScript". (ESRI, 2004) 


\subsection{SELEÇÃO E COMPATILIZAÇÃO DOS DADOS GEOGRÁFICOS}

A composição de uma base de dados geográficos, adequada à realização do trabalho, se deu através da definição dos dados de interesse, entre as diferentes fontes e formatos, e, da execução de procedimentos para a integração destes dados.

Da base cartográfica digital do Município de Paulínia foram selecionados elementos como a rede viária, hidrografia e limites regionais, utilizando ferramentas de seleção do ArcMap. Em seguida, os dados foram exportados para o formato Shapefile, mantendo-se o mesmo sistema de projeção cartográfica.

As fotografias aéreas foram georreferenciadas através da obtenção de coordenadas de pontos de controle ${ }^{9}$, extraídos da base cartográfica do Município de Paulínia. O georreferenciamento foi realizado no ArcMap sob o sistema de coordenadas UTM SAD69. As imagens foram convertidas para 0 formato GeoTIFF.

\section{4 ÁREA DE ESTUDO}

O estudo foi desenvolvido para a região do Distrito Industrial de Paulínia, onde há a concentração da atividade industrial e o armazenamento, em grandes quantidades, de substâncias perigosas. Optouse por desenvolver o estudo na região, pois, destaca-se no Estado de São

\footnotetext{
${ }^{9}$ Os pontos de controle são locais facilmente identificáveis, tais como intersecções de estradas e de rios, pistas de aeroportos, edifícios proeminentes e topos de montanha. A obtenção dessas coordenadas pode ser realizada por meio de uma base geográfica (carta topográfica, imagens ou mapas georreferenciados), ou ainda, em levantamento de campo, com auxilio de GPS (Sistema de Posicionamento Global).
} 
Paulo como um pólo de desenvolvimento de expressiva atuação no setor produtivo e tecnológico, e, com atividades relacionadas à questão proposta.

A atividade industrial em Paulínia teve inicio em 1942, quando foi instalada a primeira indústria química, a Rhodia Indústrias Químicas e Têxteis. Já nesta época, Paulínia tinha uma alta arrecadação de impostos e renda per capita elevada em comparação com outros municípios (MAZIERO e SOARES, 1999).

A área pertencia a Campinas e era ocupada por grandes fazendas de café. Em 1944 foi elevada à condição de Distrito e em 1964, foi criado o Município de Paulínia. Em 1966, o governo federal decidiu instalar uma refinaria de petróleo da PETROBRÁS, a Refinaria do Planalto - REPLAN, inaugurada em maio de 1972 (MAZIERO e SOARES, 1999). A REPLAN é hoje considerada a maior refinaria da Petrobrás em termos de produção.

O Município possui uma área de $139,33 \mathrm{~km}^{2}$ (IBGE, 2002) e está localizado a nordeste do Estado de São Paulo, a uma distância de apenas 118 km da Capital (PAULínIA, 2008). A Figura 4 mostra a localização do Município de Paulínia. 


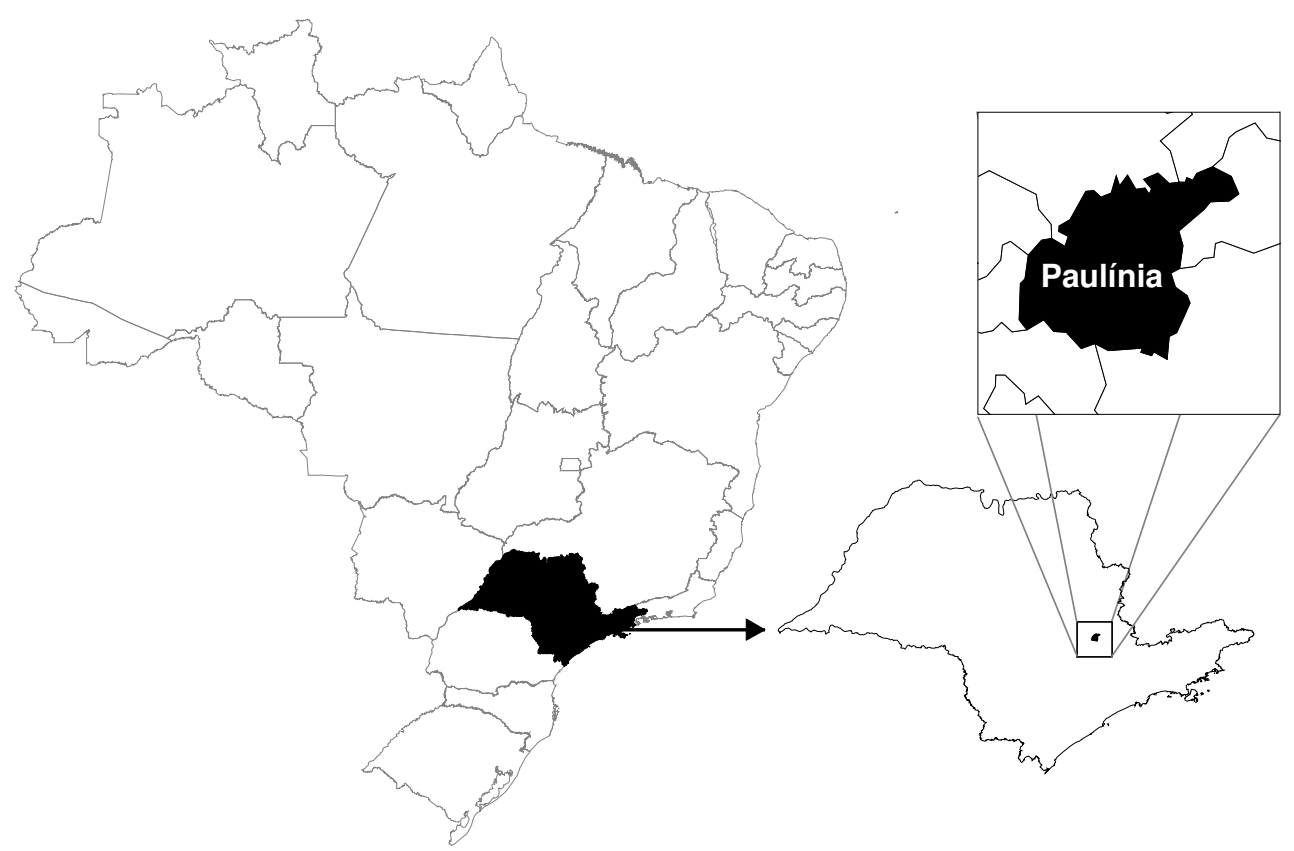

Figura 4 - Localização do Município de Paulínia.

Paulínia é um dos 19 municípios da Região Metropolitana de Campinas. Em 2004, a região foi responsável por 9,4\% do Produto Interno Bruto do estadual. Em 2005, a população da região ultrapassou os 2,5 milhões de habitantes, representando $6,5 \%$ da população do Estado (SÃO PAULO, 2007). A figura abaixo mostra a Região Metropolitana de Campinas, com destaque para o Município de Paulínia. 


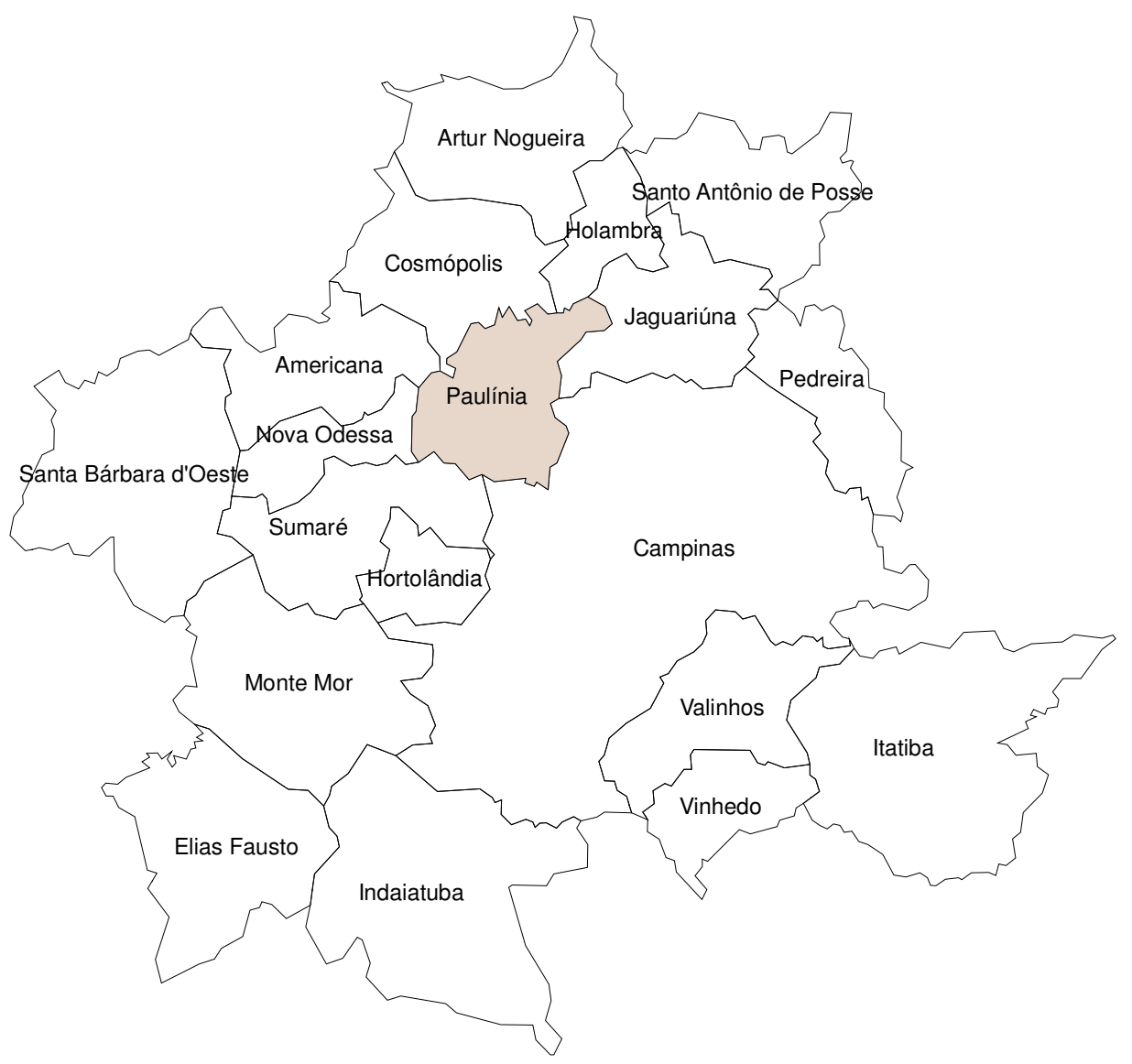

Figura 5 - Municípios da Região Metropolitana de Campinas.

A região é constituída por uma rede urbana fortemente integrada por uma boa infra-estrutura de transporte. O fluxo de transporte regional é suprido por uma excelente malha rodoviária, com destaque para as rodovias Anhanguera, Bandeirantes e D. Pedro I. Também há que se destacar o Aeroporto Internacional de Viracopos, o maior aeroporto em transporte de cargas e o segundo maior em volume do país (SÃO PAULO, 2007).

O município, assim como o Distrito Industrial, é cortado pela Rodovia General Milton Tavares de Souza (SP-332), também conhecida como Rodovia Campinas-Paulínia ou Tapetão. A rodovia possui intenso tráfego e faz a ligação entre as zonas urbanas de Campinas e Paulínia, e, a zona industrial. 
Segundo o ultimo censo demográfico, a população residente em 2000 era de 51.326 habitantes (IBGE, 2000). Em 2007 a contagem da população, recenseada e estimada, foi de 73.014 habitantes (IBGE, 2007), o que resulta em uma densidade demográfica de $524 \mathrm{hab} / \mathrm{km}^{2}$. Os dados relativos à população de Paulínia, por sexo e área de residência, são apresentados na Tabela 1.

Tabela 1 - População do Município de Paulínia, por área de residência e sexo, segundo dados do Censo Demográfico do IBGE de 2000.

\begin{tabular}{c|c|c|c|c|c}
\hline $\begin{array}{c}\text { Área de } \\
\text { residência }\end{array}$ & $\mathbf{N}$ & $\%$ & Sexo & $\mathbf{N}$ & $\%$ \\
\hline Urbana & 50.762 & 98,9 & Homens & 25.688 & 50,1 \\
Rural & 564 & 1,1 & Mulheres & 25.638 & 49,9 \\
\hline Total & $\mathbf{5 1 . 3 2 6}$ & $\mathbf{1 0 0}$ & Total & $\mathbf{5 1 . 3 2 6}$ & $\mathbf{1 0 0}$ \\
\hline
\end{tabular}

O mapa abaixo mostra a distribuição da população de Paulínia por setor censitário, segundo dados do IBGE do ano de 2000, e, a localização da zona industrial. Nesta época, a densidade demográfica municipal era de $308,44 \mathrm{hab} / \mathrm{km}^{2}$. 


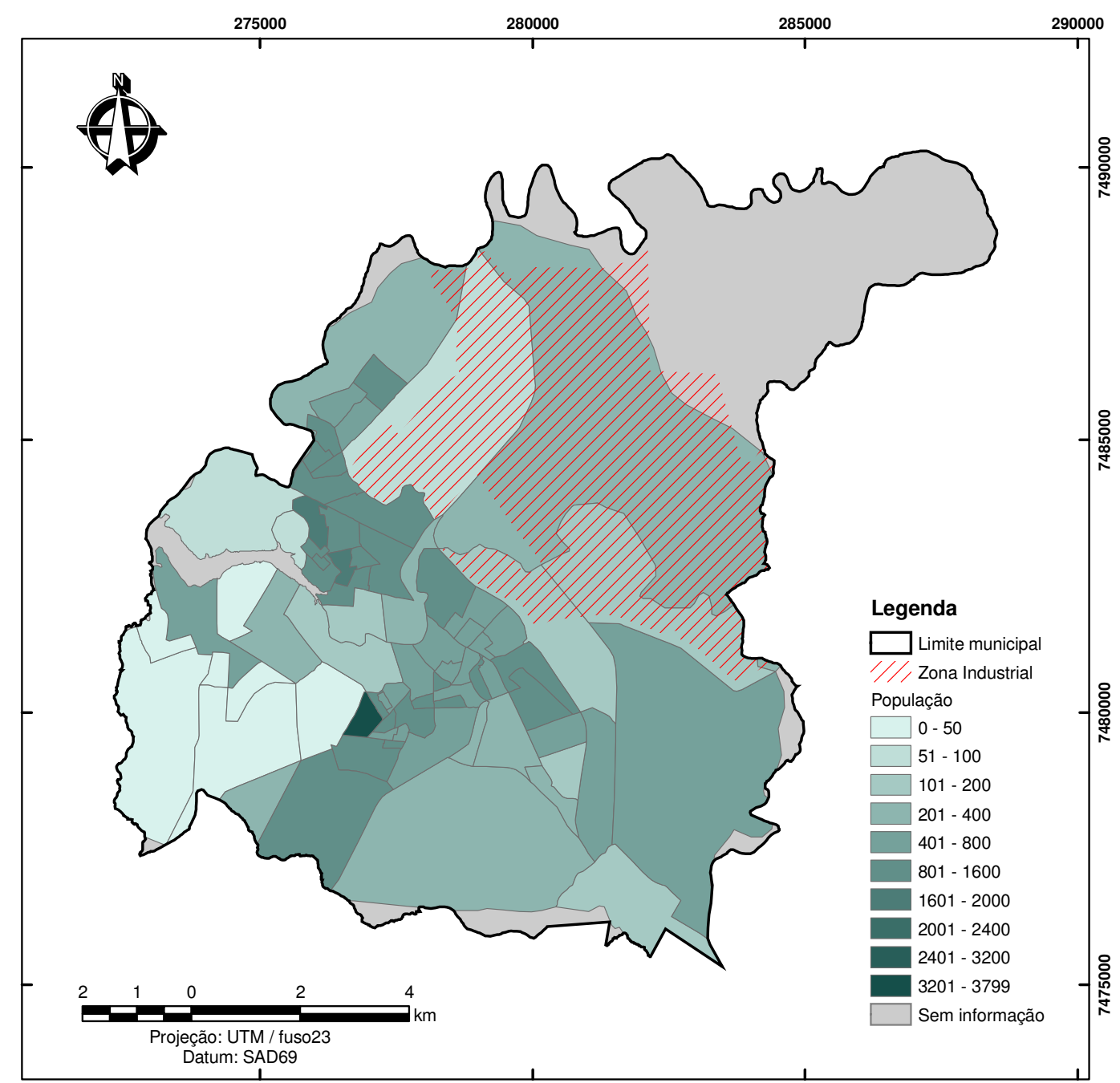

Mapa 1 - Distribuição da população de Paulínia por setor censitário, segundo dados do IBGE do ano de 2000, e localização do Distrito Industrial.

Segundo dados do Perfil Municipal da Fundação SEADE, os índices de desenvolvimento econômico e social do município, em geral, estão acima da média do Estado como, por exemplo, a taxa de mortalidade infantil em 2006 de 11,31 por mil nascidos vivos (a taxa média do Estado foi de 13,28). Para o ano de 2004, o Índice Paulista de Responsabilidade Social - IPRS Dimensão Riqueza foi de 59, enquanto o do Estado foi de 50; o IPRS Dimensão Longevidade foi de 74, contra um valor de 67 para o Estado. $O$ Índice de Desenvolvimento Humano Municipal - IDHM em 2000 foi de 0,847, enquanto o IDH do Estado foi de 0,814. 
Em relação à habitação e infra-estrutura urbana, os indicadores do perfil municipal mostram que as condições do município estão próximas da média. Também merece ser destacado o alto valor do PIB per Capita em 2005, que foi de 106.081,86 (reais correntes), enquanto o valor médio do Estado foi de 17.977,31 (reais correntes) (SEADE).

Quanto ao relevo verifica-se que o Município de Paulínia assenta-se sobre uma área de Depressão Periférica. O relevo suavizado deste compartimento geomorfológico propicia o estabelecimento de aglomerados urbanos. Além disso, os solos resultantes da desagregação de relevos que embasam a zona do Médio Tietê são potencialmente mais adequados à agricultura (SÃO PAULO, 2007).

Paulínia teve seu desenvolvimento econômico acelerado nos últimos anos, recebendo um grande número de empreendimentos industriais e estabelecimentos comerciais, relacionados direta ou indiretamente com a Refinaria de Petróleo. Entre esses empreendimentos, damos destaque às empresas de estocagem e distribuição de produtos combustíveis.

O Distrito Industrial do Município, segundo o plano diretor, é composto pela ZUPI - Zona Predominantemente Industrial e ZUI - Zona de Uso Industrial (PAULÍNIA, 2007), como mostra o Mapa 2. Nele estão localizadas empresas de distribuição dos produtos processados, como o gás liquefeito de petróleo (GLP) e combustíveis líquidos, entre eles, gasolina, diesel e álcool, em detalhe no Mapa 3. 


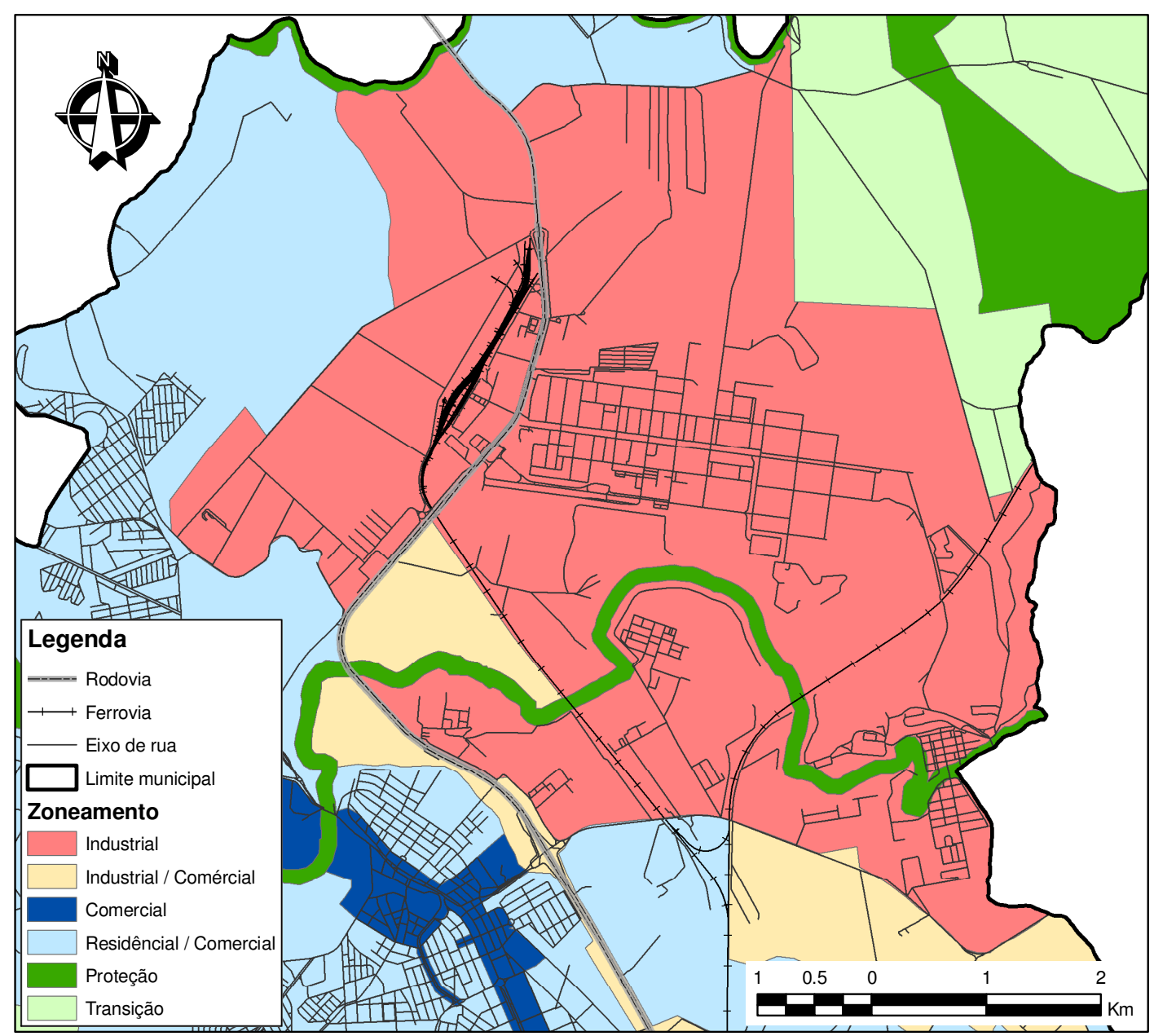

Mapa 2 - Zoneamento do uso do solo na região do Distrito Industrial de Paulínia.

\subsection{INSTALAÇÕES INDUSTRIAIS}

As empresas e instalações industriais importantes, do ponto de vista de acidentes, foram identificadas por meio de foto aérea e um levantamento de campo em junho de 2006. A foto aérea, também, foi usada para a contagem do número de tanques existentes em cada empreendimento e a definição das coordenadas dos pontos de liberação. Para cada empreendimento, foi considerado o mesmo ponto de liberação para todas as hipóteses acidentais. 
Foram identificadas 9 empresas de distribuição de GLP e 18 empresas distribuidoras de combustíveis líquidos, as quais foram consideradas neste estudo. A localização das instalações industriais na área de estudo é apresentada no Mapa 3.
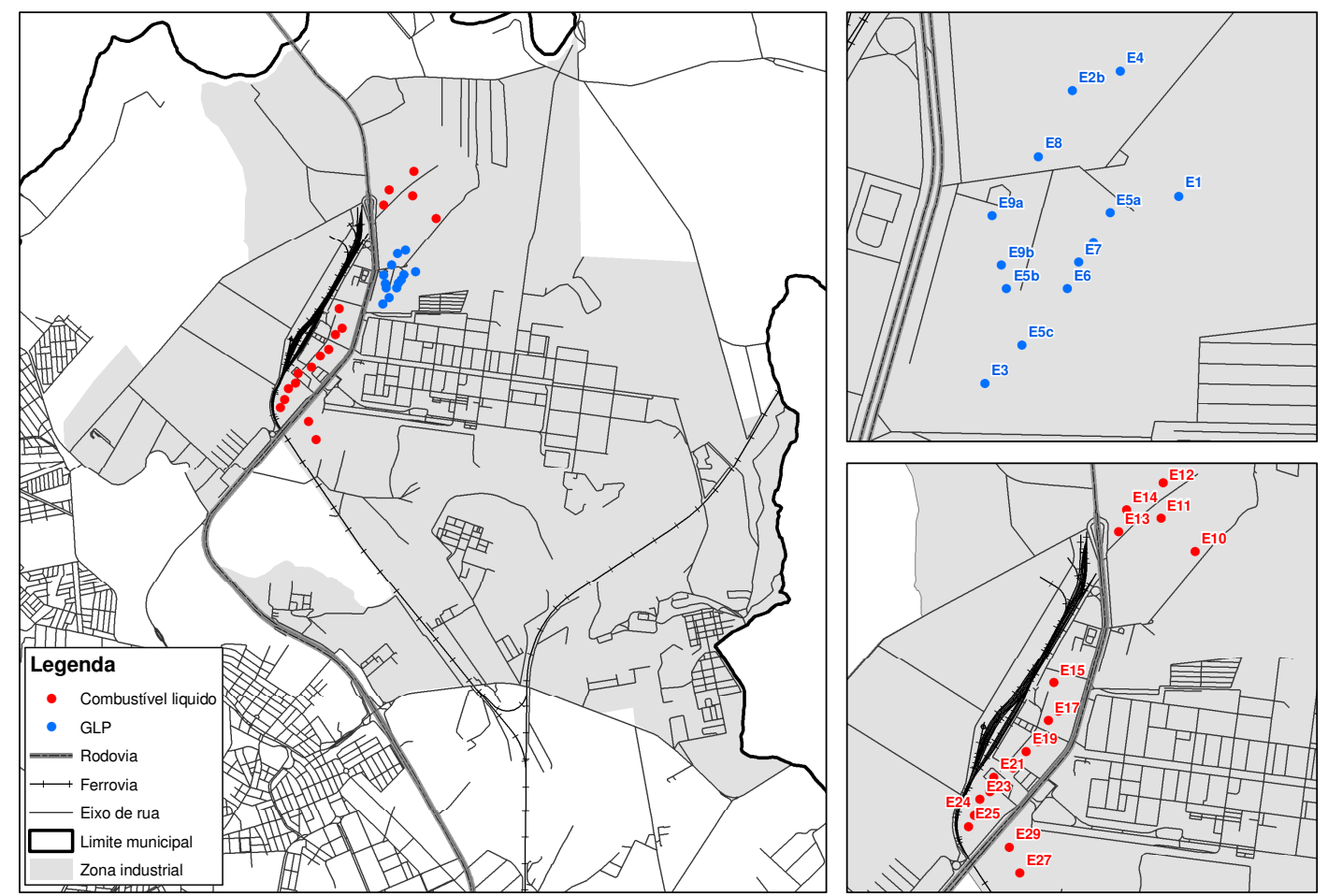

Mapa 3 - Localização das instalações industriais estudadas.

Vale ressaltar que a área onde se localizam estas empresas é cortada por uma rodovia de grande circulação, principalmente circulação de produtos que chegam e saem das instalações de distribuição de GLP e combustíveis líquidos. Dada a grande quantidade de empresas de distribuição que se concentra nesta área, a movimentação dos produtos perigosos é muito intensa. Outro aspecto a ser observado é que estas empresas se encontram relativamente próximas do limite do Distrito Industrial. 


\subsubsection{Instalações de GLP}

O GLP é uma mistura de hidrocarbonetos, incolor, inflamável e asfixiante, se aspirado em altas concentrações. No Brasil, o GLP é usado na indústria e como combustível doméstico. A queima do GLP produz baixas emissões de poluentes, quando comparada com a queima de gasolina, diesel ou óleo combustível. A crescente utilização do GLP como combustível está diretamente relacionada à estrutura de armazenamento e transporte.

As instalações de engarrafamento e distribuição de GLP propiciam o recebimento do produto via gasoduto, o armazenamento em vasos pressurizados, o engarrafamento em botijões de uso doméstico e cilindros industriais, e a distribuição por meio de caminhões-tanque. Os vasos de estocagem são do tipo cilíndrico, horizontal, pressurizado, e, as instalações operam com apoio dos devidos equipamentos de segurança e controle de emergência. A Tabela 2 apresenta informações gerais das instalações de GLP na área.

Tabela 2 - Informações gerais das instalações de armazenamento e distribuição de GLP, consideradas neste estudo.

\begin{tabular}{c|c|c|c|c}
\hline \multirow{2}{*}{ Código } & \multicolumn{2}{|c|}{$\begin{array}{c}\text { Coordenadas do ponto de } \\
\text { liberação (UTM) }\end{array}$} & $\begin{array}{c}\text { Volume } \\
\text { dos tanques } \\
\left(\mathbf{m}^{3}\right)\end{array}$ & $\begin{array}{c}\text { No de } \\
\text { tanques }\end{array}$ \\
\cline { 2 - 3 } $\mathbf{X}$ & $\mathbf{Y}$ & $140^{* *}$ & 3 \\
\hline E1 & 280408 & 7486112 & $117^{* *}$ & 8 \\
E2a $^{*}$ & 280255 & 7486027 & 117 & 12 \\
E2b* $^{*} 280217$ & 7486301 & $150^{\star *}$ & 12 \\
E3 & 280060 & 7486775 & 117 & 6 \\
E4 & 280303 & 7486336 & 117 & 8 \\
E5a* & 280285 & 7486080 & 117 & 6 \\
E5b* & 280099 & 7486945 & 117 & 12 \\
E5c* & 280127 & 7486844 & 117 & 6 \\
E6 & 280208 & 7486945 & 117 & 6 \\
E7 & 280228 & 7486992 & 117 & 8 \\
E8 & 280156 & 7486183 & 117 & 12 \\
E9a* & 280073 & 7486075 & 117 & 6 \\
E9b* & 280090 & 7486987 & \\
\hline
\end{tabular}

*referem-se à mesma empresa, mas a conjuntos de tanques distintos.

**informação obtida dos respectivos EARs. Os demais empreendimentos foram considerados iguais a E2a, por ser uma das instalações mais novas e com projeto mais moderno. 
O vazamento do produto no ambiente forma uma nuvem que pode resultar em uma explosão do tipo UVCE (explosão de nuvem não confinada) ou em um flashfire (incêndio rápido da nuvem). Outro evento acidental importante envolvendo tanques de estocagem de GLP é o BLEVE (explosão catastrófica do reservatório).

\subsubsection{Instalações de combustíveis líquidos}

A grande maioria dos combustíveis líquidos é obtida a partir do petróleo, como a gasolina, querosene e o óleo diesel. No entanto, a busca por fontes renováveis de energia tem colocado os chamados biocombustíveis em destaque. No Brasil, a maior contribuição é o etanol ou álcool combustível, produzido através da cana-de-açúcar. Os combustíveis líquidos têm certas vantagens tais como: elevado poder calorífico, facilidade de armazenagem e de distribuição.

As instalações de estocagem e distribuição de combustíveis líquidos basicamente são compostas de: tanques, barreiras de contenção, tanque de água de incêndio, plataformas de carregamento, praça de bombas, central de líquido gerador de espuma e caixa separadora de água e óleo. A distribuição dos combustíveis é feita através de caminhões-tanque e o processo de carregamento nas plataformas é conduzido por sistemas automáticos de controle. A Tabela 3 apresenta informações gerais das instalações de combustíveis líquidos. 
Tabela 3 - Informações gerais das instalações de armazenamento e distribuição de combustíveis líquidos, consideradas neste estudo.

\begin{tabular}{l|c|c|c|c|c}
\hline \multirow{2}{*}{ Código } & \multicolumn{2}{|c|}{$\begin{array}{c}\text { Coordenadas do ponto de } \\
\text { liberação (UTM) }\end{array}$} & \multicolumn{2}{c|}{$\begin{array}{c}\text { Volume } \\
\text { dos tanques }\left(\mathbf{m}^{3} \mathbf{)}\right)\end{array}$} & \multirow{2}{*}{$\begin{array}{c}\text { No de } \\
\text { tanques }\end{array}$} \\
\cline { 2 - 5 } & $\mathbf{X}$ & $\mathbf{Y}$ & Gás. & Álcool & \\
\hline E10 & 280624 & 7486684 & 3100 & 1600 & 6 \\
E11 & 280376 & 7486923 & 3100 & 1600 & 7 \\
E12 & 280391 & 7487179 & 2800 & 1600 & 6 \\
E13 & 280069 & 7486827 & 3100 & 1600 & 7 \\
E14 & 280127 & 7486983 & 3100 & 1000 & 10 \\
E15 & 279601 & 7485729 & 3100 & 1600 & 10 \\
E16 & 279634 & 7485522 & 3100 & 1600 & 6 \\
E17 & 279562 & 7485455 & 3100 & 1600 & 10 \\
E18 & 279490 & 7485304 & 3100 & 1600 & 6 \\
E19 & 279401 & 7485230 & 3100 & 1600 & 7 \\
E20 & 279308 & 7485112 & 3100 & 1600 & 6 \\
E21 & 279167 & 7485045 & 3100 & 1600 & 7 \\
E22 & 279141 & 7484943 & 2100 & 1080 & 6 \\
E23 & 279066 & 7484888 & 2110 & 870 & 8 \\
E24 & 279028 & 7484773 & 3000 & 1000 & 6 \\
E25 & 278984 & 7484689 & 3100 & 1600 & 9 \\
E27 & 279357 & 7484352 & 3100 & 1600 & 5 \\
E29 & 279279 & 7484540 & 3100 & 1600 & 6 \\
\hline
\end{tabular}

O vazamento de um produto líquido inflamável no ambiente irá acarretar a formação de uma poça do produto. As dimensões da poça dependem principalmente do volume vazado, das condições do vazamento e das características do piso no local. No caso das instalações em estudo, os produtos vazam para as bacias de contenção e, portanto, a área da poça, no caso de um grande vazamento, será igual à área da bacia de contenção. Uma vez vazado, o produto irá trocar calor com o solo e o ambiente e evaporar-se, e dar origem à formação de uma nuvem. A taxa de evaporação depende das dimensões da poça, das propriedades físico-químicas da substância, da temperatura do solo e do ambiente.

Uma vez formada a nuvem, esta pode resultar em uma explosão não confinada (UVCE) ou em um flashfire. Outro evento acidental importante envolvendo tanques de estocagem de combustíveis líquidos inflamáveis é o VCE (explosão da massa de vapor presente no tanque), evento caracterizado como uma explosão confinada. 


\subsection{SIMULAÇÃO DOS CENÁRIOS ACIDENTAIS}

Foram executadas simulações para cada uma das 31 instalações industriais identificadas. Os cenários acidentais foram gerados pelo EffectsGIS, a partir de conjuntos de hipóteses e layouts básicos. Ou seja, para empreendimentos com as mesmas características, foram consideradas as mesmas propriedades, tanto no que se referem aos equipamentos, substâncias e tubulações, como condições de operação e dados meteorológicos.

Os Quadros 1 e 2, explicitados a seguir, mostram as hipóteses definidas e os respectivos cenários acidentais para cada tipo de empreendimento: base de armazenamento e distribuição de GLP, e, de combustíveis líquidos.

Quadro 1 - Hipóteses acidentais definidas para as instalações de GLP.

\begin{tabular}{|c|c|c|}
\hline Cód. & Hipótese & Cenário \\
\hline H1 & $\begin{array}{c}\text { Ruptura catastrófica do gasoduto durante o } \\
\text { recebimento }\end{array}$ & $\begin{array}{c}\text { Flashfire } \\
\text { UVCE }\end{array}$ \\
\hline H2 & $\begin{array}{c}\text { Ruptura catastrófica da linha de transferência entre } \\
\text { tanques }\end{array}$ & $\begin{array}{c}\text { Flashfire } \\
\text { UVCE }\end{array}$ \\
\hline H3 & $\begin{array}{c}\text { Ruptura catastrófica da linha entre o tanque - } \\
\text { enchimento de cilindros }\end{array}$ & $\begin{array}{c}\text { Flashfire } \\
\text { UVCE }\end{array}$ \\
\hline H4 & $\begin{array}{c}\text { Ruptura catastrófica da linha de carregamento do } \\
\text { caminhão }\end{array}$ & $\begin{array}{c}\text { Flashfire } \\
\text { UVCE }\end{array}$ \\
\hline H5 & $\begin{array}{c}\text { Ruptura catastrófica da linha de descarga caminhão } \\
\text { - tanque }\end{array}$ & $\begin{array}{c}\text { Flashfire } \\
\text { UVCE }\end{array}$ \\
\hline H6 & Ruptura catastrófica da linha de purga do tanque & $\begin{array}{c}\text { Flashfire } \\
\text { UVCE }\end{array}$ \\
\hline H7 & Ruptura catastrófica da linha de carregamento de & $\begin{array}{c}\text { Flashfire } \\
\text { UVCE }\end{array}$ \\
\hline H8 & $\begin{array}{c}\text { Ruptura catastrófica da linha de descarga caminhão } \\
- \text { tanque }\end{array}$ & $\begin{array}{c}\text { Flashfire } \\
\text { UVCE }\end{array}$ \\
\hline H9 & Ruptura da linha de transferência entre tanques & $\begin{array}{c}\text { Flashfire } \\
\text { UVCE }\end{array}$ \\
\hline H12 & Explosão catastrófica do tanque & BLEVE \\
\hline H13 & Explosão catastrófica do tanque do caminhão & BLEVE \\
\hline H14 & Explosão catastrófica do tanque de decantação & BLEVE \\
\hline
\end{tabular}


Quadro 2 - Hipóteses acidentais definidas para as instalações de combustíveis líquidos inflamáveis.

\begin{tabular}{|c|c|c|}
\hline Cód. & Hipótese & Cenário \\
\hline H1 & Ruptura catastrófica do duto durante o recebimento & $\begin{array}{c}\text { Flashfire } \\
\text { UVCE }\end{array}$ \\
\hline H2 & Explosão da massa de vapor do tanque & VCE \\
\hline H3 & $\begin{array}{c}\text { Vazamento do tanque através da tubulação (ruptura } \\
\text { catastrófica da linha) }\end{array}$ & $\begin{array}{c}\text { Flashfire } \\
\text { UVCE }\end{array}$ \\
\hline H4 & Ruptura catastrófica do tanque & $\begin{array}{c}\text { Flashfire } \\
\text { UVCE }\end{array}$ \\
\hline H5 & Vazamento do caminhão-tanque (ruptura catastrófica & $\begin{array}{c}\text { Flashfire } \\
\text { UVCE }\end{array}$ \\
\hline H6 linha) & Explosão da massa de vapor do caminhão & VCE \\
\hline H7 & $\begin{array}{c}\text { Vazamento do tanque através da tubulação (ruptura } \\
\text { catastrófica da linha) }\end{array}$ & $\begin{array}{c}\text { Flashfire } \\
\text { UVCE }\end{array}$ \\
\hline H8 & Ruptura catastrófica do tanque & $\begin{array}{c}\text { Flashfire } \\
\text { UVCE }\end{array}$ \\
\hline H9 & Explosão da massa de vapor do tanque & VCE \\
\hline H10 & Explosão da massa de vapor do caminhão & VCE \\
\hline H11 & Ruptura catastrófica do caminhão-tanque & $\begin{array}{c}\text { Flashfire } \\
\text { UVCE }\end{array}$ \\
\hline H12 & Vazamento do caminhão-tanque & $\begin{array}{c}\text { Flashfire } \\
\text { UVCE }\end{array}$ \\
\hline H13 & Ruptura catastrófica do caminhão-tanque & $\begin{array}{c}\text { Flashfire } \\
\text { UVCE }\end{array}$ \\
\hline
\end{tabular}

Foram simulados apenas cenários que extrapolam os limites de propriedade dos empreendimentos e todas as hipóteses consideradas assumiam condições de vazamento mais conservativas, ou seja, que resultariam em conseqüências mais severas.

Para as instalações de armazenamento e distribuição GLP foram simulados cenários dos tipos Flashfire, UVCE e BLEVE, e, para as instalações de combustíveis líquidos foram simulados cenários dos tipos Flashfire, UVCE e VCE. 
Os efeitos físicos dos cenários acidentais simulados e as ocorrências consideradas estão descritos a seguir:

- BLEVE - Do original inglês Boiling Liquid Expanding Vapor Explosion. Fenômeno decorrente da explosão catastrófica de um reservatório, quando um líquido nele contido atinge uma temperatura bem acima da sua temperatura de ebulição à pressão atmosférica, com projeção de fragmentos e de expansão adiabática. Foram gerados cenários para ocorrências diurnas e noturnas, com áreas de $1 \%$ e $50 \%$ de probabilidade de fatalidade.

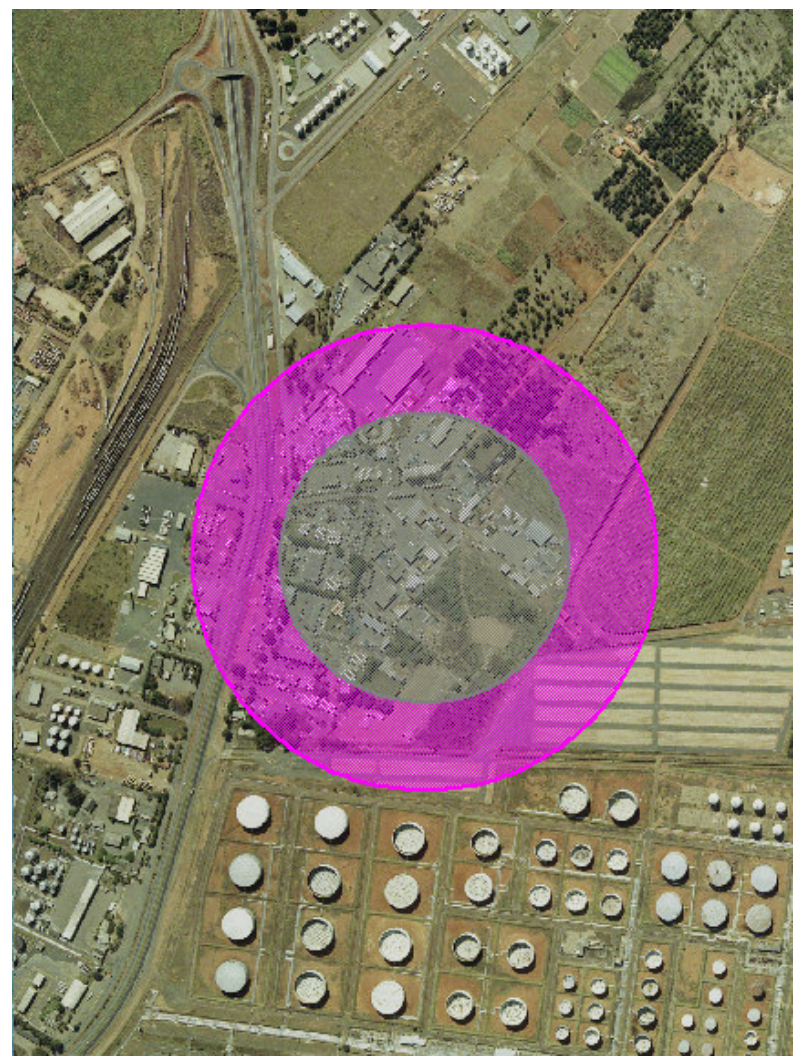

Figura 6 - Sobreposição de cenários de BLEVE, do período diurno, para uma instalação de GLP: áreas de $1 \%$ e $50 \%$ de probabilidade de fatalidade.

- Flashfire - Incêndio de uma nuvem de vapor onde a massa envolvida e o seu grau de confinamento, não são suficientes para atingir o 
estado de explosão. Nestes casos, a probabilidade de fatalidade é de $100 \%$. Foram gerados cenários para ocorrências diurnas e noturnas, e para oito direções preferenciais do vento.

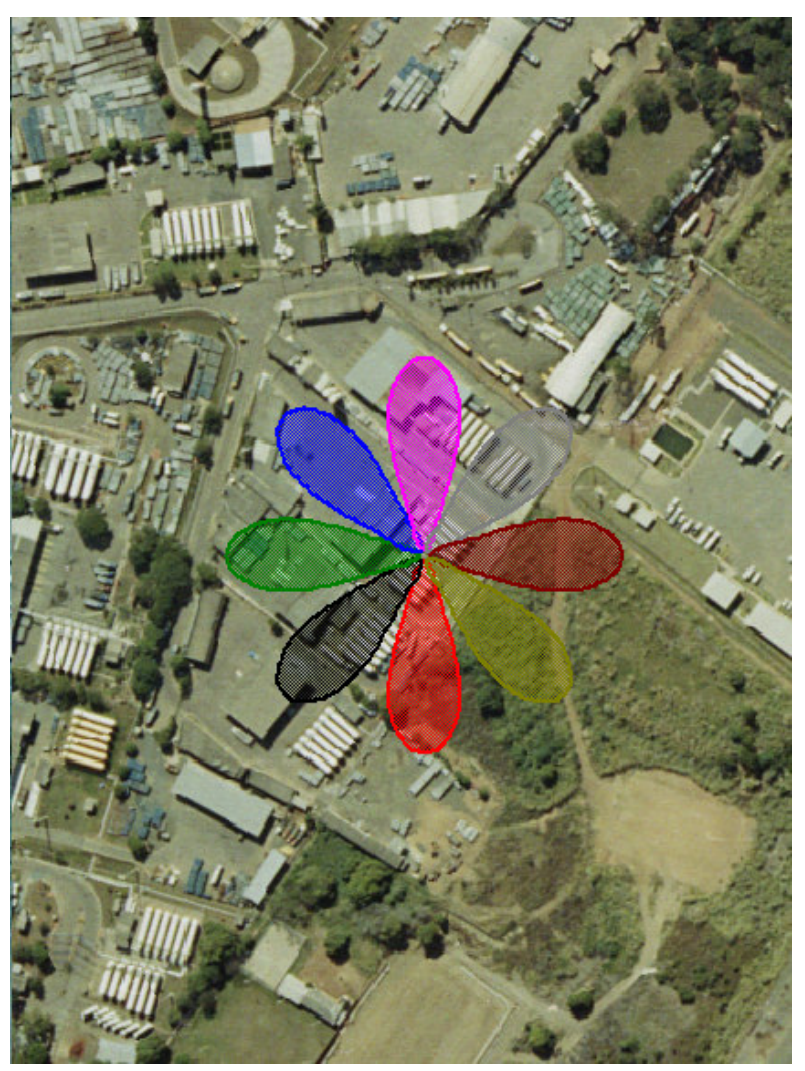

Figura 7 - Sobreposição de cenários de Flashfire, do período diurno, para uma instalação de GLP: cada uma das oito direções preferenciais do vento.

- UVCE - Explosão de nuvem não confinada, do original inglês Unconfined Vapor Cloud Explosion. Processo onde ocorre uma rápida e violenta liberação de energia, associado a uma expansão de gases acarretando o aumento da pressão acima da pressão atmosférica. Foram gerados cenários para ocorrências diurnas e noturnas, para oito direções preferenciais do vento, com áreas de 1\% e 50\% de probabilidade de fatalidade. 


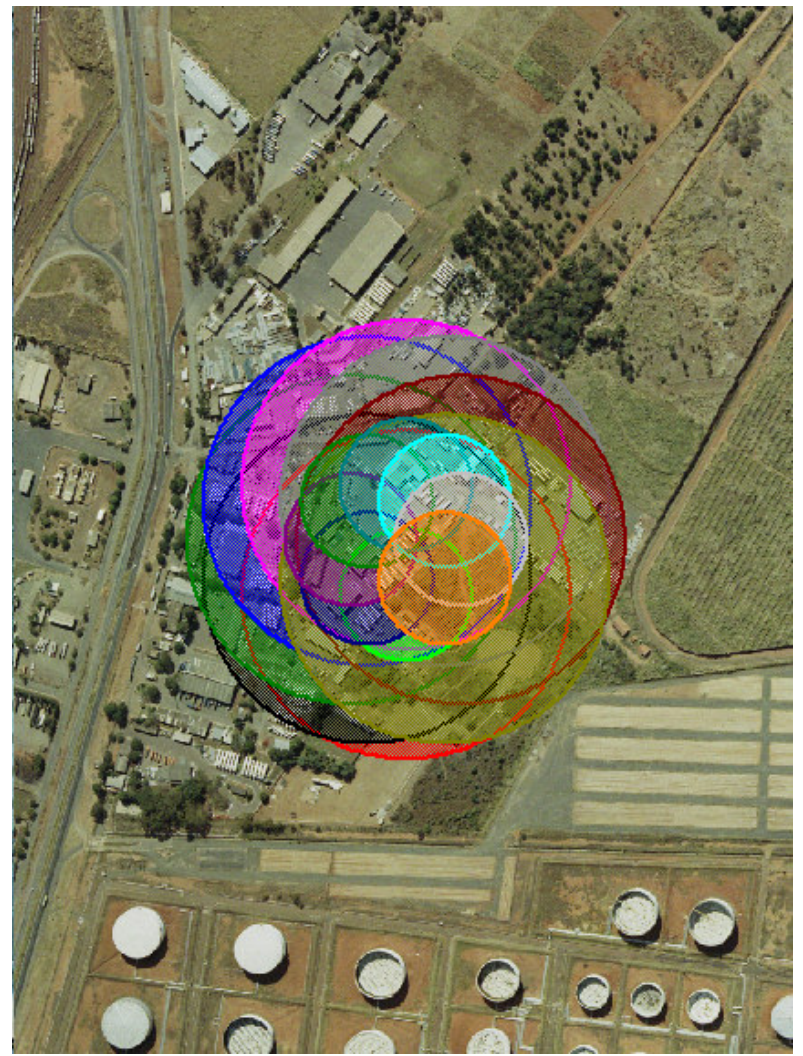

Figura 8 - Sobreposição de cenários de UVCE, do período diurno, para uma instalação de GLP: áreas de 1\% e 50\% de probabilidade de fatalidade, para cada uma das oito direções preferenciais do vento.

- VCE - Explosão de nuvem de vapor confinada, do original inglês Vapor Cloud Explosion. Processo onde ocorre uma rápida e violenta liberação de energia, associado a uma expansão de gases, acarretando o aumento da pressão acima da pressão atmosférica. Foram gerados cenários para ocorrências diurnas e noturnas, com áreas de $1 \%$ e $50 \%$ de probabilidade de fatalidade. 


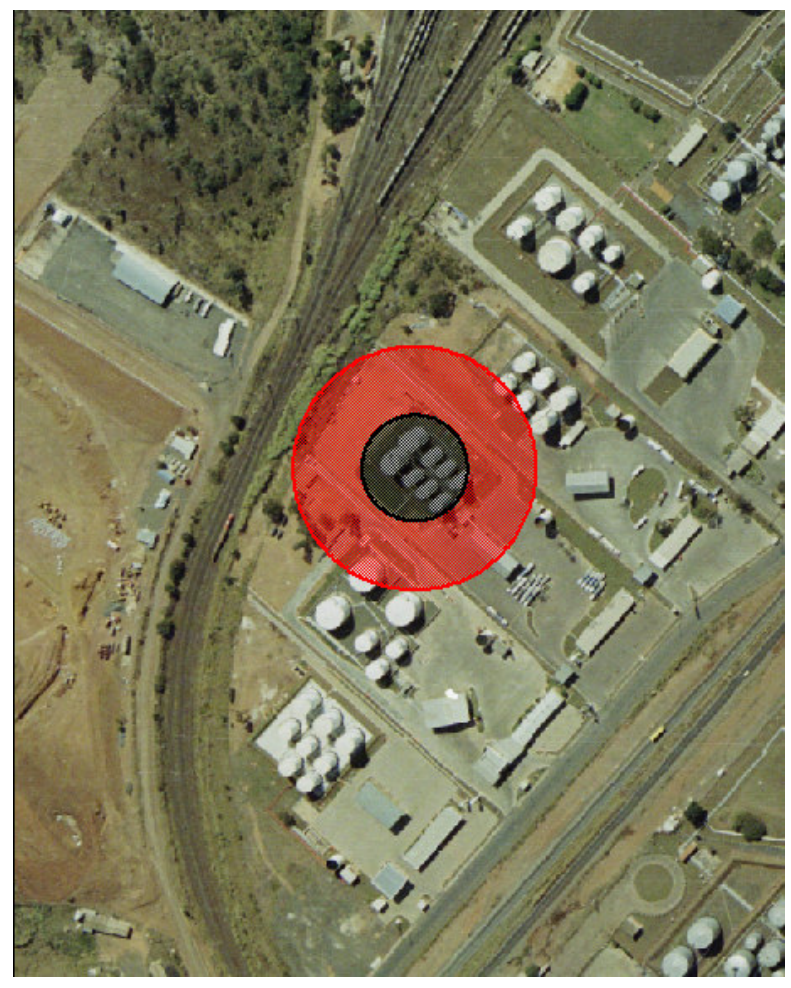

Figura 9 - Sobreposição de cenários de VCE, do período diurno, para uma instalação de GLP: áreas de $1 \%$ e $50 \%$ de probabilidade de fatalidade.

Para cada instalação de GLP foram gerados 444 cenários, para tanto, foram consideradas 12 hipóteses acidentais, sendo 9 delas utilizadas para a geração de cenários de Flashfire e UVCE, e, 3 para cenários de BLEVE, como apresenta o Quadro 3.

Quadro 3 - Número de cenários simulados para cada instalação de GLP.

\begin{tabular}{|c|c|c|c|c|c|}
\hline $\begin{array}{c}\text { Tipo de } \\
\text { cenário }\end{array}$ & $\begin{array}{c}\text { Número de } \\
\text { hipóteses } \\
\text { consideradas }\end{array}$ & $\begin{array}{c}\text { Períodos do } \\
\text { dia }\end{array}$ & $\begin{array}{c}\text { Direções } \\
\text { do vento }\end{array}$ & $\begin{array}{c}\text { Probabilidade } \\
\text { de fatalidade }\end{array}$ & $\begin{array}{c}\text { Número de } \\
\text { cenários } \\
\text { (polígonos) }\end{array}$ \\
\hline Flashfire & 9 & dia / noite & 8 & $100 \%$ & 144 \\
\hline UVCE & 9 & dia / noite & 8 & $1 \%$ e $50 \%$ & 288 \\
\hline BLEVE & 3 & dia / noite & - & $1 \%$ e $50 \%$ & 12 \\
\cline { 5 - 6 }
\end{tabular}


Para cada instalação de combustível líquido foram gerados 448 cenários, para tanto, foram consideradas 13 hipóteses acidentais, sendo 9 delas utilizadas para a geração de cenários de Flashfire e UVCE, e, 4 para cenários de VCE, como apresenta o Quadro 4.

Quadro 4 - Número de cenários simulados para cada instalação de combustível liquido.

\begin{tabular}{|c|c|c|c|c|c|}
\hline $\begin{array}{c}\text { Tipo de } \\
\text { cenário }\end{array}$ & $\begin{array}{c}\text { Número de } \\
\text { hipóteses } \\
\text { consideradas }\end{array}$ & $\begin{array}{c}\text { Períodos do } \\
\text { dia }\end{array}$ & $\begin{array}{c}\text { Direções } \\
\text { do vento }\end{array}$ & $\begin{array}{c}\text { Probabilidade } \\
\text { de fatalidade }\end{array}$ & $\begin{array}{c}\text { Número de } \\
\text { cenários } \\
\text { (polígonos) }\end{array}$ \\
\hline Flashfire & 9 & dia / noite & 8 & $100 \%$ & 144 \\
\hline UVCE & 9 & dia / noite & 8 & $1 \%$ e $50 \%$ & 288 \\
\hline VCE & 4 & dia / noite & - & $1 \%$ e $50 \%$ & 16 \\
\cline { 5 - 6 }
\end{tabular}

Os respectivos valores de risco individual dos cenários foram calculados no Excel, com base nas freqüências de ocorrência e na probabilidade de fatalidade dos eventos.

O cálculo das freqüências de ocorrência das hipóteses acidentais foi elaborado com a aplicação da técnica de Análise por Árvore de Falhas AAF. As freqüências de ocorrência, para cada um dos efeitos físicos presentes nestas hipóteses, foram estimadas com o uso da técnica de Análise por Árvore de Eventos - AAE.

No cálculo do risco foram consideradas as mesmas freqüências e probabilidades de ocorrência para os períodos diurno e noturno, e, para as oito direções do vento. Os condicionantes meteorológicos, como classe de estabilidade atmosférica, velocidade e direção preferencial do vento, são parâmetros que interferem na dispersão dos materiais após o vazamento, e devem ser levados em consideração. Como não existiam dados adequados do local, optou-se por usar a mesma probabilidade para as oito direções, bem como, os mesmos valores de velocidade média e classes de 
estabilidade recomendadas pela CETESB. Desta forma, obteve-se um resultado final mais conservativo.

\subsection{AQUISIÇÃO DOS DADOS DOS CENÁRIOS ACIDENTAIS}

Os polígonos dos cenários acidentais gerados pelo Effects-GIS e os respectivos valores de risco, previamente calculados, foram obtidos da seguinte forma:

\subsubsection{Polígonos gerados pelo Effects-GIS}

Uma vez que o Effects-GIS não possui recursos para a exportação direta dos resultados, os arquivos dos cenários acidentais foram copiados da própria estrutura de diretórios do programa.

Constatou-se que os dados eram criados e armazenados temporariamente dentro do diretório "ITNO Industrial SafetylVersion 5.5\EffectsGISI", e, sobrescritos automaticamente sempre que executada uma nova operação. Desta forma, a cada simulação, os arquivos tiveram de ser copiados para um novo diretório. Os arquivos foram renomeados e organizados em novas pastas através do ArcCalatog, para posteriormente comporem o banco de dados de cenários acidentais.

Como os cenários para diferentes direções do vento foram simulados simultaneamente, e, estas simulações ficam armazenadas no mesmo arquivo; os Shapefiles de Flashfire e UVCE contém oito polígonos cada. Desta forma, adquiriu-se um total de 66 Shapefiles para cada instalação de GLP e 70 Shapefiles para cada instalação de combustível liquido. 
Para garantir um identificador único em cada polígono, as simulações no Effects-GIS foram nomeadas conforme a seqüência exemplificada na Figura 10. Optou-se por um sistema de codificação onde o nome do cenário é composto por seu conjunto de atributos, separados por traço.

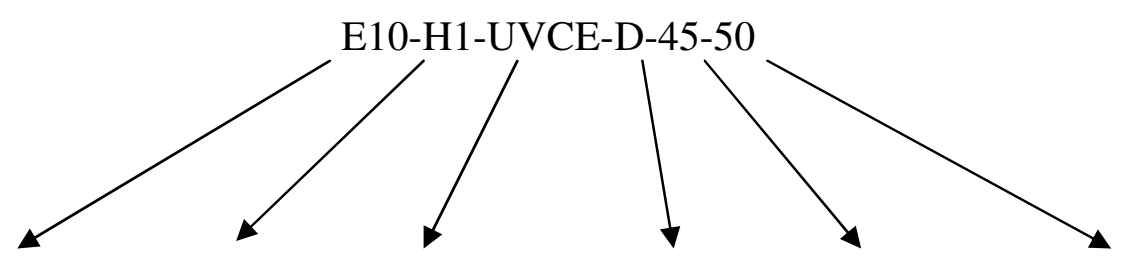

$\begin{array}{cccccc}\text { Empresa ou } & \text { Hipótese } & \text { Tipo de } & \text { Período do } & \text { Direção do } & \text { Probabilidade } \\ \text { instalação } & \text { considerada } & \text { cenário } & \text { dia } & \text { vento } & \text { de fatalidade } \\ & & \text { (graus) } & \end{array}$ Figura 10 - Sistema de código identificador do cenário.

A Figura 11 mostra a tela principal do Effects-GIS, com detalhe para 0 campo de entrada do nome do cenário. O nome escolhido é transferido automaticamente para o campo "Title" da tabela de atributos do Shapefile. 


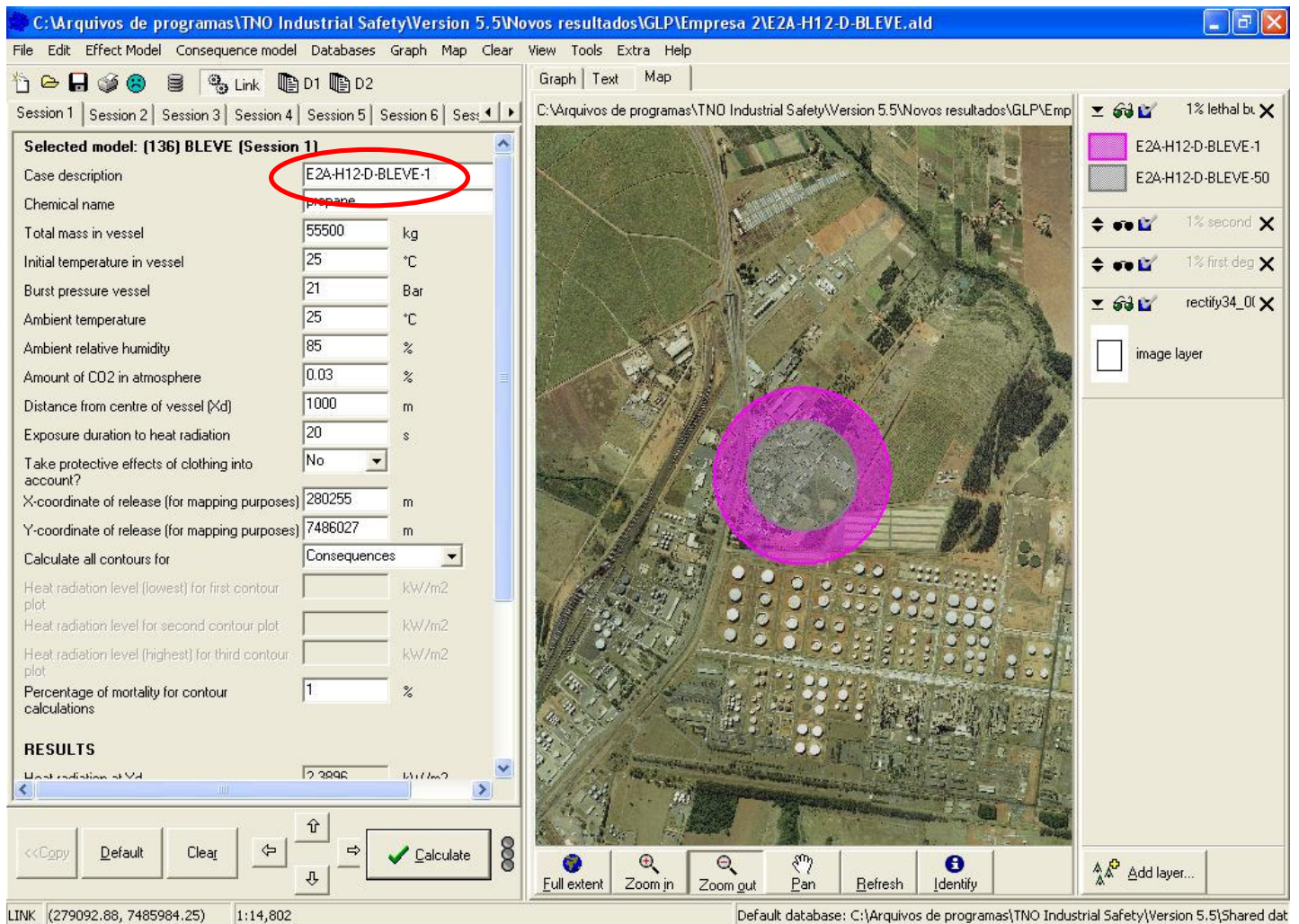

Figura 11 - Tela do Effects-GIS, com destaque para o nome da simulação.

Todos estes resultados, em conjunto com os valores de risco individual de cada cenário, abastecerão o SIG para o cálculo total do risco individual e social.

\subsubsection{Valores de risco individual}

Além dos polígonos dos cenários, foram adquiridos os respectivos valores de risco. Os dados foram obtidos em formato de planilhas do Excel, consistindo uma planilha para cada instalação industrial. 


\subsection{CRIAÇÃO DO BANCO DE DADOS DE CENÁRIOS ACIDENTAIS}

O banco de dados foi elaborado de modo a auxiliar as operações de análise integrada dos riscos. Desta forma, optou-se por desenvolver um banco no formato Personal Geodatabase, para ser utilizado neste estudo, exclusivamente, em aplicações desktop.

A montagem do banco de dados requereu o pré-tratamento dos dados em duas etapas: espacial e alfanumérica. Essa divisão foi concebida visando uma melhor estruturação dos dados. Ambas as etapas, também, levaram em consideração o grande número de instalações industriais e cenários acidentais.

Os dados espaciais foram organizados utilizando os recursos do ArcGIS. Inicialmente, fez-se a conferência dos polígonos e tabelas de atributos de todos os arquivos. Os ajustes necessários foram realizados a fim de garantir a consistência da base de dados.

A seguir, todos os polígonos foram agrupados em novos arquivos utilizando a ferramenta "Merge" do ArcToolbox. Para tanto, este procedimento se deu em duas fases: para cada instalação industrial e, em seguida, por tipo de empreendimento. O Quadro 5 mostra os campos existentes nas tabelas de atributos dos arquivos finais.

Quadro 5 - Campos das tabelas de atributos dos Shapefiles.

\begin{tabular}{|l|l|l|}
\hline \multicolumn{1}{|c|}{ Nome do campo } & \multicolumn{1}{c|}{ Tipo de dado } & \multicolumn{1}{c|}{ Descrição } \\
\hline OBJECTID & AutoNumeração & \\
\hline Shape & Polygon & \\
\hline Title* & Texto & Identificador do cenário \\
\hline
\end{tabular}


Os dados alfanuméricos foram tratados no editor de planilhas Excel e salvos no formato DBF (Data Base File). Para cada tipo de empreendimento, foi elaborada uma tabela com os valores de risco e outra para a organização dos atributos dos cenários acidentais.

Primeiramente, foram elaboradas as tabelas de atributos, a partir das tabelas dos arquivos resultantes do agrupamento. Desta forma, o campo "Title" pôde ser utilizado na estruturação de novos campos no banco de dados.

Os dados presentes no campo "Title" foram fragmentados através do delimitador "-" e dispostos em novas classes de atributos. Esta preparação foi concebida de modo a facilitar as consultas em SQL (Structured Query Langage) nas etapas de análise dos dados.

Em seguida, fez-se necessário criar um campo para vincular a tabela de atributos à tabela de valores de risco. Optou-se por um sistema de codificação, semelhante ao do identificador do cenário, como mostra o exemplo na Figura 12.

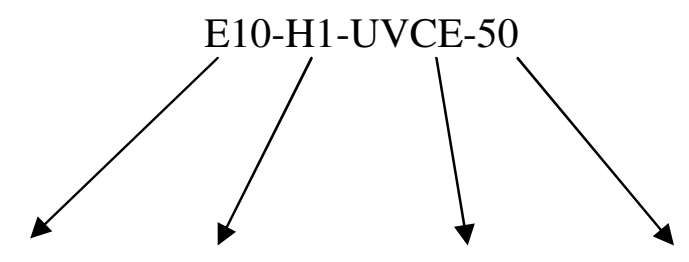

Empresa ou Hipótese Tipo de Probabilidade instalação considerada cenário de fatalidade

Figura 12 - Sistema de código identificador do valor de risco.

O Quadro 6 apresenta os campos das novas tabelas de atributos, com destaque para o campo identificador do cenário e do risco. 
Quadro 6 - Campos das novas tabelas de atributos.

\begin{tabular}{|l|l|l|}
\hline \multicolumn{1}{|c|}{ Nome do campo } & Tipo de dado & \multicolumn{1}{c|}{ Descrição } \\
\hline Title $^{*}$ & Texto & Identificador do cenário \\
\hline EMPRESA & Texto & Instalação industrial \\
\hline HIP & Texto & Hipótese acidental \\
\hline ACID & Texto & Tipo de acidente (efeito físico) \\
\hline PER & Texto & Período do dia \\
\hline DIR & Número & Direção do vento \\
\hline PROB & Número & Probabilidade de fatalidade \\
\hline COD_RISCO* & Texto & Identificador do risco \\
\hline & *Identificador &
\end{tabular}

Os valores de risco dos cenários acidentais, obtidos através das planilhas em formato Excel, foram reorganizados em novas tabelas com o respectivo identificador do risco. O Quadro 7 apresenta os campos existentes nas tabelas de valores de risco.

Quadro 7 - Campos da tabela de valores de risco.

\begin{tabular}{|l|l|l|}
\hline \multicolumn{1}{|c|}{ Nome do campo } & \multicolumn{1}{c|}{ Tipo de dado } & \multicolumn{1}{c|}{ Descrição } \\
\hline COD_RISCO* & Texto & Identificador do risco \\
\hline RISCO & Número & Valor de risco individual \\
\hline${ }^{*}$ Identificador
\end{tabular}

Concluída a preparação dos dados espaciais e alfanuméricas, foi criado um arquivo Geodatabase no ArcCatalog. Em seguida, fez-se a importação dos polígonos e das tabelas ao Geodatabase. Utilizou-se o mesmo sistema de projeção definido no inicio do projeto (UTM, fuso 23 , SAD $69)$.

Os Shapefiles foram convertidos em feature class e armazenados em uma feature dataset. As feature class de polígonos incorporaram e atualizam, automaticamente, valores de perímetro e área em sua tabela de atributos. 
O relacionamento entre as tabelas do banco de dados foi executado no ArcMap através da opção "Join table", por meio de atributos comuns. A Figura 13 mostra o relacionamento das entidades espaciais e alfanuméricas para os cenários das instalações de GLP.

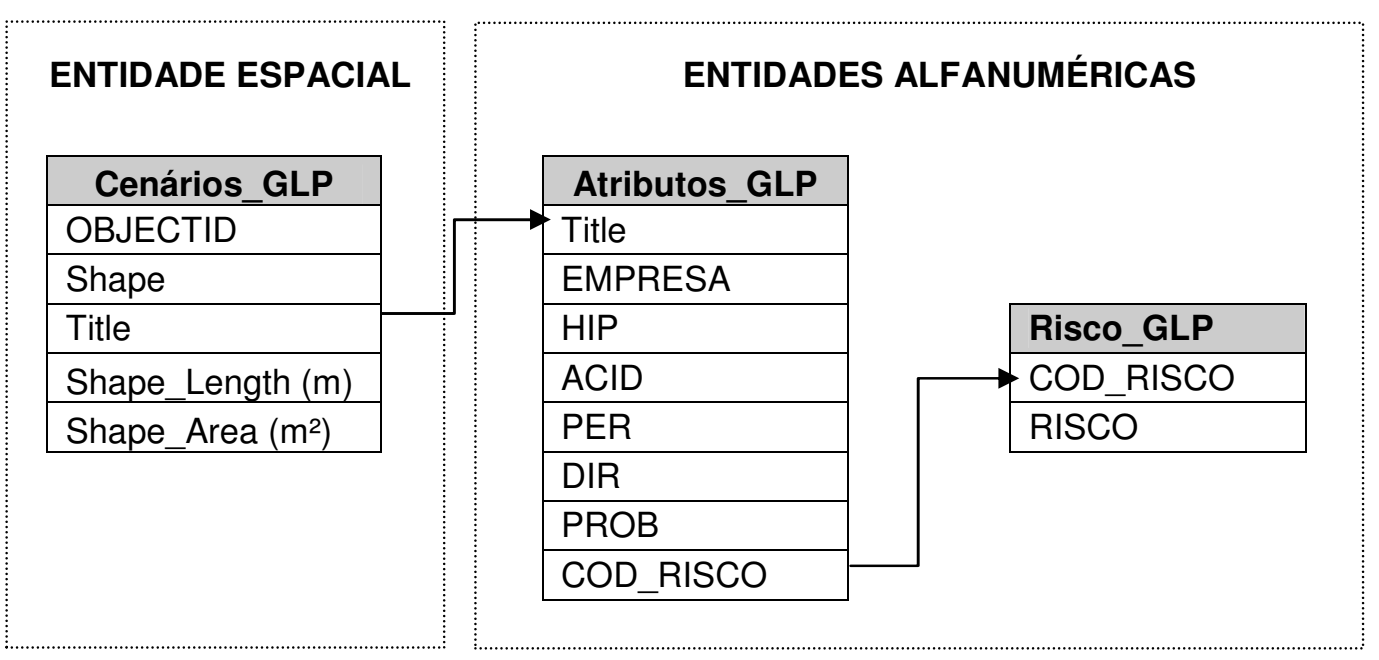

Figura 13 - Relacionamento entre as entidades alfanuméricas e espaciais.

O Quadro 8 apresenta os campos do banco de dados após o relacionamento das tabelas.

Quadro 8 - Campos do banco de dados.

\begin{tabular}{|l|l|l|}
\hline \multicolumn{1}{|c|}{ Nome do campo } & \multicolumn{1}{c|}{ Tipo de dado } & \multicolumn{1}{c|}{ Descrição } \\
\hline OBJECTID & AutoNumeração & \\
\hline Shape & Polygon & \\
\hline Title* & Texto & Identificador do cenário \\
\hline Shape_Length & Número & Perímetro $(m)$ \\
\hline Shape_Area & Número & Área $\left(\mathrm{m}^{2}\right)$ \\
\hline EMPRESA & Texto & Instalação industrial \\
\hline HIP & Texto & Hipótese acidental \\
\hline ACID & Texto & Efeito \\
\hline PER & Texto & Período do dia \\
\hline DIR & Número & Direção do vento \\
\hline PROB & Número & Probabilidade de fatalidade \\
\hline COD_RISCO* & Texto & Identificador do risco \\
\hline RISCO & Número & Valor de risco individual \\
\hline *Identificador & &
\end{tabular}

*Identificador 


\subsection{SOMATÓRIA DOS VALORES DE RISCO INDIVIDUAL}

Sabemos que o risco individual num determinado ponto da vizinhança de uma planta industrial é a somatória dos valores de risco de todos os possíveis cenários. Conseqüentemente, duas ou mais fontes geradoras de risco podem contribuir para o cálculo do valor de risco individual num determinado ponto.

Desta forma, foram somados os valores de risco nas áreas onde havia sobreposição de cenários. A somatória do risco requereu o tratamento dos dados em duas etapas: vetorial e raster. $\mathrm{O}$ tratamento em cada etapa está descrito detalhadamente a seguir:

\subsubsection{Tratamento vetorial}

Como existiam muitos cenários acidentais, foram criados grupos de dados, a fim de facilitar o processamento. Para cada instalação industrial foram criados sete grupos de dados, com no máximo 72 cenários cada, como mostram os Quadros 9 e 10. Para tanto, fez-se a seleção dos cenários no banco de dados através de expressões em SQL. O tratamento vetorial foi realizado no processo de soma dos riscos de cada grupo de dados isoladamente.

Quadro 9 - Grupos de cenários para a somatória dos riscos de instalações de GLP.

\begin{tabular}{|c|c|c|c|c|}
\hline $\begin{array}{c}\text { Grupo de } \\
\text { cenários }\end{array}$ & $\begin{array}{c}\text { Tipo de } \\
\text { cenário }\end{array}$ & $\begin{array}{c}\text { Período do } \\
\text { dia }\end{array}$ & $\begin{array}{c}\text { Probabilidade } \\
\text { de fatalidade }\end{array}$ & $\begin{array}{c}\text { Número de } \\
\text { polígonos }\end{array}$ \\
\hline 1 & Flashfire & dia & $100 \%$ & 72 \\
\hline 2 & Flashfire & noite & $100 \%$ & 72 \\
\hline 3 & UVCE & dia & $1 \%$ & 72 \\
\hline 4 & UVCE & noite & $1 \%$ & 72 \\
\hline 5 & UVCE & dia & $50 \%$ & 72 \\
\hline 6 & UVCE & noite & $50 \%$ & 72 \\
\hline 7 & BLEVE & dia e noite & $1 \%$ e $50 \%$ & 12 \\
\hline
\end{tabular}


Quadro 10 - Grupos de cenários para a somatória dos riscos de instalações de combustíveis líquidos.

\begin{tabular}{|c|c|c|c|c|}
\hline $\begin{array}{c}\text { Grupo de } \\
\text { cenários }\end{array}$ & $\begin{array}{c}\text { Tipo de } \\
\text { cenário }\end{array}$ & $\begin{array}{c}\text { Período do } \\
\text { dia }\end{array}$ & $\begin{array}{c}\text { Probabilidade } \\
\text { de fatalidade }\end{array}$ & $\begin{array}{c}\text { Número de } \\
\text { polígonos }\end{array}$ \\
\hline 1 & Flashfire & dia & $100 \%$ & 72 \\
\hline 2 & Flashfire & noite & $100 \%$ & 72 \\
\hline 3 & UVCE & dia & $1 \%$ & 72 \\
\hline 4 & UVCE & noite & $1 \%$ & 72 \\
\hline 5 & UVCE & dia & $50 \%$ & 72 \\
\hline 6 & UVCE & noite & $50 \%$ & 72 \\
\hline 7 & VCE & dia e noite & $1 \%$ e $50 \%$ & 16 \\
\hline
\end{tabular}

Cada grupo de cenários corresponde a um Shapefile com polígonos sobrepostos. O primeiro processamento foi executado para a identificação das áreas de intersecção entre polígonos e secções adjacentes. Para tanto, utilizou-se um recurso de reestruturação de polígonos, transformando as varias camadas de polígonos sobrepostos em apenas uma camada com novas geometrias. O recurso mencionado foi a ferramenta "Clean Gaps" do software ET GeoWisards.

A ferramenta Clean Gaps gera uma classe nova de polígonos, com uma nova tabela de atributos, como mostra a Figura 14. Os polígonos recém criados têm valor em aberto, portanto, foi necessário determinar um Identificador para cada elemento (feição), que passaremos a chamar de secções de cálculo. A definição dessas áreas foi fundamental para a soma, ou seja, para o cálculo do risco onde havia sobreposição de polígonos. 

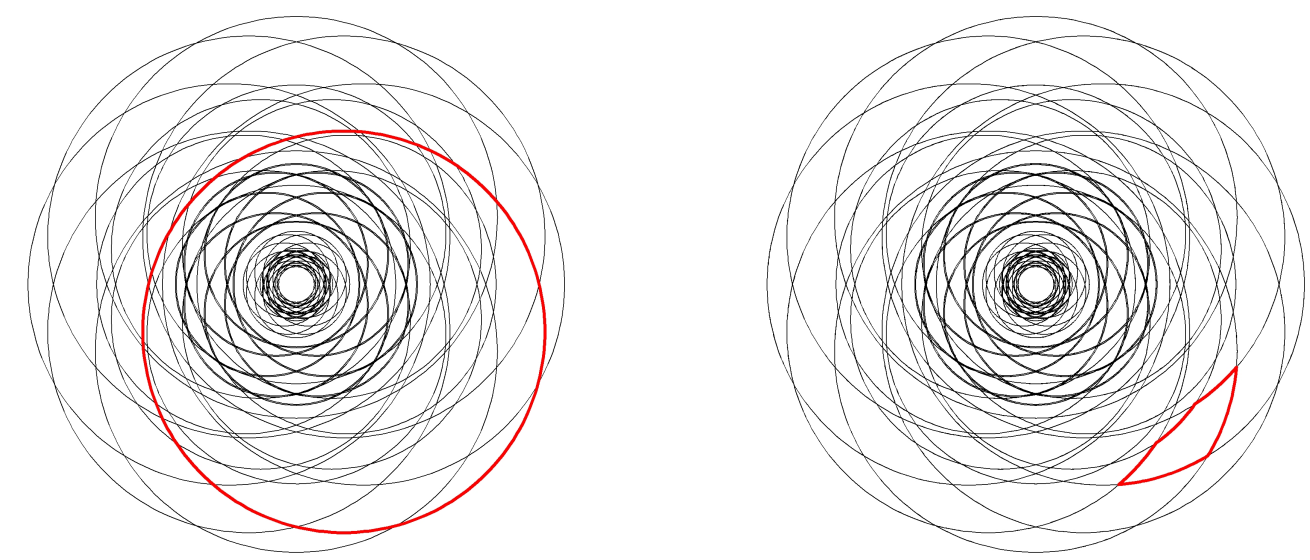

Figura 14 - Seleção de um cenário e seleção de uma secção de cálculo

O segundo processamento foi realizado para determinar os valores que deveriam ser somados dentro de cada secção de cálculo. Para tanto, foi realizada uma operação de intersecção entre os arquivos criados de secções de cálculo e os arquivos originais de grupo de dados.

O recurso utilizado para a Intersecção foi a função "Intersect" da caixa de ferramentas "Geoprocessing Wizard" do ArcView 3.2. Optou-se, exclusivamente neste caso, pela versão mais antiga do ArcView, pois o mesmo conceito aplicado no ArcView 9.1 resultou em falhas de processamento e graves erros topológicos. Segundo a assistência técnica da ESRI no Brasil, o problema pode ocorrer por falta de memória RAM.

A ultima etapa estabelecida para o processamento dos dados em formato vetorial foi a somatória dos valores de risco definidos através da intersecção com as secções de cálculo. Para tanto, foi utilizada a função "Dissolve", com o objetivo de mesclar as feições de mesmo identificador e, ao mesmo tempo, somar os valores de risco. A Figura 15 exemplifica o processo de tratamento dos dados nesta etapa. 


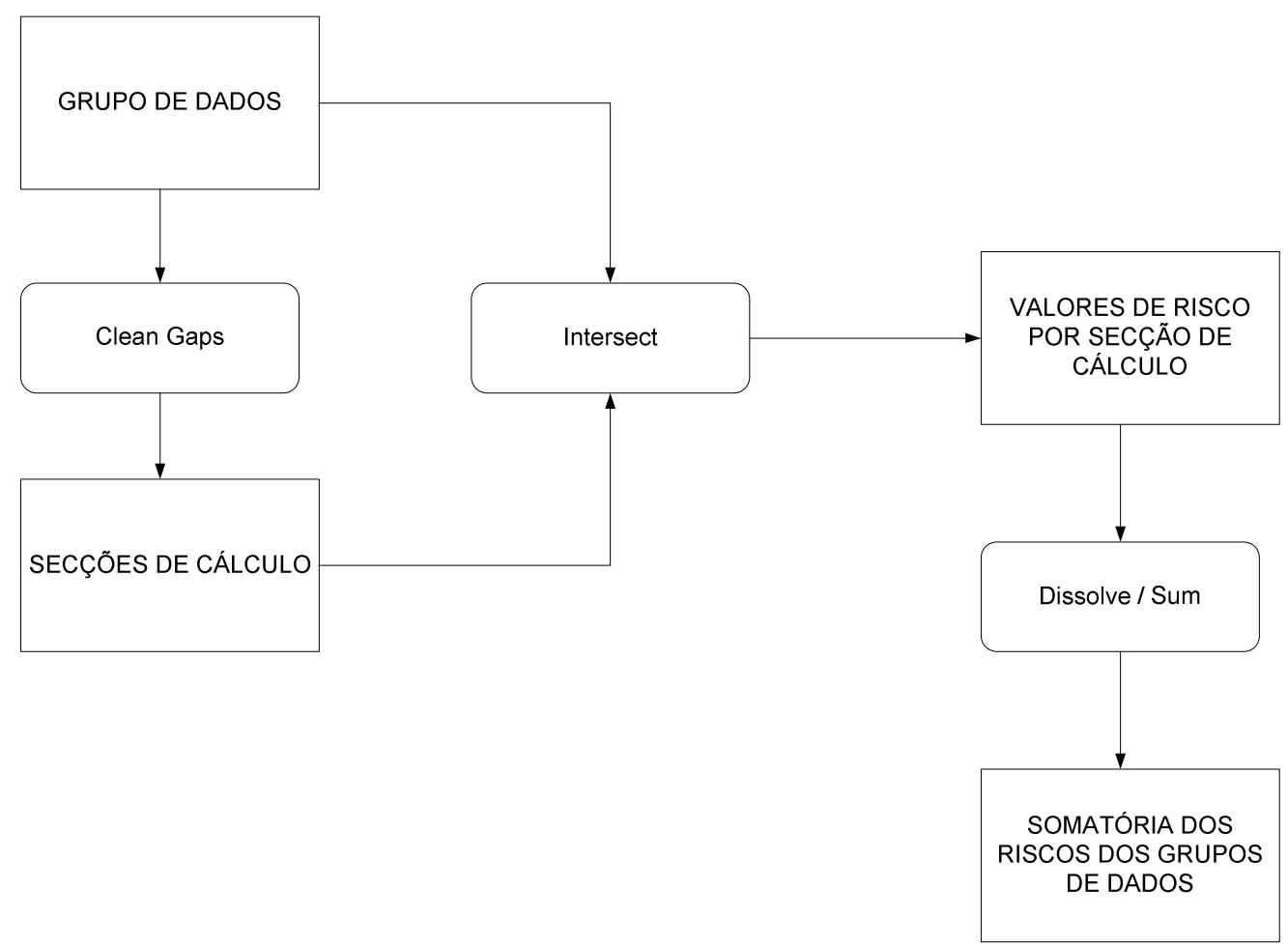

Figura 15 - Fluxograma do processo de soma dos dados em formato vetorial.

A fim de preparar os dados para a soma no formato matricial, ainda foi acrescentado aos arquivos finais, referentes a cada grupo de dados, o polígono do retângulo envolvente da área de estudo, através da função "Merge" do "ArcToolbox".

\subsubsection{Tratamento matricial}

Após a soma, para diminuir a complexidade das operações, os resultados foram convertidos no formato matricial, considerando-se a resolução espacial de $1 \times 1$ metro, para efetuar a soma dos riscos individuais de todos os empreendimentos.

Primeiramente, foi realizada a conversão vetor - raster dos arquivos de soma dos grupos de cenários, utilizando-se a extensão "Spatial Analyst" 
do ArcGIS. Optou-se por criar todas as grades regulares com resolução espacial de 1 metro.

A representação dos riscos no formato de dados matricial procura facilitar a integração dos dados, visto que os valores de risco são associados a cada célula.

Abaixo (Figura 16) pode-se ver um exemplo de rasterização de um layer em questão. Após a conversão de todos os dados fizeram-se as sobreposições de soma.

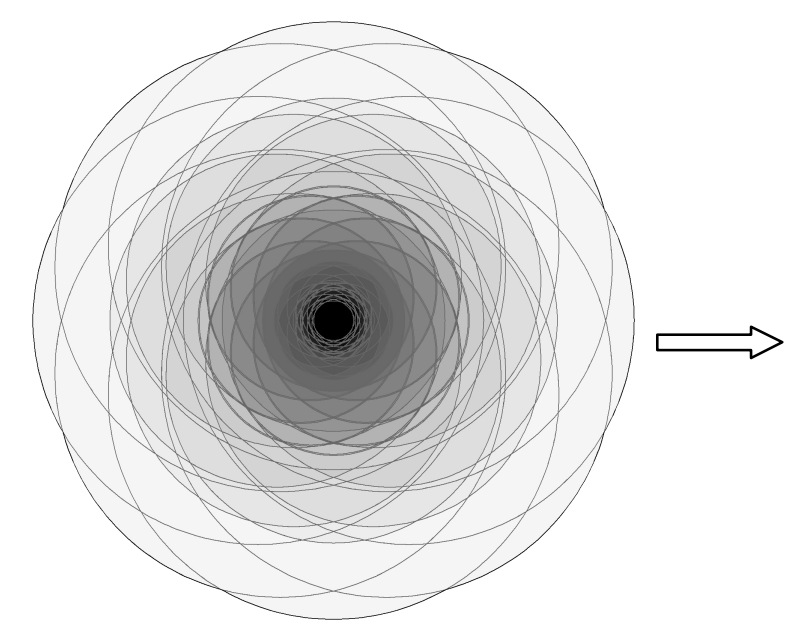

Figura 16 - Conversão do formato vetorial para matricial, com células de 1 x 1m.

Como apresenta a Figura 17, os dados foram somados, primeiramente, para cada instalação industrial, em seguida, por tipo de empreendimento e, finalmente, para todo o distrito industrial. Executados estes procedimentos de soma dos dados obteve-se o risco individual total em cada $\mathrm{m}^{2}$ da área de estudo. 


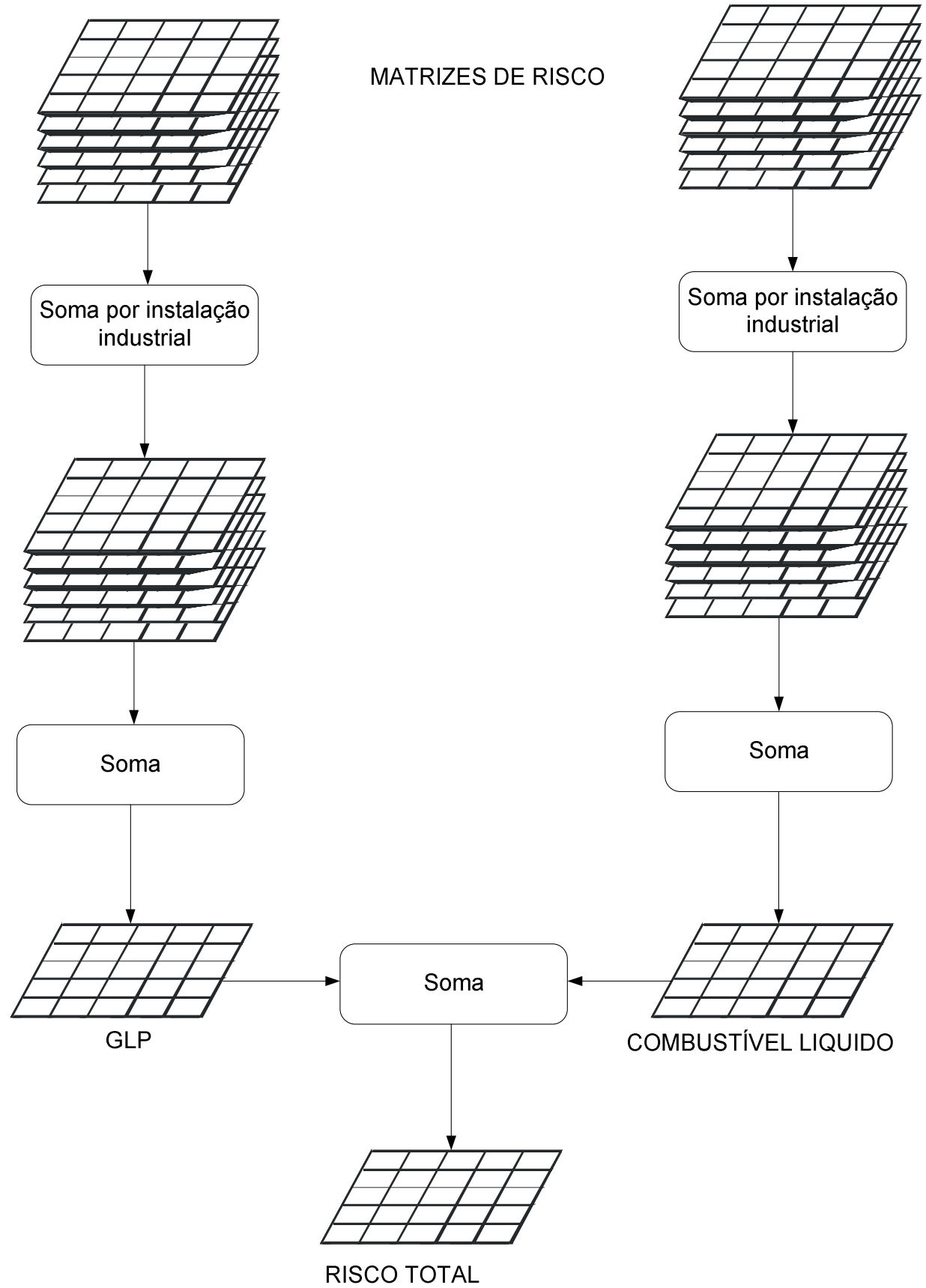

Figura 17 - Fluxograma do processo de soma dos dados em formato matricial

\subsection{CÁLCULO DO NÚMERO DE PESSOAS EXPOSTAS}

As curvas de risco social F-N foram elaboradas utilizando-se uma tabela, produzida pelo SIG, com os dados de freqüência e população atingida em cada um dos cenários acidentais. 
Para a definição da população exposta, foram utilizados valores de densidade populacional (população $/ \mathrm{m}^{2}$ ) baseados nos dados do Censo Demográfico do IBGE de 2000. Assim, todos os polígonos do banco de dados de cenários acidentais foram recortados segundo o setor censitário, por meio da função "Clip" do ArcGIS. Como mostra a Figura 18.

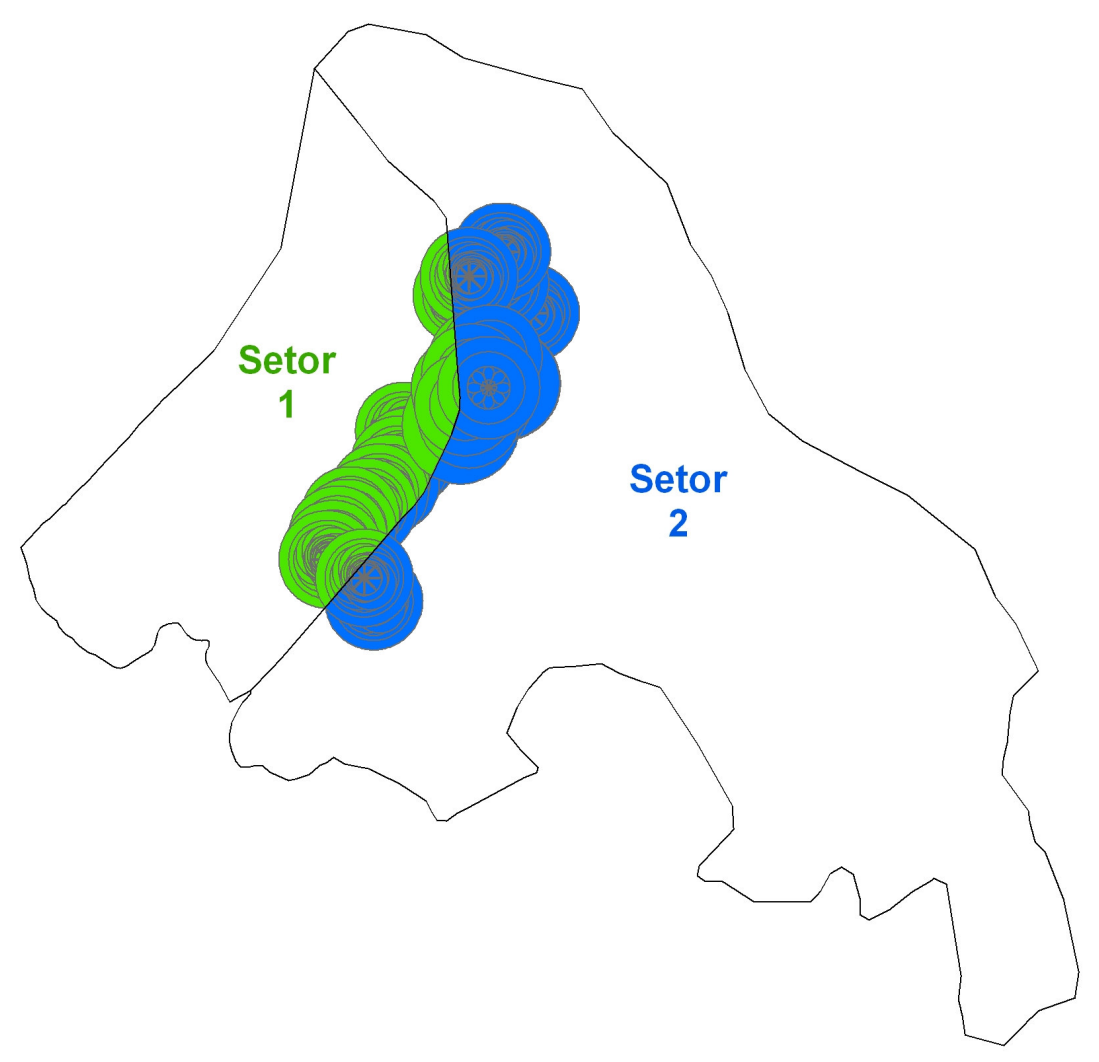

Figura 18 - Definição da população exposta com base nos setores censitários

Em seguida, foram recalculadas as áreas de todos os polígonos e multiplicadas pela densidade populacional dos setores censitários, a fim de estimar a população atingida em cada recorte.

Para definir a população atingida em cada cenário, os polígonos foram novamente unidos, somando-se o número de pessoas atingidas, 
através da função "Dissolve" do ArcGIS, visto que um cenário acidental pode atingir mais de um setor censitário.

Finalmente, os resultados foram convertidos em uma tabela no formato Microsoft Excel onde puderam ser organizados na forma adequada para 0 cálculo das freqüências acumuladas. Como a densidade populacional da área é muito baixa, na apresentação das curvas F-N, foi adotado um critério de arredondamento dos valores.

\subsection{APRESENTAÇÃO DOS RESULTADOS}

Os valores acumulados de risco individual foram apresentados por meio de mapas e cartogramas, em escalas entre 1:10.000 e 1:30.000, uma vez que estas possibilitam visualizar detalhadamente a distribuição geográfica dos riscos. O risco social foi apresentado por meio de gráficos de curva F-N. Na apresentação dos dados, considerou-se o risco total de cada ramo de atividade (Instalações de GLP e combustível líquido), e, o risco total do Distrito Industrial de Paulínia. 


\section{RESULTADOS E DISCUSSÃO}

Através dos procedimentos metodológicos desenvolvidos, foi possível estruturar uma extensa base de dados geográficos sobre os riscos de acidentes no distrito industrial de Paulínia. $O$ desafio foi de sistematizar e sintetizar informações contidas em um grande volume de dados. A seguir estão descritos estes resultados, ou seja, o banco de dados espaciais e a análise integrada dos riscos.

\subsection{BANCO DE DADOS ESPACIAIS}

O banco de dados foi desenvolvido de modo a auxiliar as operações de análise integrada dos riscos. Foram incluídos os cenários acidentais mais relevantes para a avaliação de risco, com as seguintes informações: identificador da instalação industrial, hipótese acidental considerada, efeito físico (BLEVE, Flashfire, UVCE ou VCE), período do dia, direção do vento, área atingida, risco individual e estimativa da população exposta.

Ao todo, foram incorporados ao banco de dados, em formato Geodatabase, 13.836 polígonos referentes aos cenários de acidentes de instalações de GLP e de combustíveis líquidos, respectivamente, com 5.772 e 8.064 registros. Também, foram anexadas ao banco de dados 31 grades regulares, no formato Grid, relativas ao risco individual total de cada instalação industrial pesquisada.

A organização dos dados facilita os procedimentos de consulta, manipulação e alteração dos dados, tendo em vista o grande número de instalações industriais e cenários acidentais. $O$ risco individual, calculado para cada instalação industrial, simplifica as sobreposições e a 
reconfiguração da soma, na análise integrada dos riscos, caso haja a desativação de algum empreendimento ou a implantação de uma nova instalação industrial.

\subsection{ANÁLISE INTEGRADA DOS RISCOS}

Os dados foram divididos em 3 categorias: instalações de GLP; instalações de combustíveis líquidos; e, instalações de GLP + combustíveis líquidos (risco total calculado para o Distrito Industrial). Essas categorias contemplam tanto a somatória do risco individual como do risco social.

\subsubsection{Instalações de GLP}

No cálculo do risco individual para o conjunto de empresas de armazenamento e distribuição de GLP foram consideras 13 instalações industriais. O Mapa 4 mostra um gradiente de risco individual. O Mapa 5 apresenta uma classificação do risco individual, nela é possível demonstrar que a faixa de risco de $1 \times 10^{-05}$ a $1 \times 10^{-04}$ eventos/ano alcança uma área bastante significativa, abrangendo inclusive parte da rodovia. 


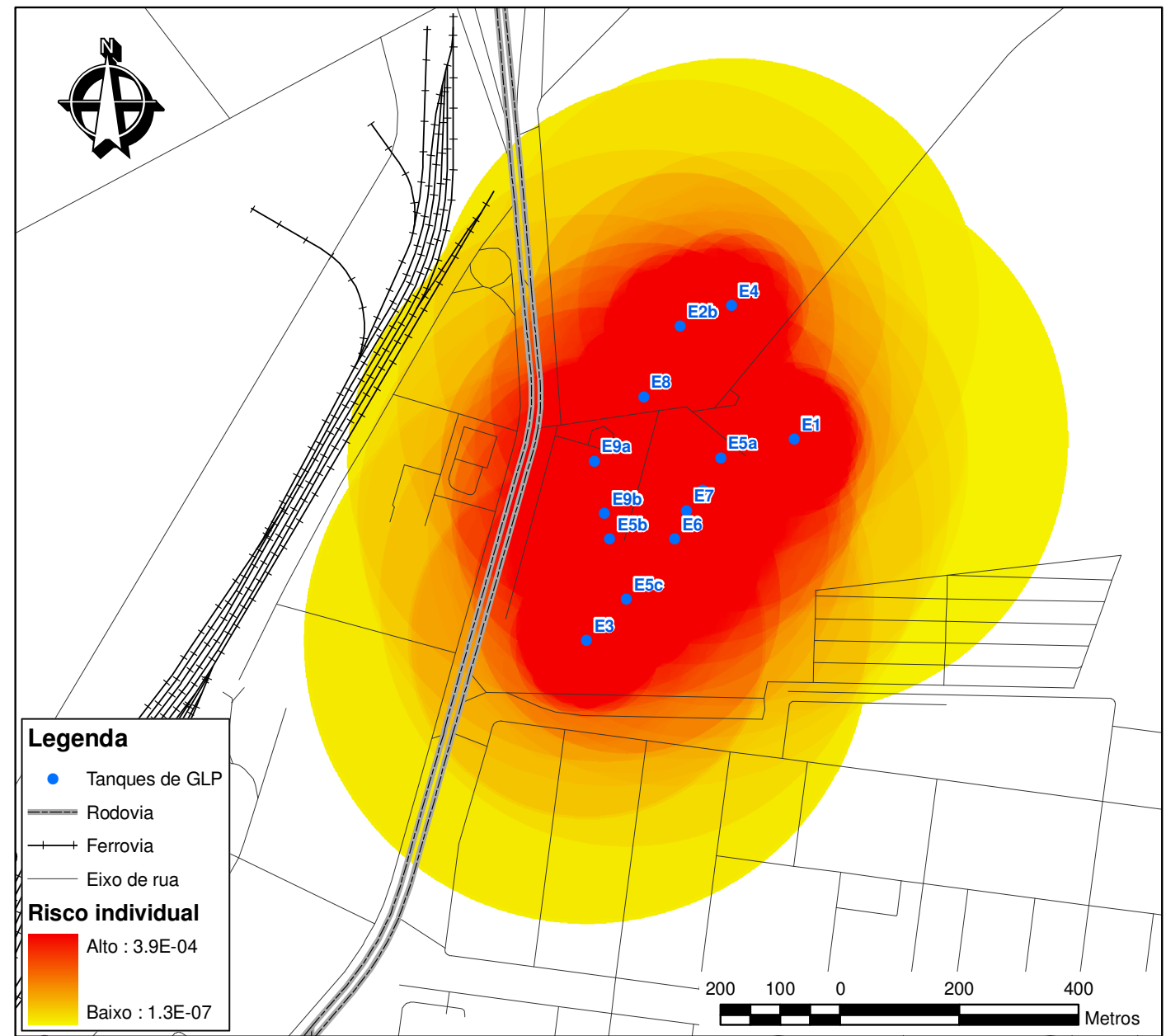

Mapa 4 - Risco individual para as Instalações de armazenamento e distribuição de GLP. 


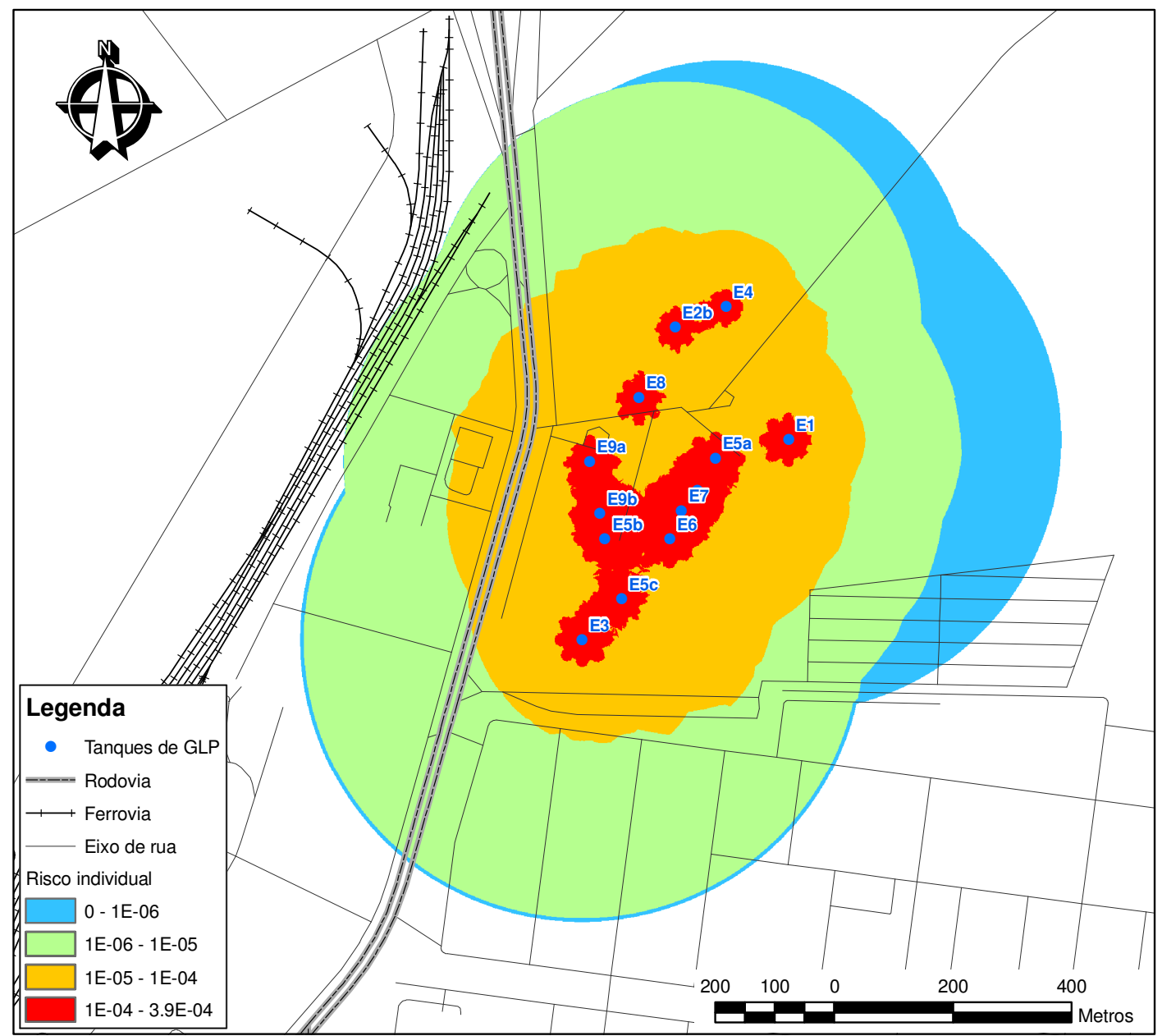

Mapa 5 - Classes de risco individual para as instalações de armazenamento e distribuição de GLP.

A curva do risco social, resultante do cálculo de todas as instalações de GLP, ainda se manteve abaixo do critério considerado intolerável pela CETESB, apenas para uma fatalidade a freqüência acumulada alcançou o limite. Como mostra o Gráfico 2. 


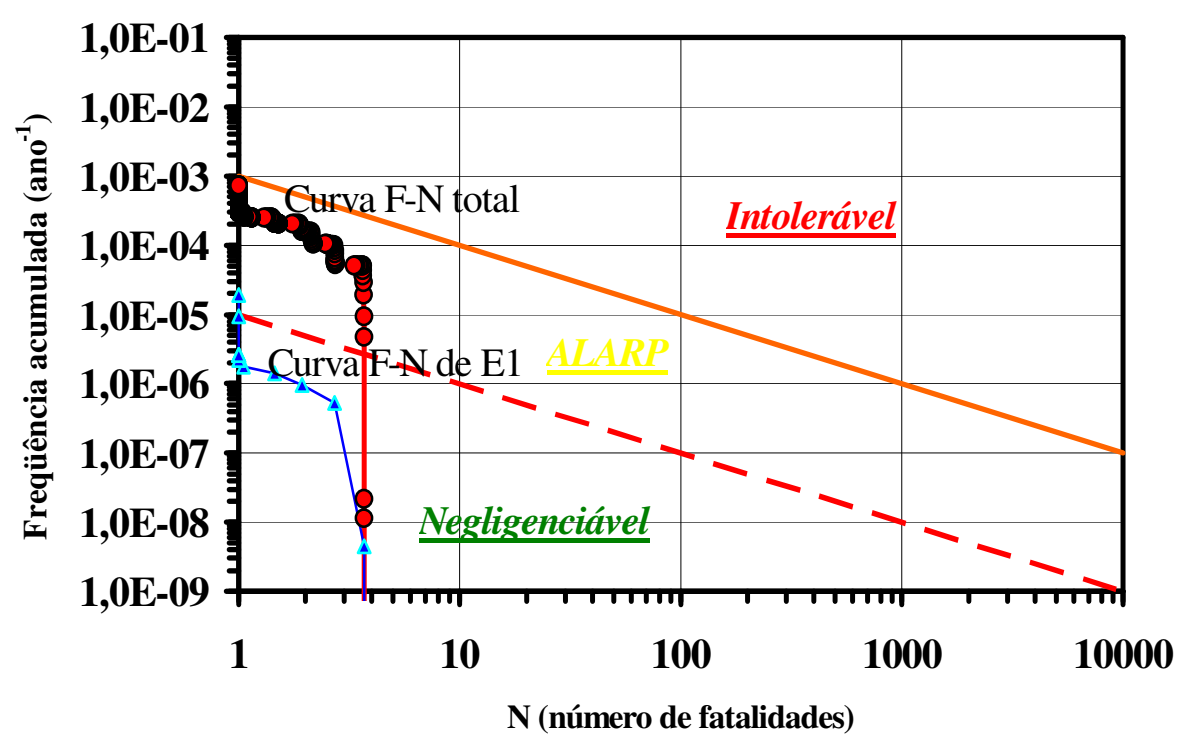

Gráfico 2 - Risco social para as instalações de armazenamento e distribuição de GLP.

\subsubsection{Instalações de combustíveis líquidos}

No cálculo do risco individual para o conjunto de empresas de armazenamento e distribuição de combustíveis líquidos foram consideras 18 instalações industriais. O Mapa 6 mostra um gradiente de risco individual. $\mathrm{O}$ Mapa 7 apresenta uma classificação do risco individual, neste caso, os resultados mostram que, a faixa de risco de $1 \times 10^{-06}$ a $1 \times 10^{-05}$ chega a ultrapassar o limite da zona industrial. 


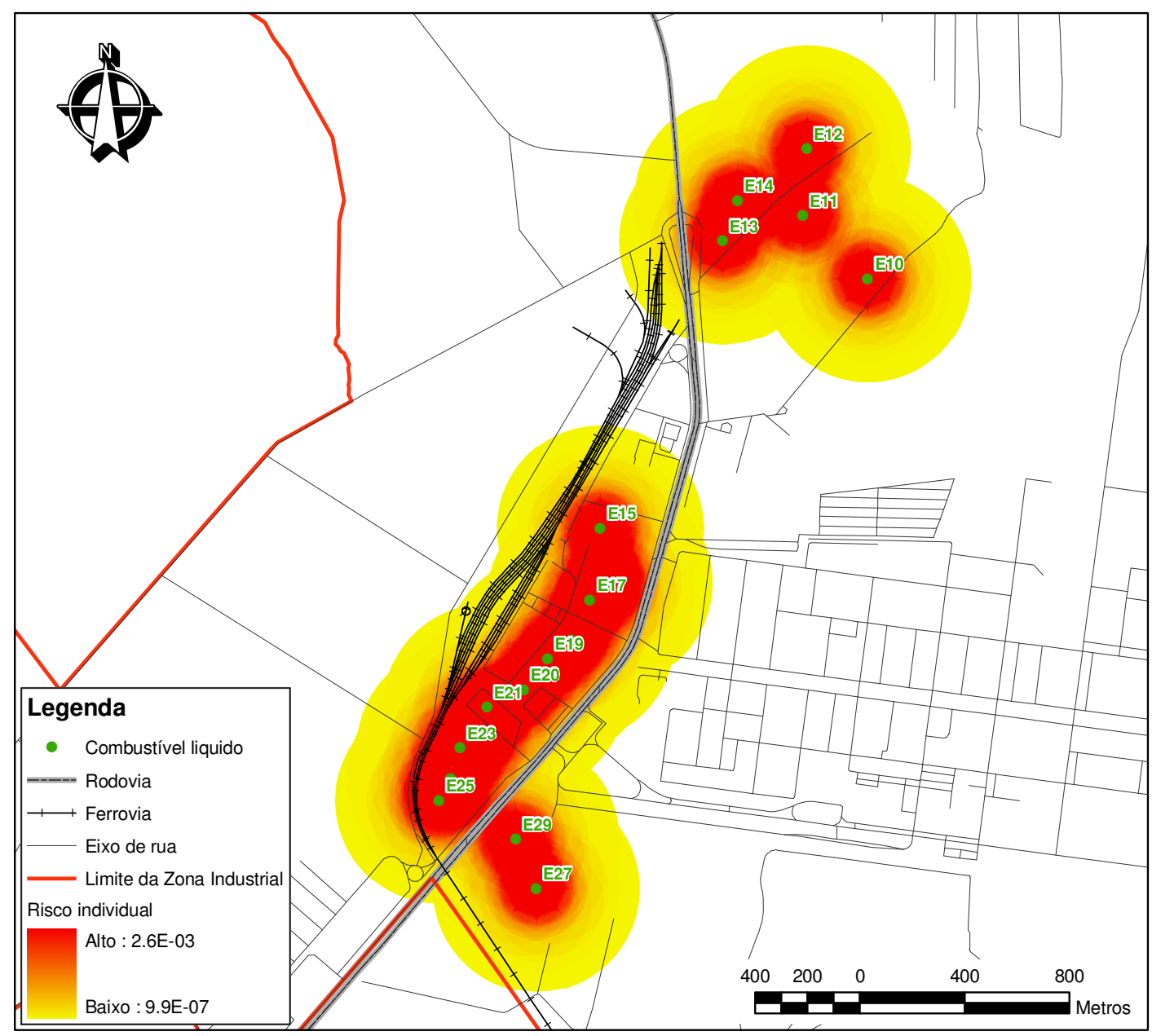

Mapa 6 - Risco individual para as instalações de armazenamento distribuição de combustível líquido. 


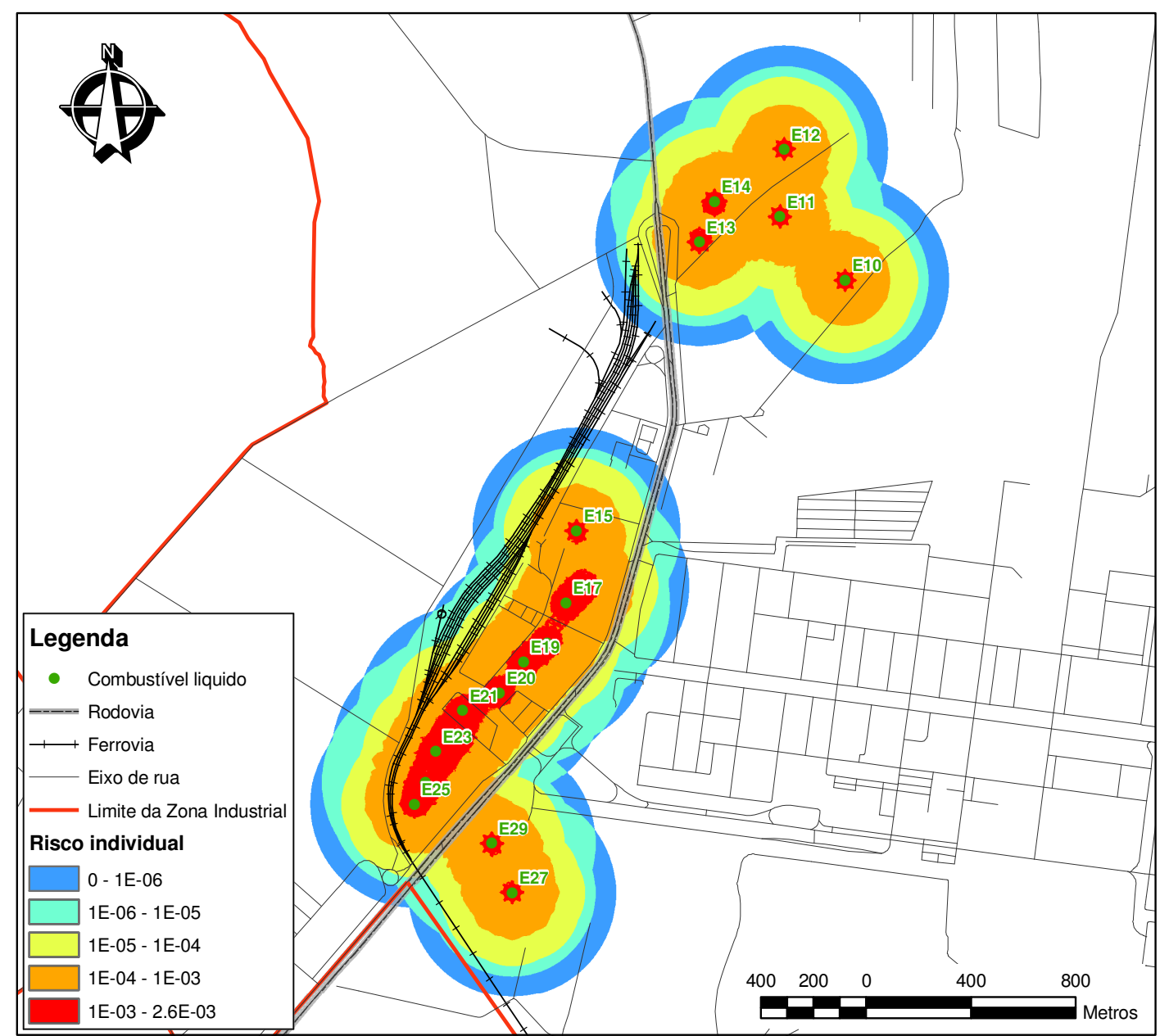

Mapa 7 - Classes de risco individual para as instalações de armazenamento e distribuição de combustível líquido.

A curva do risco social, resultante do cálculo de todas as instalações de combustíveis líquidos, encontra-se fora da faixa de tolerabilidade postulada pela CETESB, pois apesar do número de fatalidades esperado ser baixo, a freqüência acumulada é muito alta. Como mostra o Gráfico 3. 


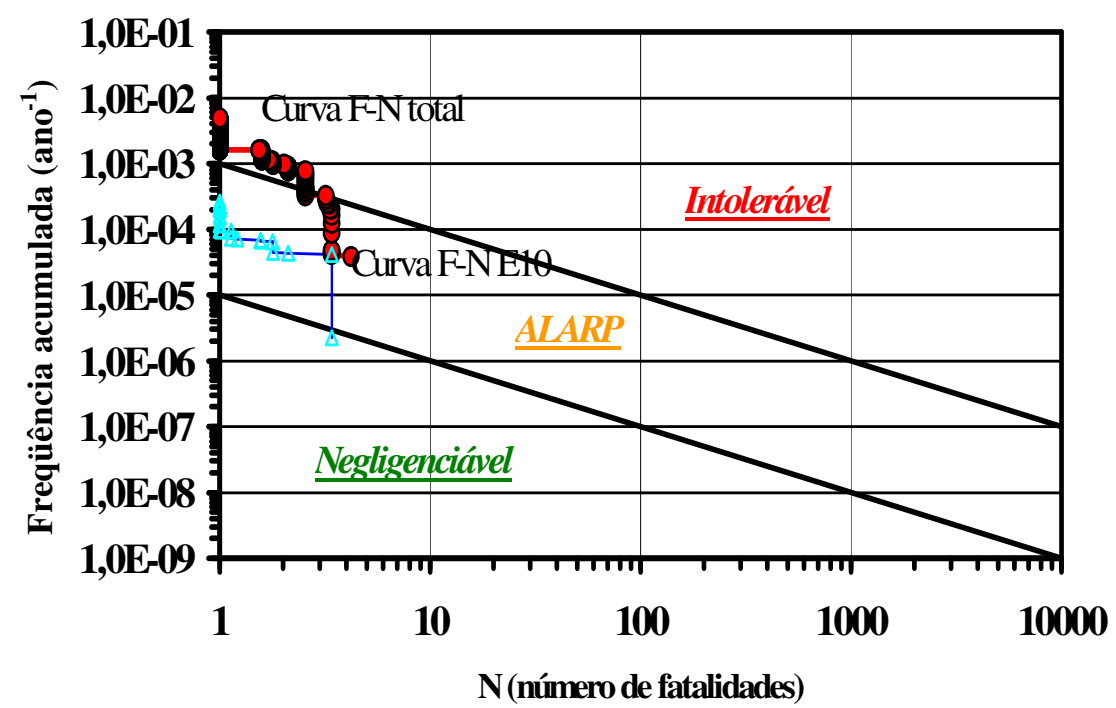

Gráfico 3 - Risco social para as instalações de armazenamento e distribuição de combustível líquido.

6.2.3 Instalações de GLP + combustíveis líquidos

Por fim, calculou-se o risco individual total para toda a área do Distrito Industrial, considerando as instalações de GLP e de combustíveis líquidos, cujos resultados são mostrados nos Mapas 8 e 9, a seguir. 


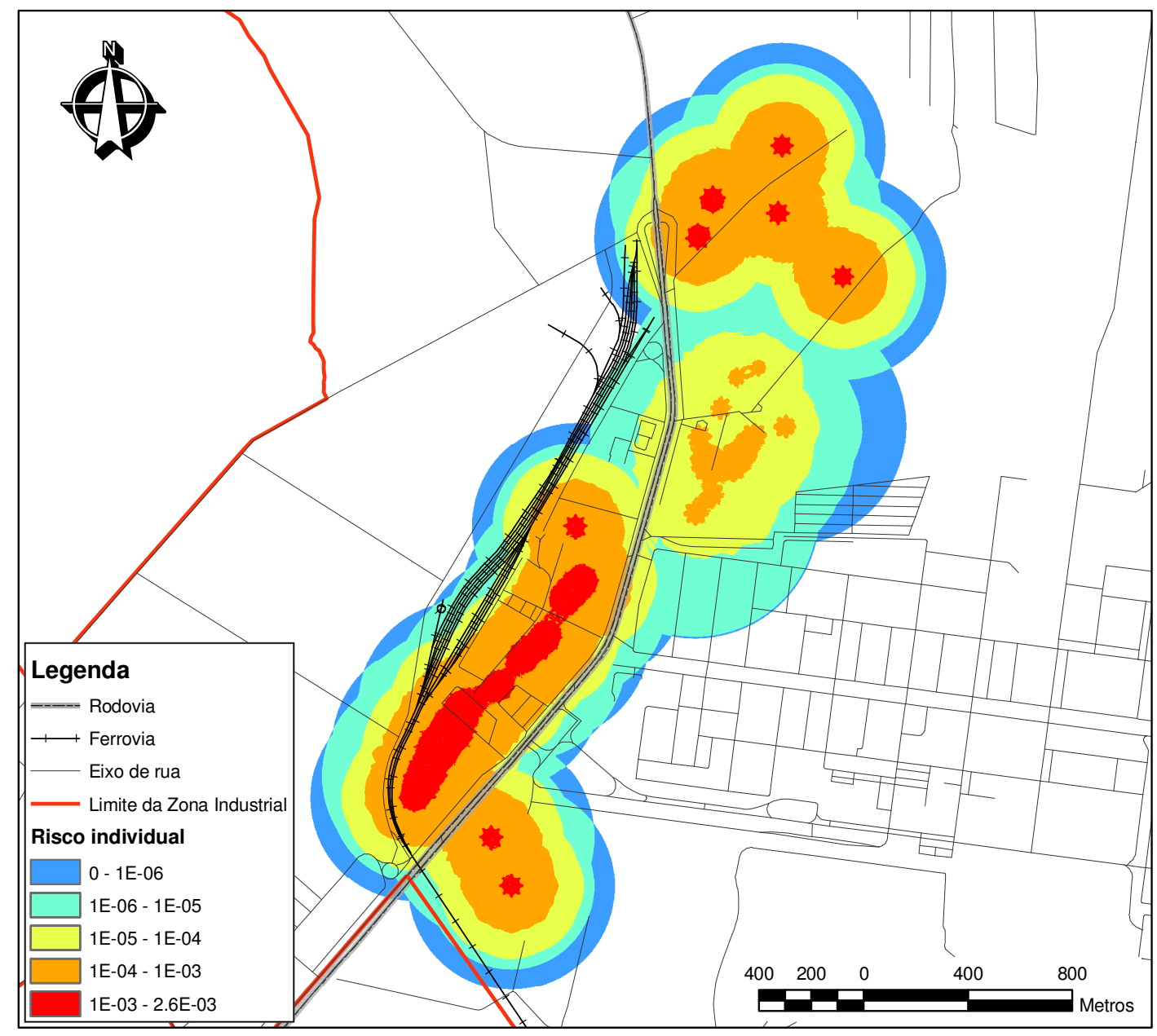

Mapa 8 - Classes de risco individual total (instalações de GLP + combustível líquido). 



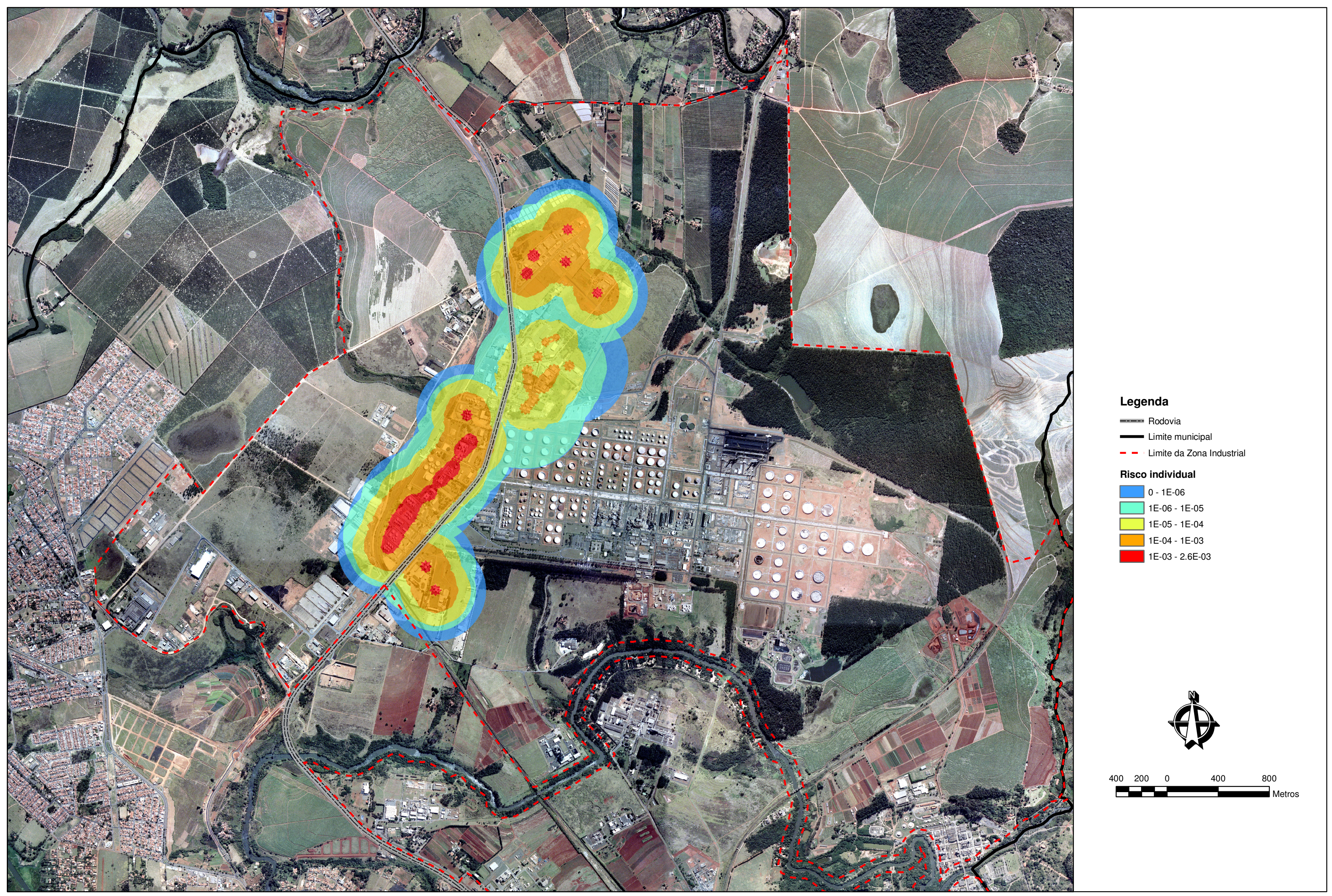

Mapa 9 - Vista geral da área e classes de risco individual total (instalações de GLP + combustível líquido). 

A curva F-N observada, também, encontra-se fora da faixa de tolerabilidade determinada pela CETESB, exigindo, portanto, medidas para a redução dos riscos. Como mostra o Gráfico 4.

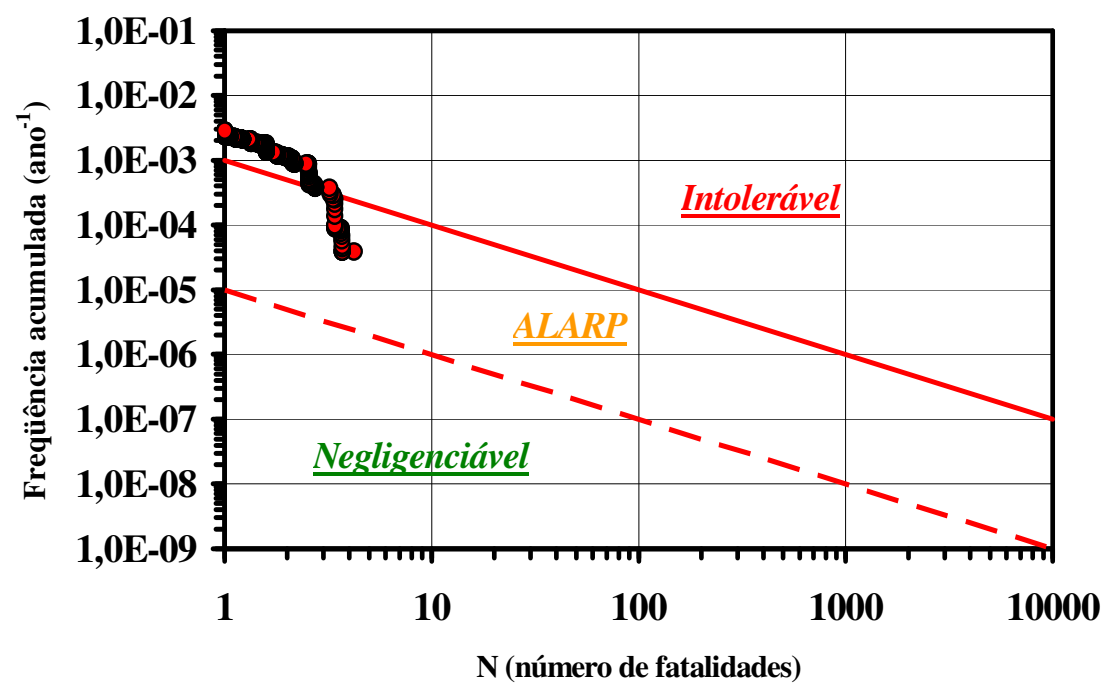

Gráfico 4 - Risco social total para o Distrito Industrial de Paulínia (instalações de GLP + combustível líquido).

Como pôde ser observado nos mapas acima, a sobreposição e soma dos valores de risco individual de diversas instalações proporciona um efeito importante, pois amplia as áreas de determinados valores de risco.

Deve ser enfatizado que as curvas de tolerabilidade apresentadas nos gráficos de risco social são as definidas pela CETESB para uma única instalação, pois no Brasil não há valores de tolerabilidade para grandes áreas industriais. No entanto, estes valores não diferem significativamente de critérios utilizados por outros países, como Itália, França, Holanda e Canadá.

Os resultados obtidos para o risco individual demonstram claramente que a consideração de várias empresas, certamente, é significativa, e, que a análise integrada dos riscos de todas as instalações em áreas industriais, 
deve ser efetuada para o gerenciamento dos riscos de grandes acidentes. Desta forma, o risco individual total pode ser avaliado e adequadamente representado por áreas de iso-risco, facilitando a visualização das áreas atingidas. Estes resultados são importantes para o planejamento de ações emergenciais e, também, para o planejamento do uso e ocupação do solo.

O risco individual, como já enfatizado por outros autores (SPADONI, EGIDI e CONTINI, 2000; CONTINI et al, 2000; KIRCHHOFF, 2004; COZZANI et al, 2006), é um critério importante para o gerenciamento de riscos de grandes acidentes industriais, facilitando a comparação de atividades e áreas distintas.

Da mesma forma, as curvas F-N referentes ao risco social também se mostraram indicadores convenientes, já que na soma de vários empreendimentos elas foram significativamente mais acentuadas. Embora 0 número de fatalidades esperado seja pequeno, em virtude da baixa densidade populacional da área próxima às instalações, a freqüência acumulada dos eventos é alta.

É importante destacar que os resultados evidenciam a importância do zoneamento e do controle de ocupação da área, pois, se houver um aumento da população do entorno, estes eventos poderão resultar em um número elevado de mortes. Embora, atualmente, a densidade populacional seja baixa, deve-se considerar que a taxa de crescimento populacional do município foi relativamente alta nos últimos anos, e que a área urbana cresce em direção ao Distrito Industrial, que, por sua vez, faz divisa com áreas residenciais, comerciais e de serviço.

Deve ser destacado, também, que no local há uma rodovia estadual de grande circulação de veículos de transporte de produtos perigosos e de veículos leves, que atravessa áreas de risco elevado ( $1 \times 10^{-04}$ a $\left.1 \times 10^{-03}\right)$. Além deste fato, por se tratar de uma área de distribuição de produtos, há 
uma intensa movimentação de caminhões e de pessoas no entorno das instalações, o que aumenta o número de pessoas presentes constantemente na área, além dos trabalhadores das unidades industriais, o que pode ampliar o número de fatalidades, em caso de ocorrência de um acidente.

O Distrito Industrial de Paulínia é relativamente novo e suas atividades tiveram um crescimento expressivo nos últimos anos em virtude da presença da REPLAN, considerada a maior refinaria da América da Latina, e, do aumento das atividades de produção e refinamento de petróleo no Brasil. As perspectivas apontam para um crescimento das atividades relacionadas à produção e distribuição de combustíveis na área. Sendo assim, torna-se central a preocupação com um melhor ordenamento destas atividades. Deve ser destacado ainda que a REPLAN, não foi incluída neste estudo. Caso fosse considerada, muito provavelmente os resultados ultrapassariam os limites da zona industrial.

Além destes aspectos, destaca-se que os riscos das atividades de transporte de produtos químicos, rodoviário e dutoviário, bem como, a possibilidade de ocorrência de efeitos dominó, não foram considerados neste trabalho. Desta forma, os resultados obtidos para a área podem ser considerados subestimados. 


\section{CONCLUSÕES}

A ocorrência de graves acidentes tecnológicos e a magnitude das conseqüências para a saúde pública é uma importante preocupação da sociedade atual. Muitos países têm investido no desenvolvimento de estudos e ferramentas que contribuam para o gerenciamento dos riscos destes eventos. No entanto, no Brasil, a avaliação quantitativa de risco de uma grande área industrial é pioneira e deve contribuir para ampliar não apenas 0 entendimento dos danos provocados pelos diferentes cenários acidentais como, também, para a elaboração de políticas públicas mais adequadas.

Os métodos de geoprocessamento empregados para o cálculo da sobreposição dos riscos foram adequados. No entanto, a somatória dos valores de risco individual para cada instalação industrial demandou muito tempo de processamento e de tratamento dos dados. A manipulação de um grande número de hipóteses e cenários acidentais requer métodos digitais adequados para a geração de banco de dados. Uma forma de minimizar o tempo e o trabalho para a análise de grandes áreas industriais é o desenvolvimento de um software, a partir da metodologia utilizada neste trabalho, que receba os dados das simulações e efetue o cálculo de risco de forma mais rápida e automatizada.

Os resultados demonstram que a sobreposição e a soma dos riscos, individual e social, em áreas industriais que concentram diversas instalações perigosas, são significativas e evidenciam a importância da análise integrada de riscos, a exemplo de outros estudos encontrados, como em COZZANI et al (2006) e SPADONI, EGIDI e CONTINI (2000).

Tanto o risco individual quanto 0 risco social variaram significativamente quando comparados os valores de uma instalação e do conjunto de empreendimentos analisados. O risco individual é um critério 
importante para a comparação dos riscos de diferentes atividades, para o planejamento de ações emergenciais e para o planejamento do uso e ocupação do solo.

O risco social pode ser considerado o critério de tolerabilidade mais importante para grandes cenários acidentais, pois é uma medida de magnitude da vulnerabilidade da região em termos de fatalidades imediatas ocasionadas por possíveis eventos. No caso do Distrito Industrial de Paulínia, a densidade populacional atual é baixa e, portanto, o número de fatalidades esperado é baixo. No entanto, se houver um adensamento populacional no entorno do Distrito, o número de fatalidades pode ser significativamente aumentado.

Além disto, especialmente para as instalações de combustíveis líquidos, a freqüência acumulada de ocorrência dos eventos é alta, o que faz com que as curvas $\mathrm{F}-\mathrm{N}$ total da área extrapolem os limites de tolerabilidade. A redução das freqüências só é possível por meio da melhoria das instalações, como por exemplo, através da utilização de sistemas mais modernos e confiáveis e da introdução de novos sistemas de segurança

Diante do exposto, duas considerações são relevantes:

1. A necessidade do controle de ocupação da área do entorno do Distrito, a fim de evitar o adensamento de população em áreas de risco não tolerável;

2. A necessidade do planejamento da ocupação do solo e distribuição de novos empreendimentos perigosos, a fim de melhor controlar as áreas de risco dentro do próprio Distrito Industrial e, portanto, evitar que áreas de riscos não toleráveis extrapolem os limites do Distrito. 
Os resultados obtidos podem ser considerados subestimados para a área devido a não consideração dos riscos da refinaria da Petrobrás (REPLAN), do transporte rodoviário e dos dutos, bem como, a existência de população flutuante (trabalhadores e pessoas que circulam na rodovia) e a possibilidade de efeitos dominó, tendo em vista a proximidade das instalações, especialmente as de GLP. 


\section{RECOMENDAÇÕES}

Trabalhos futuros podem realizar as seguintes propostas:

1. Desenvolvimento de um software para análise integrada dos riscos de áreas industriais que facilite a entrada dos dados e automatize todas as etapas de cálculo.

2. Reavaliação dos riscos considerando as atividades de transporte de produtos perigosos (rodoviário e dutoviário), população flutuante e efeitos dominó. 


\section{REFERÊNCIAS}

ARONOFF, S. Geographic information systems: a management perspective. Ottawa: WDL Publications, 1989.

BAILEY, T. C. A review of statistical spatial analysis in geographical information systems. In: FOTHERINGHAM, S.; ROGERSON, P. Spatial analysis and GIS. Londres: Taylor \& Francis, 1994.

BAILEY, T. C.; GATRELL A. C. Interactive spatial data analysis. Essex: Longman Scientific \& Technical, 1995.

BARCELLOS, C.; BASTOS, F. I. Geoprocessamento, ambiente e saúde: uma união possível?. Cad. Saúde Pública, Rio de Janeiro, v.12, n. 3, p. 389-397, jul./set. 1996.

BARTELS, C. J.; van BEURDEN, A. U. C. J. Using geographic and cartographic principles for environmental assessment and risk mapping. Journal of Hazardous Materials, v. 61, p. 115-124. 1998.

BEDFORD, T.; COOKE, R. T. Probabilistic risk analysis: foundations and methods. Cambridge: Cambridge University Press, 2001.

BESIO, M. et al. Risk maps: theoretical concepts and techniques. Journal of Hazardous Materials, v. 61, p. 299-304. 1998.

BRAZIER, A.M., GREENWOOD, R.L. Geographic information systems: a consistent approach to land use planning decisions around hazardous installations. Journal of Hazardous Materials, v. 61, p. 355-361. 1998. 
BURROUGH, P. A. Principles of geographical information systems for land resources assessment. New York: Oxford University Press, 1986.

BURROUGH, P. A.; FRANK A. U. (Ed.). Geographic Objects with Indeterminate Boundaries. Londres: Taylor \& Francis, 1996.

BURROUGH, P. A.; MCDONNEL, R. A. Principles of geographical information systems. Oxford: Oxford University Press, 1998.

CÂMARA, G.; MEDEIROS, J. S. Geoprocessamento para Projetos Ambientais. São José dos Campos: Instituto Nacional de Pesquisas Espaciais - INPE, 1996.

CÂMARA, G. et al. Introdução à Ciência da Geoinformação. 2. ed. São José dos Campos: Instituto Nacional de Pesquisas Espaciais - INPE, 2001.

CAMACHO, E. N. Uma proposta de metodologia para a análise quantitativa de riscos. 2004. 140 p. Tese (Mestrado em Engenharia Civil) COPPE, Universidade Federal do Rio de Janeiro, Rio de Janeiro.

CARVALHO, M. S. Aplicação de métodos de análise espacial na caracterização de áreas de risco a saúde. 1997. Tese (Doutorado em Engenharia Biomédica) - COPPE, Universidade Federal do Rio de Janeiro, Rio de Janeiro.

CARVALHO, M. S.; PINA, M. F.; SANTOS, S. M. Conceitos básicos de sistemas de informação geográfica e cartografia aplicados à saúde. Brasília, DF: Ministério da Saúde, 2000. 
CETESB - Companhia Estadual de Tecnologia de Saneamento Ambiental. Manual de orientação para elaboração de Estudos de Análise de Riscos: Norma P4.261. São Paulo: CETESB, 2003.

CONTINI, S. et al. The use of geographic information systems in major accident risk assessment and management. Journal of Hazardous Materials, v. 78, p. 223-245. 2000.

COZZANI, V. et al. Application of land-use planning criteria for the control of major accident hazards: A case-study. Journal of Hazardous Materials, v. 136, p. 170-180. 2006.

CHRISTOU, M. Industrial and Environmental Risks. Joint Research Centre. European Commission, 2006.

DEMAJOROVIC, J. Sociedade de risco e responsabilidade socioambiental: perspectivas para a educação corporativa. São Paulo: SENAC, 2003.

DRUK, S.; CARVALHO, M. S.; CÂMARA, G.; MONTEIRO, A. V. M. (Ed.). Análise Espacial de Dados Geográficos. Brasília: EMBRAPA, 2004.

EPA - U. S. Environmental Protection Agency. Tri-State Geographic Initiative Air Risk Assessment Work Plan. Brasil: Air \& Waste Management Association, 1997. Tradução de M. N. SOGABE.

ESRI - Environmental Systems Research Institute. What is ArcGIS? Califórnia: ESRI, 2004.

FEDRA, K. Integrated risk assessment and management: overview and state of the art. Journal of Hazardous Materials, v. 61, p. 5-22. 1998. 
FEDRA, K. Urban environmental management: monitoring, GIS, and modeling. Computer, Environment and Urban Systems, v. 23, p. 443-457. 1999.

FREITAS C. M., PORTO M. F. S., GOMEZ C. M. Acidentes químicos ampliados: um desafio para a saúde pública. Revista de Saúde Pública, São Paulo, v. 29, p. 503-514. 1995.

GLASMEYER, S. P. Acidentes industriais maiores: uma proposta para o gerenciamento de riscos a partir de uma revisão de requisitos legais. 2006. Dissertação (Mestrado em Sistema Integrado de Gestão) - Centro Universitário SENAC São Paulo, São Paulo.

GOODCHILD, M. F.; BRUSEGARD, D. Spatial analysis using GIS: Seminar Workbook. New Orleans: NCGIA, 1989.

GOODCHILD, M. F. 1992. Geographical information science. International Journal on Geographical Informations Systems, v. 6, p. 31-45. 1992.

HSE - Health and Safety Executive. HSC consults on amended major accident hazards regulations. Disponível em: <http://www.hse.gov.uk/press /2004/c04031.htm>. Acesso em: 22 out. 2007.

IBGE - Instituto Brasileiro de Geografia e Estatística. Área Territorial Oficial. Resolução $n^{\circ} 5$, de 10 de outubro de 2002. Disponível em: $<$ http://www.ibge.gov.br/home/geociencias/areaterritorial/area.shtm>. Acesso em: 16 jan. 2008.

IBGE - Instituto Brasileiro de Geografia e Estatística. Censo Demográfico 2000. Resultados do universo. Disponível em: <http://www.ibge.gov.br/home /estatistica/populacao/censo2000/defaulttab_munic.shtm>. Acesso em: 16 jan. 2008. 
IBGE. Instituto Brasileiro de Geografia e Estatística. Contagem da População 2007. Disponível em: <http://www.ibge.gov.br/home/estatistica /populacao/contagem2007/default.shtm>. Acesso em: 16 jan. 2008.

IOANNIDIS, C., et al. Spatial information management for risk assessment of major industrial accidents. FIG Commission 3 Annual Meeting and Seminar, Budapest, Hungary, 1999.

JONES, D. Nomenclature for hazard and risk assessment in the process industries. London: Institution of Chemical Engineers, 1992.

KIRCHHOFF, D. Avaliação de risco ambiental e o processo de licenciamento: o caso do gasoduto de distribuição gás brasiliano: trecho São Carlos - Porto Ferreira. 2004. Dissertação (Mestrado em Engenharia Hidráulica e Saneamento) - Escola de Engenharia de São Carlos, Universidade de São Paulo, São Carlos.

KIRCHSTEIGER, C. et al. (Ed.). Risk assessment and management in the context of the "Seveso II Directive". Amsterdam: Elsevier Science, 1998.

LANDIM, P. M. B. Análise Estatística de Dados Geológicos. São Paulo: Editora Unesp, 1998.

LOURENÇO R. W., LANDIM P. M. B. Mapeamento de áreas de risco à saúde pública por meio de métodos geoestatísticos. Cad. Saúde Pública, Rio de Janeiro, v. 21, p. 150-160, jan./fev. 2005.

MAheswaran, R.; CRAGLIA, M., (Ed.). GIS in Public Health Practice. Boca Raton, FL: CRC Press, 2004. 
MAZIERO, M. D.; SOARES, M. T. M. Paulínia: dos trilhos da Carril às chamas do progresso: 1770-1970. Paulínia, SP: Unigráfica, 1999.

MENDES, R. F. et al. MARA - Elaboração de Metodologia para a análise de riscos ambientais. Rio Pipeline Conference \& Exposition, 2005.

MIRANDA, E. E. et al. Impacto ambiental y sostenibilidad agricola: la contribuición de los Sistemas de Informaciones Geográficas. Santiago de Chile: RIMISP, 1995.

MOLAK, V. Fundamentals of risk analysis and risk management. Cincinatti: Lewis Publishers; 1996.

MOURA, A. C. M. Reflexões metodológicas como subsídio para estudos ambientais baseados em Análise de Multicritérios. In: SIMPÓsıO BRASILEIRO DE SENSORIAMENTO REMOTO, 13., 2007, Florianópolis. Anais... São José dos Campos: INPE, 2007, p. 2899-2906.

NARDOCCI, A. C. Risco como instrumento de gestão ambiental. 1999. Tese (Doutorado em Saúde Pública) - Faculdade de Saúde Pública, Universidade de São Paulo, São Paulo.

NARDOCCI, A. C. Estudo da distribuição dos riscos de acidentes ampliados na região de Campinas, Estado de São Paulo: relatório científico. São Paulo: FAPESP, 2007.

OPENSHAW, S. Developing appropriate spatial analysis methods for GIS. In: MAGUIRE, D. J.; GOODCHILD, M. F.; RHIND, D. W. (Ed.). Geographical Information Systems: Principles and Applications. Londres: Longman, 1991. v. 1, p. 389-402. 
OPENSHAW, S.; OPENSHAW, C. Artificial intelligence in geography. Chichester: John Wiley \& Sons, 1997.

PAULÍNIA. Lei Complementar no 36, de 31 de dezembro de 2007. Dispõe sobre o parcelamento, uso e ocupação do solo no Município de Paulínia, e dá outras providências. Disponível em: < http://www.paulinia.sp.gov.br/leismunicipais/usosolo/lei-complementar-362007.pdf>. Acesso em 16 jan. 2008.

PAULÍNIA. Prefeitura Municipal. Desenvolvido pela Prefeitura do Município de Paulínia. Disponível em: <http://www.paulinia.sp.gov.br/nossa_cidade.php >. Acesso em: 16 jan. 2008.

PRUPPERS, M. J. M. et all. Accumulation of environmental risks to human health: geographical differences in the Netherlands. Journal of Hazardous Materials, v. 61, p. 187-196, 1998.

RAYNER, S. Social, cultural and psychological paradigms: cultural theory and risk analysis. Westport: Greenwood, 1992.

ROCHA, C. H. B. Geoprocessamento: tecnologia transdisciplinar. Juis de Fora, MG: Ed. do Autor, 2000.

ROSA, R.; BRITO, J. L. Introdução ao Geoprocessamento: Sistema de Informação Geográfica. Uberlândia, MG: EDUFU, 1996.

SÃO PAULO (Estado). Secretaria de Economia e Planejamento. Região Metropolitana de Campinas. São Paulo, 2007.

SÃO PAULO (Estado). Secretaria do Meio Ambiente do Estado de São Paulo. Legislação ambiental: série Documento. São Paulo: SMA, 1998. 
SEADE - Fundação Sistema Estadual de Análise de Dados. Perfil Municipal. Disponível em: <http://www.seade.gov.br/produtos/perfil/>. Acesso em: 16 jan. 2008.

SPADONI, G.; EGIDI, D.; CONTINI, S. Through ARIPAR-GIS the quantified area risk analysis supports land-use planning activities. Journal of Hazardous Materials, v. 71, p. 423-437. 2000.

TOMLIN, D. Geographic Information Systems and Cartographic Modeling. New York: Prentice Hall, 1990.

WIERSMA, T.; ROOS, W.; de WIT, M. Area-specific societal risk, societal risk on the map. [TNO-Report, 2006-A-R0021/B]. Netherland: TNO, 2005. 